\title{
A reassessment of the concept of reproductive risk in maternity care and family planning services
}

Judith Rooks

Beverly Winikoff

Population Council

Follow this and additional works at: https://knowledgecommons.popcouncil.org/departments_sbsr-rh How does access to this work benefit you? Let us know!

\section{Recommended Citation}

Rooks, Judith and Beverly Winikoff. 1990. "A reassessment of the concept of reproductive risk in maternity care and family planning services," Robert $\mathrm{H}$. Ebert Program on Critical Issues in Reproductive Health Publication Series. New York: Population Council. 


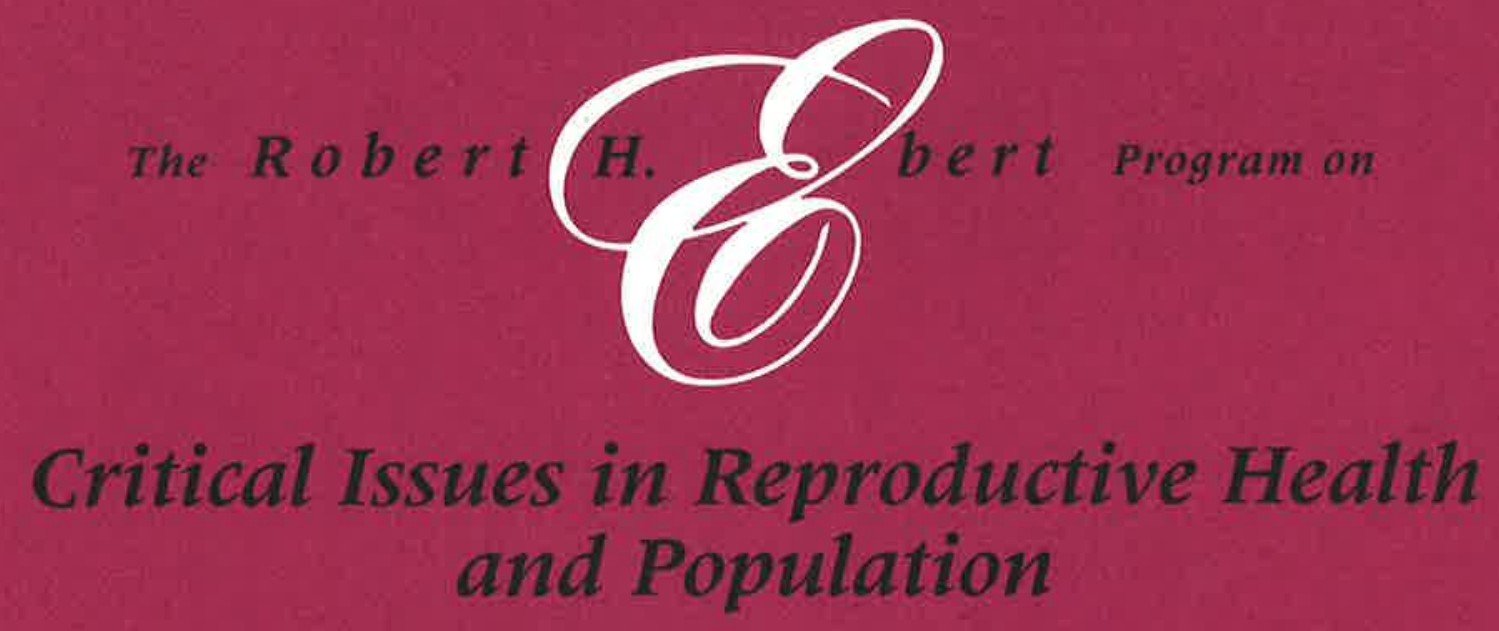

A REASSESSMENT OF THE CONCEPT

OF REPRODUCTIVE RISK IN

MATERNITY CARE AND

FAMILY PLANNING SERVICES

\section{The Population Council}


POPULATION COUNCIL LIBRARY

1 Dag Hammarskjold Plaza.

New York, N.Y.. 10017 USA

\section{A REASSESSMENT OF THE CONCEPT}

OF REPRODUCTNE RISK IN

MATERNITY CARE AND

\section{FAMILY PLANNING SERVICES}

\section{Proceedings of a seminar presented under the Population Council's Robert H. Ebert Program on Critical Issues in Reproductive Health and Population}

February 12-13, 1990

The Population Council

New York, New York

Judith Rooks

and

Beverly Winikoff

Editorial assistance

Alice L. Tufel 
The Robert H. Ebert Program on Critical Issues in Reproductive Health and Population, The Population Council, One Dag Hammarskjold Plaza, New York, NY 10017 USA.

(4) Cover and text printed on recycled paper in the USA. 


\section{ACKNOWLEDGMENTS}

We are grateful to the John D. and Catherine T. MacArthur Foundation and the Rockefeller Foundation for their support of the seminar and publication. We also wish to thank Virginia Kallianes for her administrative assistance, both in organizing the meeting and in producing the proceedings; and Chris Quigley for her assistance with graphics and word processing. 
TABLE OF CONTENTS

PREFACE

Chapter 1:

The Robert H. Ebert Program on Critical Issues in Reproductive Health and Population $\ldots . .1$

What is the "Risk Assessment Approach" in Reproductive Health Care? . . . . . . . . . 2

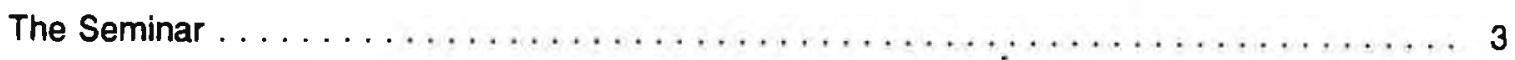

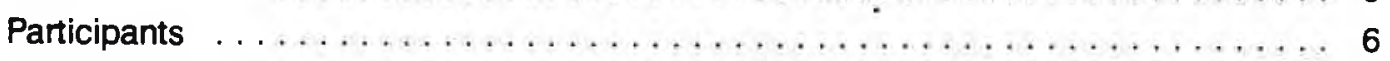

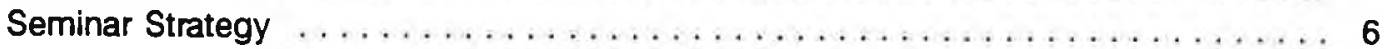

Chapter 2:

HISTORY OF THE CONCEPT OF REPRODUCTIVE RISK $\ldots \ldots \ldots \ldots \ldots \ldots \ldots \ldots$.

As Applied in Maternal and Infant Health Care $\ldots \ldots \ldots \ldots \ldots \ldots \ldots \ldots \ldots$

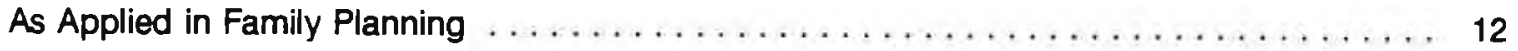

Chapter 3:

THE EPIDEMIOLOGY OF REPRODUCTIVE RISK SCREENING: DEGREE OF ACCURACY

AND INHERENT LIMITATIONS $\ldots \ldots \ldots \ldots \ldots \ldots \ldots \ldots \ldots \ldots \ldots \ldots \ldots \ldots$

Epidemiologic Terminology $\ldots \ldots \ldots \ldots \ldots \ldots \ldots \ldots \ldots \ldots \ldots \ldots \ldots \ldots \ldots \ldots$

Screening Versus Risk Assessment $\ldots \ldots \ldots \ldots \ldots \ldots \ldots \ldots \ldots \ldots \ldots \ldots$

Efficiency and Predictive Capability $\ldots \ldots \ldots \ldots \ldots \ldots \ldots \ldots \ldots \ldots \ldots$

Relative Risk, Attributable Risk, and Absolute Risk $\ldots \ldots \ldots \ldots \ldots \ldots \ldots \ldots \ldots$

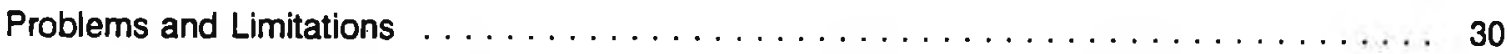

Predicting Complications During Labor and Delivery: Formalized Risk

Assessment Versus the Judgment of Trained Clinicians . . . . . . . . . 30

Inherent Limitations in the Usefulness of Risk Assessment . . . . . . . . . 30

Problems with Using Maternal and Infant Mortality Data to Identify Risk Factors and Evaluate Risk Assessment Systems . . . . . . . . . . . . . . 32

\section{Chapter 4:}

EXPERIENCE WITH IMPLEMENTATION OF THE RISK APPROACH IN MATERNITY CARE IN

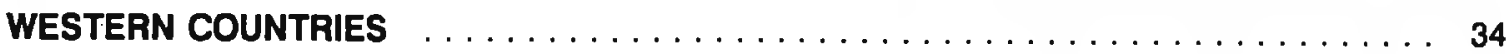

Efforts to "Regionalize" Perinatal Care in the United States $\ldots \ldots \ldots \ldots \ldots \ldots \ldots \ldots$ 
Low-Risk Women Nonhospital Childbirth Care: Antepartum Assessment of Intrapartum

Risk in American Birth Centers

The Women

Limitations of Available Risk-Screening Tools

Prenatal Referrals

Outcomes for Women Admitted to Birth Centers for Intrapartum Care

Should Birth Centers Use More Sensitive Screening Methods?

Summary

New Zealand's Regionalized Perinatal System

Conclusions

Is Western Experience Applicable in Less Developed Countries?

Developing Country Needs

Applicability of Western Experience to Developing Countries

Chapter Summary

\section{Chapter 5:}

IMPLEMENTATION IN POORER COUNTRIES

Shunyi County, People's Republic of China

Identification of Major Perinatal Health Problems

Assessing Performance Problems Within the Health Care System

Planning and Implementing the Intervention Strategies

Objectives and Evaluation

Conclusions and Plans for the Future

Mexico City, Mexico

The Risk Assessment Instrument

A Study to Evaluate the Risk Assessment Process

Conclusions

Karawa Health Zone, Zaire

Rationale for the Use of the Risk Approach at Karawa $\ldots \ldots \ldots \ldots \ldots \ldots \ldots . \ldots 2$

The TBA Training Program . . . . . . . . . . . . . . . . . . . . 73

Evaluation of the TBAs' Learning and Actual Referrals $\ldots \ldots \ldots \ldots \ldots \ldots \ldots 75$

Problems With Application of the Risk Approach $\ldots \ldots \ldots \ldots \ldots \ldots \ldots \ldots 76$

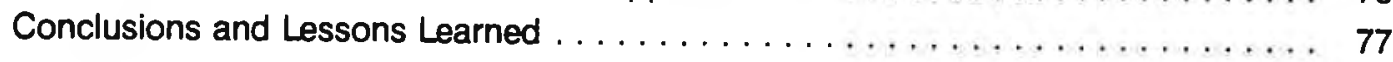

Sources of Additional Information on this Program $\ldots \ldots \ldots \ldots \ldots \ldots \ldots$

Northeastern Brazil $\ldots \ldots \ldots \ldots \ldots \ldots \ldots \ldots \ldots \ldots \ldots \ldots \ldots \ldots \ldots \ldots \ldots$

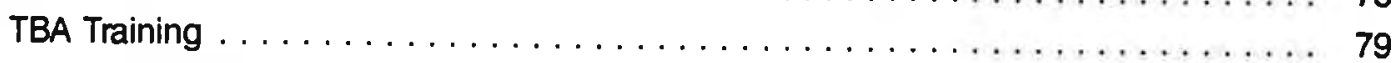

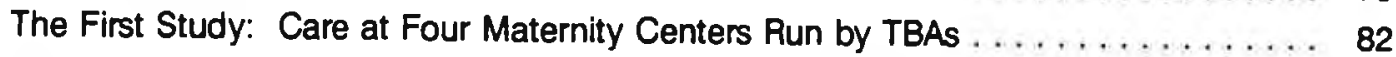

The Second Study: All Births in Trairi, May 1984-April $1985 \ldots \ldots \ldots \ldots \ldots \ldots$. 84 
Problems

The Need For Local Data $\ldots \ldots \ldots \ldots \ldots \ldots \ldots \ldots \ldots \ldots, 8 \ldots \ldots \ldots$

The "Inverse Care Law" . . . . . . . . . . . . . . . . . . . . . 89

Inability to Conduct Accurate Assessments . . . . . . . . . . . . . . 90

Unwillingness of Providers to Comply with Referral Guidelines . . . . . . . . . . . . 91

Lack of Transportation and Financial, Cultural, and Social Factors .......... 92

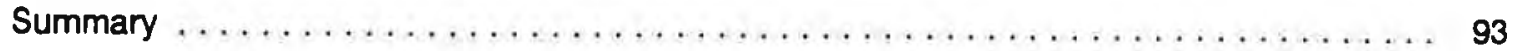

Chapter 6:

POSSIBLE EFFECTS ON THE HEALTH CARE SYSTEM $\ldots \ldots \ldots \ldots \ldots \ldots \ldots \ldots \ldots$

Effects on Traditional Birth Aftendants $\ldots \ldots \ldots \ldots \ldots \ldots \ldots \ldots \ldots \ldots \ldots \ldots$

\section{Chapter 7:}

REPRODUCTIVE RISK ASSESSMENT IN FAMILY PLANNING $\ldots \ldots \ldots \ldots \ldots \ldots \ldots$

Delivery of Family Planning Services at the Mexican Social Security Institute (IMSS) on

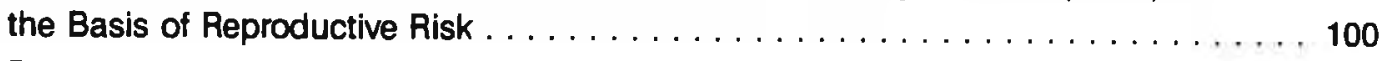

Development and Evaluation of the Risk Assessment Form . . . . . . . . . . . . 101

Program Strategy and Objectives . . . . . . . . . . . . . . . . . . . 102

Methodology for Evaluating the Risk Assessment Program . . . . . . . . . . . . 102

Results of the Evaluation . . . . . . . . . . . . . . . . . . . . 103

Effects on Family Planning in Mexico and Other Latin American Countries . . . . . . 114

Conclusions ............................... 116

PAHO's Perspective on The Latin American Experience $\ldots \ldots \ldots \ldots \ldots \ldots \ldots \ldots$

The Effect of the Risk Approach on Family Planning in Latin America: PAHO's

Conclusions .......................... 119

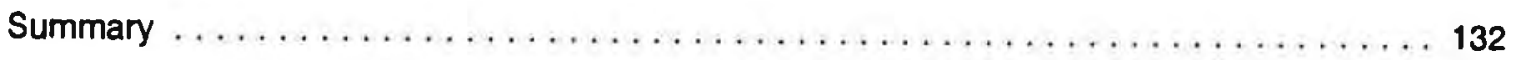

Chapter 8:

COSTS

Evaluating the Cost-Effectiveness of Risk Assessment $\ldots \ldots \ldots \ldots \ldots \ldots \ldots \ldots \ldots$

Chapter 9:

WOMEN'S PERSONAL RISK-BENEFIT CALCULATIONS 
Chapter 10:

OTHER USES OF THE RISK APPROACH

Chapter 11:

ETHICAL CONSIDERATIONS

Summary

Chapter 12:

CONCLUSIONS

Costs and Allocation of Resources

Information and Outreach

Objectives

Predictive Ability

Risk Assessment and Family Planning

159

Chapter 13:

RECOMMENDATIONS

Additional Recommendations

Appendix 1:

DEVELOPING A REPRODUCTIVE RISK ASSESSMENT INSTRUMENT AND SCORING SYSTEM

Appendix 2:

THE WORLD HEALTH ORGANIZATION RISK APPROACH IN MATERNAL AND CHILD HEALTH AND FAMILY PLANNING 


\section{PREFACE}

The concepts, theories, and philosophies that underlie health care services have a profound impact on the quality of care experienced by users of those services. The content of care, its accessibility, the way providers interact with clients, the extent to which individuals are treated with respect and encouraged to make their own decisions are all affected by the ideology, rationale, and professional ethos, both explicit and implicit, that support the services.

The idea of using reproductive risk as a fundamental concept on which to build services has gained currency in recent years. The proposition is that individuals can be identified and classified according to how likely they are to experience health problems and that those most "at risk" can be given care to avoid the predicted problems. The appeal of this approach is, in part, due to its scientific/epidemiologic base, its logical framework, the sense of active decisionmaking it gives providers, and the apparent possibilities of cost-savings making it feasible to provide only - and no more than - the amount of care each patient requires.

Reproductive risk has been used in service design and delivery for maternity care and has been advocated and tried as a basis for providing family planning services. Yet very little has been done to evaluate critically the experiences to date in using this paradigm for service delivery. Clear difficulties in implementation, uncritical acceptance of statements of effectiveness, and lack of elaboration of the possible costs (broadly speaking, not simply monetary) of use of risk prediction as a basis for services led us to seek a more comprehensive discussion of the entire issue.

The result of that inquiry was the seminar whose proceedings are recorded here. This document is an amalgam of the thoughts and experiences of many people. It describes the main themes of the meeting, incorporating elements of the presentations made by some participants with discussion, elaboration, and interpretations by others. The document also refers to data from published literature that were not discussed at the seminar.

The weight of evidence suggests that there are major drawbacks to basing service delivery on risk scoring systems. Most of these problems have not been described clearly or debated openly heretofore. While in some circumstances the construct of "reproductive risk" is useful for service delivery, our deliberations suggest that its role is narrower than previously advocated. Application of any risk system must be approached with caution, taking into account technical 
weaknesses as well as potentially negative side effects. In the enthusiasm for the potential of risk screening, too little consideration has been given to these issues. They deserve more careful thought and research. If risk-based systems tend to skew resource allocation and undermine equal access to care, freedom of choice, and personal autonomy, the public health community will need to be vigilant about their use and continue to debate the extent to which risk paradigms should be applied in health care delivery systems. 


\section{Chapter 1:}

\section{INTRODUCTION}

This monograph provides a summary and synthesis of the papers and discussion from a Population Council invitational seminar on the use of reproductive risk assessment in maternity care and family planning. The seminar was held at the Population Council headquarters in New York City on February 12-13, 1990. The monograph also incorporates and cites other sources of data on this subject.

\section{The Robert H. Ebert Program on Critical Issues in Reproductive Health and Population}

The Seminar to Reassess the Concept of Reproductive Risk in Maternity Care and Family Planning Services was the fourth in a series of seminars convened by the Population Council as part of its Robert $\mathrm{H}$. Ebert Program on Critical Issues in Reproductive Health and Population. The Ebert Program focuses on four critical and interactive objectives:

- improving the quality of care in family planning and reproductive health services,

- managing unwanted pregnancy and preventing the consequences of unsafe abortion,

- improving and devising new approaches to postpartum care, and

- incorporating attention to sexually transmitted diseases (STDs), including AIDS, into reproductive health care.

The Ebert Program grew from an awareness that many important reproductive health problems - and the ways women experience them - have been neglected by policymakers, program planners, and practitioners. Consequently, Council staff involved in the Program work closely with governments, institutions, and scientists in developing countries to improve women's reproductive health through scientific inquiry, technology assessment, service experimentation, international meetings, and information dissemination.

The Ebert Program was established in June of 1988. It is named for Roben H. Ebert, former chairman of the Board of Trustees of the Population Council and now chairman emeritus 
and trustee. The Council plans to work on these issues for at least the next decade. The Ebert Program is ongoing; it has no scheduled ending date.

The issue of maternal risk assessment is being addressed as part of the Council's concern, within the Ebert Program, for improving the quality of family planning and reproductive health care. This concern springs from the perception that two decades of emphasis on increasing the supply of family planning services has in many instances led to neglect of the content and quality of those services. The Council believes that improvements in service content and quality and an increased responsiveness to users' needs will yield a larger, more committed contraceptive clientele and will therefore increase the demographic effectiveness of family planning programs.

\section{What is the "Risk Assessment Approach" in Reproductive Health Care?}

The concept of reproductive risk screening began in the late 1950s, when epidemiologic studies found associations between certain maternal characteristics and a higher-than-average incidence of poor maternal and child outcomes. This led to the development of increasingly formalized efforts to predict poor outcomes through "risk assessment," to organize different intensities of care to meet the needs of women with different levels of risk, and to guide individual women into the kind of care that they have been predicted to need.

More recently, the concept of reproductive risk assessment has been expanded to include attempts to identify nonpregnant women who are more likely than others to experience complications and poor outcomes if and when they become pregnant. Some family planning programs have begun to use such assessments as a way to identify individual women who are "most in need of family planning," to use high-risk assessment as a way to motivate women to practice contraception and to choose the more effective methods, including sterilization, and to focus family planning program efforts on women with certain risk factors, often including parity and age.

The World Health Organization (WHO) sees maternal risk assessment as a potential tool for actualizing their concept of "Something for all, but more for those in need - in proportion to that need" and has produced a sequence of documents related to the use of the "risk approach" in maternal and child health (MCH) care and family planning (FP). The first 
document, entitled Risk Approach For Maternal and Child Health Care (1978), focused primarily on the development and use of tools to assess the risk status of individual women, but also discussed the use of risk assessment to identify high-risk communities (Backett et al., 1984; WHO, 1978, 1984; Yan et al., 1989). Later documents on the subject give evidence of an evolving concept of "the WHO Risk Approach," with each subsequent publication broadening the definition to give greater emphasis to the use of epidemiologic and other data, including but not restricted to those derived from risk assessments, as the basis for planning and evaluating MCH/FP programs. The most recent publication on the WHO Risk Approach (1989) describes the use of the risk approach to improve perinatal health in one county in the People's Republic of China (Yan et al., 1989). The report of this project (also described in chapter 5 of this monograph) defines the WHO Risk Approach as "an ongoing process of (1) identifying priority health problems and their associated risk factors; (2) assessing performance of the local health care delivery system; (3) planning strategies for modifying risk factors and decreasing health problems; and (4) evaluating the strategy's effectiveness and application" (Yan et al., 1989). Although the WHO concept includes the use of a formalized risk-scoring system, it has evolved into a much broader process and concept. Nevertheless, risk assessment per se - the use of a list of risk factors, and usually some kind of scoring system, to determine which women are high-risk and thus in need of special care - is the part of the process that has received the most attention. The 1989 WHO document was published by the United States Centers for Disease Control, rather than by WHO itself, and has not been widely circulated. (See Appendix 2 in this monograph for a more thorough discussion of the WHO Risk Approach,)

Although efforts to formalize risk assessment and to use it as a way to organize the delivery of reproductive health care are relatively recent, risk assessment itself is not new. Assessing individuals for characteristics that put them at higher-than-average risk of specific health problems has always been part of good clinical judgment, as well as a basis of epidemiologic research.

\section{The Seminar}

The purpose of this seminar was to examine a limited and specific application of the reproductive risk assessment approach - the programmatic use of a formalized reproductive risk assessment tool (a list of risk factors and some kind of scoring system) as a way to separate apparently well women into low-risk and high-risk categories, and to provide different advice or care to those identified as being at high risk for poor pregnancy outcomes. We did 
not attempt to examine the utility of WHOs wider concept of a data-based assessment of health problems in specific communities based on risk assessment, and we did not focus on risk assessment as an inherent but informal part of clinical judgment. In particular, this seminar did not address the use of risk screening as a way to identify women who are more likely than others to experience health problems associated with the use of specific methods of contraception - for example, smoking as a factor that increases the risk of some complications associated with use of oral contraceptives.

Although the idea of reproductive risk has been discussed extensively, this seminar was the first gathering that proposed to examine critically the impact of using that concept as a way to organize the delivery of services. The title of the seminar specifies a "reassessment"; however, we might simply have called it an assessment, considering that the results of using the reproductive risk model had not been as broadly examined previously.

We hoped to learn about the impact of the use of risk assessment on service delivery systems, providers, and clients. We had particular concerns about quality of care, availability of choices, and the women who do not get services because they have been directed elsewhere.

The seminar was designed to examine certain technical issues inherent in risk screening, especially to determine whether risk-based service delivery can handle the complexities of sensitivity and specificity, absolute and relative risk, and individual desires and the differences between communities. What happens to services under the influence of a risk-based approach in the most developed service delivery environments? What happens to the quality and content of services, and to their impact on individuals and communities, in places such as the United States and New Zealand, which have generally good infrastructure, reasonable budgets, and adequate personnel? And then, what has the experience been in more constrained environments? Do screening and scoring systems work there? Can risk-scoring be taught to the often poorly trained and overworked people who provide health care to women in less developed countries? How difficult and costly is it to implement such systems? What kinds of referral systems are required? Can developing-country management methods cope with the additional burdens imposed by these referral systems?

What happens when the idea of "risk" is carried over into family planning? What is the reasoning behind this extension of risk-based services? Does it result in more women being better served? Are risk-based services more cost-effective? What are the implications for 
training health care workers? How should they counsel women? What is the effect on women of being labeled as high-risk? Are messages regarding risk accurate and ethical, or is "risk" used as a coercive tool? Do women make their own calculus of reproductive risk and, if so, is it likely to be different from or in concordance with the medical system's wisdom on this point?

While the theory of the risk assessment approach had been expounded and explored, its practical implications and effects had not been critically analyzed; the Council intended for this meeting to be the beginning of such an analysis.

The explicitly stated purposes of the seminar were to examine the concept of reproductive risk assessment in order to:

- understand the development and evolution of this concept;

- review the epidemiologic principles on which it is based;

- describe how it has been applied in the organization of maternity care in both Western and developing countries;

- describe actual and proposed uses of the concept in the provision of family planning services;

- examine a variety of specific examples of implementation of the concept in order to understand how well it has worked in actual practice and to identify some of the positive and negative results, both direct and indirect;

- discuss the potential and limitations of reproductive risk assessment as a strategy to improve pregnancy outcomes and as a strategy to encourage higher-risk women to practice contraception;

- identify possible psychological, social and ethical probiems related to the use of reproductive risk assessment as a basis for organizing the delivery of reproductive health care; and

- consider how to avoid or minimize the problems and to maximize the benefits of using reproductive risk assessment within organized systems of reproductive health care, including consideration of those circumstances and purposes that are most conducive to its success. 
We hoped that the seminar would help answer many questions: Should we try to formalize risk assessment into a costly program? What are the advantages and disadvantages of using a formalized risk assessment tool and bureaucratic system as compared with using a riskoriented mind set and relying on clinical judgment? When is it appropriate to formalize risk assessment, and when is it not? When a risk-based program is warranted, what can be done to increase the benefits and decrease the costs? Should risk assessment be based on demographic factors as well as factors that are part of the chain of causation? How many resources should be used for a risk assessment program as compared with investments in other aspects of reproductive health care?

There was no expectation that this seminar would answer all of the important questions related to this issue; rather, the Council hoped that it would bring new issues to light and reframe old ones, and that ultimately it would contribute to the improvement of reproductive health services.

\section{Participants}

The Council works in close collaboration with a large network of scientists and institutions throughout the world, especially those in the developing countries. For a seminar like this, the Council must draw on the enormous intellectual capacity and program experience outside of its own staff. The concerns that led the Council to convene this meeting required the thought and expertise of people from diverse streams of experience. The persons invited to participate in the seminar came from a very wide spectrum of academic backgrounds and program and policy responsibilities. Most of them are directly involved in family planning and/or maternal and child health care in less developed countries (LDCs). The participants brought to the discussion expertise in biostatistics, demography, economics, epidemiology, ethics, family medicine, midwifery, neonatology, nursing, obstetrics and gynecology, psychology, public health, sociology, and women in development, as well as their experience as policymakers, program planners and managers, researchers and academicians, trainers, clinicians, and executives. The seminar was structured so as to encourage a maximum of audience participation and interchange.

\section{Seminar Strategy}

The seminar was held over two days. Because the value of "risk assessment" (often vaguely defined) has become widely accepted, the questions and issues raised in the seminar were controversial. Therefore, a large amount of the time was reserved for reaction to the 
presented papers and for discussions in which everyone in attendance was invited to participate.

The first morning was used to provide historical background on how the concept of reproductive screening got started (by epidemiologists) and how it has been applied (first as a way to organize maternal and infant health care and more recently as a way to promote and organize the provision of family planning services), to lay out the epidemiologic principles involved in reproductive risk screening, and to summarize information on the efficiency of risk assessment in predicting infant mortality and low birthweight.

The first afternoon was used to describe three applications of the risk approach to maternal and infant care in two Western industrialized countries - the development of regionalized perinatal care systems in the United States and New Zealand (both based on referring high-risk women to hospitals able to provide complex, technical care) and the development of nonhospital birth centers in the United States (which use risk assessment to prevent high-risk women from using a form of care designed to meet the needs of low-risk women). The last session of the afternoon was devoted to a discussion of lessons to be learned from experiences in industrialized countries and how those lessons may (or may not) be applicable to programs in developing countries.

The first session on the second day of the seminar was used to describe four applications of the risk approach to maternity care in poorer countries. The first presenter described a WHO program that used the risk approach as a management tool, to identify and address the major causes of poor pregnancy outcomes in Shunyi Province, China. The second speaker described a risk assessment program that is used primarily to keep low-risk women out of hospitals in Mexico City, in order to conserve limited hospital resources for the higher-risk women who need life-saving care. The third presenter described a program based on training traditional birth attendants (TBAs) in Karawa, Zaire to use a list of risk factors to refer high-risk women to a hospital maternity center. The last speaker described a program in northeastern Brazil that combined the development of TBA birth centers with a functional referral system, including transportation.

The second session during the second day of the seminar was on the use of risk assessment in family planning, with emphasis on efforts to demonstrate and apply this approach in Central and South America. It began with a description of a program in Mexico City in which nonpregnant women are classified as being either high- or low-risk for poor pregnancy 
outcomes, and high-risk women are informed of their risk status and are given easier access to family planning. That presentation was followed by a description of efforts by the Pan American Health Organization (PAHO) to encourage both governments and nongovernmental

organizations (NGOs) to apply the risk approach in order to achieve reproductive health goals in the Americas. The PAHO paper was followed by a discussion of some of the strengths and weaknesses of this approach, also from a Latin American perspective. The last presenter discussed womens perceptions of the risks associated with contraception and with childbearing.

The afternoon of the second day of the seminar was devoted to presentations on how women assess their own reproductive risks, cost considerations, and ethical issues, including issues related to counseling. During the final session, three leaders who had participated in the entire seminar summarized lessons learned and principles to be applied in the future.

\section{References}

Backett, E.M., A.M. Davies, and Petros-Barvazian. The Risk Approach in Health Care: With Special Reference to Maternal and Child Health, Including Family Planning. Public Health Papers No. 76. Geneva: World Health Organization, 1984.

World Health Organization (WHO). A Workbook on How to Plan and Carry Out Research on the Risk Approach in Maternal and Child Health Including Family Planning. Geneva: World Health Organization, 1984.

—. WHO Offset Publication No. 39. Geneva: World Health Organization, 1978.

Yan, R.Y., B.J. McCarthy, H.F. Ye, C.Y. Qu, Z. Li, T.X. Chen, and D. Kowal. The Risk Approach in Perinatal Health: Sunyi County, People's Republic of China. U.S. Department of Health and Human Services Publication No. HHS 89-8412. Atlanta, GA: Centers for Disease Control, 1989. [A copy of this report can be obtained from the Centers for Disease Control, Atlanta, GA 30333.] 


\title{
Chapter 2:
}

\section{HISTORY OF THE CONCEPT OF REPRODUCTIVE RISK}

\author{
As Applied in Maternal and Intant Health Care \\ (Taken primarily from a paper presented by Deborah Maine, M.P.H., Program Director, \\ Prevention of Maternal Mortality, Center for Population and Family Health, School of Public \\ Health, Columbia University, New York City.)
}

It is impossible to date the origin of the idea of reproductive risk: Obsenvant clinicians have always noticed that some kinds of women are more likely than others to have unfavorable pregnancy outcomes. However, that is not the same as using the concept of reproductive risk to design service programs.

Before the 1920s, women in Great Britain or the United States did not ordinarily seek medical care during pregnancy, especially when there were no obvious complications. Even upper-class women who were under the care of a physician received little special attention unless they had some troubling symptom. It was not that the medical community of the eighteen and nineteenth centuries was uninterested in pregnancy. On the contrary, one of the favorite occupations of physicians seems to have been writing advice for pregnant women. But the dominant theme of that advice was to maintain a moderate and healthy lifestyle during pregnancy, rather than to be on the lookout for impending problems.

The first prenatal clinics were established in Sydney (Australia), Boston (U.S.A.), and Edinburgh (Scotland) between 1910 and 1915. These clinics represented a fundamentally new approach to pregnancy, which was to monitor as many pregnant women as possible, including those who were apparently healthy, in order to detect signs of abnormality as early as possible. Descriptions of the care provided to pregnant women in these early clinics sound surprisingly modern. Nevertheless, they were not really employing what we now call "the risk approach," since the doctors were looking for early signs of actual pathology and not for characteristics that are only statistically associated with risk, such as age, parity, marital status, and race.

During the 1920 s prenatal care came to be viewed as an important factor capable of improving the chance of a favorable pregnancy outcome for both the mother and the child. The initial enthusiasm for prenatal care was followed, in the early 1930 s, by a period of reassessment. In Great Britain and the United States, maternal mortality did not decline between 
the beginning of the century and the beginning of the Second World War (DHEW, 1954). And, while infant mortality rates had fallen substantially since the turn of the century, most of the decline was in the postneonatal period; rates of stillbirth and death in the neonatal period had not declined appreciably (Browne, 1934).

That was discouraging, considering that in Great Britain, for example, approximately 80 percent of the women were receiving some prenatal care. Although some members of the medical community considered the possibility that prenatal care could not accomplish all they had hoped it would, the consensus was that the quality of prenatal care needed to be improved. However, it was not until the late 1950 s that the emphasis began to shift from detection to prediction, particularly of chronic handicapping conditions of infants and other birth defects.

In 1955 Lilienfeld and Pasamanick published a study of risk factors for cerebral palsy (Lilienfeld and Pasamanick, 1955). Included among the risk factors were not only characteristics of the child's gestation and birth (such as toxemia), but also the mother's history of stillbirths. Abraham Lilienfeld, the lead author of this landmark study, was one of the great pioneers of modern epidemiology. The rise of epidemiology contributed significantly to the evolution of the risk approach. The development of new statistical techniques and the collection of data on large numbers of people encouraged statisticians and clinicians to identify characteristics of individuals associated with increased risk, and to try to develop efficient screening mechanisms.

A number of studies conducted in the United States and Great Britain during the late 1950 s and 1960s identified risk factors for perinatal mortality. (By this time, maternal mortality was so low in industrialized countries that the emphasis had shifted to the infant.) The best known of these studies - the British Perinatal Mortality Survey - collected data on about 17,000 births that occurred in Great Britain during 1958 (Butler and Bonham, 1963). In the analysis of the data, various "socio-biological risk factors" were identified. These included not only such attributes as age, parity and stature, but also social class and area of residence. This kind of analysis paved the way for the development, beginning in the late 1960s, of increasingly formalized efforts to predict poor outcomes through risk assessment, to organize different intensities of care to meet the needs of women with different levels of recognized risk, and to guide individual women into the kind of care they are predicted to need.

The enthusiasm for these schemes has been based on faith both in the power of prediction and in the ability to prevent bad outcomes once we have been forewarned. In 
reading the numerous articles proposing risk-scoring schemes, it becomes clear that most of the authors firmly believed that they would eventually be able to develop a score by which the vast majority of cases could be predicted in a small proportion of the population in question. In the 1950s, '60s, and '70s (after an effective vaccine against polio had been developed and before anyone knew about AIDS), there was a pervasive feeling (especially in the United States) that there were virtually no limits to the powers of medicine and research.

However, even in the first enthusiastic years of prenatal care, problems were evident. An article on the first prenatal clinic in the United States, published in the Boston Medical and Surgical Journal in 1913, reported that 17 women with symptoms of toxemia had been safely delivered in a hospital. The article also noted that three women had developed eclampsia in the hospital without having had any symptoms beforehand, and that one of those women had died (Huntington, 1913).

A variety of obstetrical risk-scoring systems have been developed since then. More than 30 different systems had been described in papers published in the North American medical literature as of 1982 (Selwyn, 1982). One, which was integrated into a computerized obstetric record system (the Problem Oriented Perinatal Risk Assessment System, or POPRAS), is in particularly widespread use in the United States. Nevertheless, the clinical value of these systems is controversial. Several studies to evaluate their effectiveness have concluded that people have unrealistic expectations of the ability of such systems to predict which women will or will not need higher-level care (Fortney and Whitehorne, 1982), that modifications and validation of risk assessment methods are necessary when they are applied to populations other than the one for which they were originally developed (Baruffi et al., 1984), that the best of them improve little on clinical judgment (Acheson et al., 1990; Kelly et al., 1988), that they are much more useful when applied to parous (compared with nulliparous) women (Acheson et al., 1990; Kelly et al., 1988; Mueller-Heuback and Gizick, 1989), and that their accuracy is so limited that any out-of-hospital birth service must be prepared to transport low-risk women who develop complications during labor and delivery (Marshall, 1989). 


\section{As Applied in Family Planning}

(based on remarks by George Brown, M.D., M.P.H., Vice President, Programs Division, The Population Council; Anrudh Jain, Ph.D., Deputy Director, Programs Division, The Population Council, and published articles)

The concept of risk has been of interest to family planning program managers since very early in the development of family planning service programs. The concept of risk, if not risk assessment itself, has been applied in pursuit of several different goals: (1) to optimize the use of limited family planning program resources by using factors such as age and parity to identify women who are especially likely to want to prevent pregnancies, (2) to improve maternal and child health by reducing pregnancies among those women who are most likely to have poor outcomes, and (3) to attract and involve physicians in the delivery of family planning services.

During the 1960 s one of the first large, organized family planning service programs, in Taiwan, determined characteristics (age, number of children, and number of sons) of women who were most likely to want no more children and then focused their outreach efforts on families with those characteristics. This approach is an example of using risk assessment information in order to optimize the use of limited family planning service funds.

The second purpose - to improve maternal and child health by reducing the number of high-risk pregnancies - has also been with us since the $1960 \mathrm{~s}$, and has been particularly stressed in the United States. In 1976 the U.S. Children's Bureau reported that 56 large metropolitan counties accounted for more than one-third of the nation's "excess infant deaths" and thus held "the key to any successful effort to sharply reduce the nation's infant mortality rate" (DHEW, 1967). Calculations by the U.S. Department of Health, Education and Welfare (DHEW) determined that a voluntary family planning program serving low-income women who have borne at least three children would lower the infant mortality rate in those counties by 25 percent. The DHEW projections indicated that no other single health measure would be equally productive of an improvement in the survival of infants born in these high-risk counties (Planned Parenthood, 1967). In response to this information, and in response to other reasons for supporting family planning, the U.S. Congress authorized the use of large amounts of American government funds to support the provision of family planning services in the United States. While the major goal of the funding was to reduce unintended pregnancies, upgrading reproductive health generally was an important secondary purpose (Alan Guttmacher Institute, 1985). Federal government expenditures for family planning rose from less than $\$ 13$ million in 
1968 to almost $\$ 240$ million in 1977 , by which time more than four million American women were obtaining family planning services through government-funded clinics (Torres, 1979). During the period 1965 to 1972, the U.S. infant mortality rate dropped from about 25 to less than 20 deaths per 1,000 live births. A study published in 1975 attributed 27 percent of that reduction solely to reductions in the proportion of U.S. births that were occurring to women who were high-risk on the basis of parity and/or age (Morris et al., 1975). Those benefits were obtained, however, through programs that targeted high-risk communities (not individuals) or programs that tried to make family planning available to everyone.

During the 1980s, some family planning programs, including several in Latin America, extended the concept of risk assessment by applying it to individuals, using tools and borrowing methods from the risk approach as applied to maternity care. This extension of the concept using risk assessment to identify and provide special family planning counseling and services to women with high-risk characteristics - was an important focus of this seminar. The example of the Mexican Social Security Institute program (described in chapter 7) also discusses the use of risk assessment as a way to make family planning more interesting and attractive to physicians by focusing on health outcomes and on a technical, quantitative methodology consistent with a medical orientation.

\section{References}

Acheson, L.S., S.E. Harris, and S.J. Zyzanski. "Patient selection and outcomes for out-of-hospital births in one family practice." Journal of Family Practice 31 (1990): 128-36.

Alan Guttmacher Institute. "Two decades of United States support for family planning." Issues in Brief 5, no. 1 (1985).

Baruffi, G., D.M. Strobino, and W.S. Dellinger. "Definitions of high risk in pregnancy and evaluation of their predictive validity." American Journal of Obstetrics and Gynecology 148 (1984): 781-86.

Browne, F.J. "Are we satisfied with the results of ante-natal care?" The British Medical Journal (1934): 194-97.

Butler, N.R. and D.G. Bonham. Perinatal Mortality: The First Report of the 1958 British Mortality Survey. Edinburgh: Livingstone, 1963. 
Fortney, J.A. and E.W. Whitehorne. "The development of an index of high-risk pregnancy." American Journal of Obstetrics and Gynecology 143 (1982): 501-7.

Huntington, J.L. "Relationship of the hospital to the hygiene of pregnancy." Boston Medical and Surgical Journal 169 (1913): 763-65.

Kelly, R.B., L.S. Acheson, and S.J. Zyzanski. "Comparison of three prenatal risk scores in a series of low-risk pregnancies." Family Medicine 20 (1988): 122-27.

Lilienfeld, A.M. and B. Pasamanick. "The association of maternal and fetal factors with the development of cerebral palsy and epilepsy." American Journal of Obstetrics and Gynecology 1 (1955).

Marshall, V.A. "A comparison of two obstetric risk assessment tools." Journal of Nurse-Midwifery 34 (1989): 3-7.

Morris, N.M., J.R. Udry, and C.L. Chase. "Shifting age-parity distribution of births and the decrease in infant mortality." American Journal of Public Health 65 (1975): 329-62.

Mueller-Heuback, E. and D.S. Gizick. "Evaluation of risk scoring in a preterm birth prevention study of indigent patients." American Journal of Obstetrics and Gynecology 160 (1989): 829-37.

Planned Parenthood-World Population. Family Planning and Infant Mortality: An Analysis of Priorities. New York: PPWP, June 1967.

Selwyn, B.J. "Review of obstetrical risk assessment methods." In Research Issues in the Assessment of Birth Settings. Washington, DC: Institute of Medicine, National Academy Press, 1982. Pp. 149-70.

Torres, A. "Organized family planning services in the United States, 1976-1977." Family Planning Perspectives 11 (1979): 342-47.

United States Department of Health, Education and Welfare (DHEW). Infant and Perinatal Mortality Rates, by Age and Color: United States, Each State and County, 1951-1955, 1956-1960. Washington, DC: USDHEW, Children's Bureau, 1967.

— Vital Statistics of the United States, 1950. Vol. 1. Washington, DC: U.S. Government Printing Office, 1954. 


\section{Chapter 3:}

THE EPIDEMIOLOGY OF REPRODUCTIVE RISK SCREENING: DEGREE OF ACCURACY AND INHERENT LIMITATIONS

(based on a paper presented by Beatrice J. Selwyn, Sc.D., Associate Professor in Epidemiology, University of Texas School of Public Health, on discussions held during the seminar, and on other sources)

Even a preliminary discussion of the subject of risk requires an understanding of certain epidemiologic terms. Several of those terms were defined at the beginning of the seminar and are explained below.

\section{Epidemiologic Terminology}

\section{Screening Versus Risk Assessment}

Screening implies the systematic observation of all members of a specified group, usually involving the use of tests or examinations that can be applied quickly, for the purpose of presumptive identification of previously unrecognized cases of disease. Screening is not intended to be diagnostic; rather, it is intended only to sort out apparently well people who may have the disease from those who don't have the disease.

Risk factors are ascertainable characteristics and/or circumstances that are known to be associated with a higher-than-average incidence of a nonoptimal health outcome. The process by which those factors are identified is called risk assessment.

Risk status refers to the category or classification assigned to individuals based on risk assessment, usually low-risk or high-risk. Many risk assessment systems assign numeric weights or scores to each of the separate risk factors included in the assessment. The weights assigned to each risk factor are thought to reflect the degree of risk associated with each factor. After the risk assessment, each individual patient or client is assigned a summative or other type of compiled risk score based on the weights assigned to her individual risk factors. Usually a cut-off point is then selected to divide the group into high- and low-risk subgroups.

Reproductive risk assessment attempts to identify women and infants who are more likely to die or experience disease or complications during pregnancy, labor, delivery, or the postpartum or neonatal periods, and to separate them from those women and infants who are 
relatively unlikely to experience serious problems.

The purpose of screening is to detect untreated current pathology in people who are not obviously ill. The "yield" of any screening program is the amount of previously unrecognized disease that is diagnosed and brought to treatment as a result of the screening. The purpose of risk assessment is to predict problems before they occur - that is, to quantify the probability of future pathology. Risk statements based on risk assessment are statements of probability, not of facts. Probability implies an element of chance and thus of error.

In actual practice, reproductive risk assessment combines some screening procedures with risk assessment procedures; that is, some of the observations and tests are conducted to identify complications that may be present at the time of the assessment; others are done to identify characteristics and conditions that are not themselves complications but that are associated with a higher frequency of complications. However, the main focus of this seminar was risk assessment, not screening.

Greater clarity is needed reganding the definition of risk factors as compared with early symptoms of obstetric pathology, such as albumin in the urine and elevated blood pressure. A true risk factor is an attribute that is not an early symptom of the unfavorable outcome in question. However, early symptoms are often used by researchers as risk factors.

\section{Efficiency and Predictive Capability}

Screening and risk assessment procedures are assessed for efficiency using measures of sensitivity and specificity, and for predictive capability using measures of predictive value.

Sensitivity refers to the ability of the risk assessment to identify accurately women who will have serious complications during pregnancy and/or childbirth, or whose newborns will have health problems and need special care. Complications not predicted by the risk classification system constitute false negatives (missed diagnoses). An example is perinatal deaths of mothers who were labeled as low-risk. A very sensitive risk assessment results in few false negatives.

The sensitivity of a risk assessment process can be quantified by determining the percentage of those who develop actual complications who were identified as being high-risk. $A$ very sensitive risk assessment process will predict a high proportion of those who ultimately 
experience problems. A process with low sensitivity will predict a lower percentage of those who ultimately experience problems.

However, except for systems that categorize almost all women as high-risk, even a very sensitive assessment tool cannot identify all or, in some cases, most of the women who will develop obstetric complications. Some women who have no risk factors during pregnancy develop obstetric complications. A Scottish study showed that 30 percent of cases of preeclampsia presented for the first time during labor or after delivery and so were not detected by screening. In a New York City study, one of every five low-risk women (aged 20-29 and with no pre-existing disease, prenatal complication, or previous fetal loss) developed complications during delivery. Not only do low-risk women develop complications, but, because most women are "low-risk," the majority of complications may occur to low-risk women, even though the rate of complications is higher among the women identified as "high-risk."

The data presented in Table 3.1 provide an example. These data document the association between poor obstetric history (the risk factor) and obstructed labor during the current pregnancy (the poor outcome) among births that occurred in Kasongo, Zaire, between 1971 and 1975 (Kasongo Project Team, 1984). The relative risk associated with having a poor pregnancy history was 9.2; that is, women with a poor history were over nine times more likely than those without a poor history to experience obstructed labor during their current pregnancy. This is a very high relative risk; indicative of a very strong association. Nevertheless, poor pregnancy history was not a sensitive predictor of obstructed labor in the current pregnancy; most of the women whose current labors were obstructed did not have this risk factor. 
Association Between Obstetric History and Obstructed Labor During Current Pregnancy, Kasongo, Zaire, 1971-1975

Current Pregnancy

\begin{tabular}{lccc}
\hline & Poor & Good & All \\
Obstructed labor & 15 & 36 & 51 \\
Normal labor, not obstructed & 141 & 3,422 & 3,563 \\
Total & 156 & 3,458 & 3,614
\end{tabular}

Data from: Kasongo Project Team: Antenatal screening for fetopelvic dystocias: A costeffectiveness approach to the choice of simple indicators for use by auxiliary personnel. Journal of Tropical Medicine and Hygiene 1984; 84 (4): 173-183.

In another example, 16 percent of birth center clients in the United States had to be transferred to hospitals during or immediately after labor and delivery. This was true even though most of them had careful prenatal screening and were screened again at the time of their first examination during labor (Rooks et al., 1989).

Specificity refers to the ability of the risk assessment to identify correctly those women who will not experience serious complications as low-risk. Pregnancies that proceed without complications but were labeled high-risk are false positives (overdiagnosis). A very specific risk assessment results in few false positives.

The specificity of a risk assessment system can be quantified by determining what percentage of those who actually turn out to have no serious complications were identified as being low-risk. However, some women avoid bad outcomes precisely because they receive preventive care or special treatment. Thus, the incidence of false positives may include some cases that would have experienced a bad outcome if not for the risk assessment process and its effect on subsequent care. This means that our measures of specificity are almost always going to be lower than is actually the case.

The efficiency of a screening method is reflected by the proportion of screened people who are identified correctly - that is, the number of true positives plus the number of true negatives divided by the total number of people who were screened. 
Positive predictive value is the proportion of women identified as high-risk who actually experience poor outcomes. It is a measure of the accuracy of the prediction (assignment of high-risk status). Reproductive risk assessment implies the desire to predict the eventual outcome of pregnancy based on information currently available, usually prenatally, about pregnant women. Women are assessed as high-risk or low-risk while they are still pregnant that is, before the actual outcome of their pregnancy is known. The positive predictive value measures how well the high-risk designation identifies the women who will actually go on to experience complications. The positive predictive value of a screening test increases with the prevalence of the condition.

Sensitivity and specificity are usually inversely related to each other. In most cases, an increase in sensitivity results in a decrease in specificity and an increase in specificity results in a decrease in sensitivity.

Tables 3.2, 3.3, and 3.4 summarize some of the findings from a large number of studies based on the use of specific maternal risk assessment instruments. Table 3.2 summarizes data from risk assessment systems that were being used to predict perinatal and/or neonatal mortality. Table 3.3 presents results from risk assessment systems that were used to predict low birthweight and preterm birth. Table 3.4 shows results from risk assessment systems intended to predict intrapartum and neonatal complications. The majority of these studies were conducted in the United States and Europe; very few are from developing countries. The tables show the proportion of the population that are in the high-risk group, the sensitivities and specificities, the positive predictive value, a measure of relative risk, and the frequency with which the condition (the particular suboptimal outcome being measured in each.study) occurs in the total population. As seen in those tables, highly sensitive risk assessment instruments are not very specific, and highly specific risk assessment instruments are not very sensitive. 


\section{TABLE 3.2}

Sensitivity, Specificity, and Predictive Value of Published Risk Assessment Systems with Regard to Mortality (ordered by level of sensitivity for perinatal mortality)

\begin{tabular}{|c|c|c|c|c|c|c|c|c|c|c|c|c|c|c|}
\hline \multicolumn{2}{|l|}{ Publ ication } & \multicolumn{3}{|c|}{$\%$ in Each Risk } & \multicolumn{5}{|c|}{$\begin{array}{l}\text { Perinatal mortality } \\
\text { Group }\end{array}$} & \multicolumn{5}{|c|}{ Neonatal mortality } \\
\hline Author & Date & high & med. & LOW & $\begin{array}{l}\text { Rate } \\
\text { in } \\
\text { pop. }\end{array}$ & $\begin{array}{c}\text { sens } \\
\% \\
\end{array}$ & $\begin{array}{l}\text { spec } \\
\% \\
\end{array}$ & $\begin{array}{c}\text { PV+ } \\
\% \\
\end{array}$ & $\begin{array}{l}\mathbf{R} \cdot \mathbf{R} \text {. } \\
\end{array}$ & $\begin{array}{l}\text { Rate } \\
\text { in } \\
\text { pop. }\end{array}$ & $\begin{array}{c}\text { sens } \\
\% \\
\end{array}$ & $\begin{array}{l}\text { spec } \\
\% \\
\end{array}$ & $\begin{array}{l}\text { PV+ } \\
x \\
\end{array}$ & R.R. \\
\hline Edwards et al. & 1979 & 47 & $\cdot$ & 53 & 3 & 89 & 54 & 6 & 9 & 2 & 100 & 54 & 3 & inf \\
\hline Hebb et al. & 1980 & 10 & 75 & 15 & 3 & 86 & 15 & 22 & 115 & & & & & \\
\hline Sokol et al. & 1977 & 26 & 43 & 31 & 3 & 82 & 31 & 9 & inf & 2 & 88 & 31 & 6 & inf \\
\hline $\begin{array}{l}\text { Morrison } \\
\& \text { Olsen }\end{array}$ & 1979 & 19 & - & 81 & 2 & 70 & 82 & 7 & 10 & & & & & \\
\hline $\begin{array}{l}\text { Fortney \& } \\
\text { Whitehorne }\end{array}$ & 1982 & 38 & - & 62 & 3 & 69 & 78 & 6 & 2 & & & & & \\
\hline Davies \& Harlap & 1974 & 39 & - & 61 & 2 & 62 & 62 & 4 & 3 & & & & & \\
\hline Hobel et al. & 1976 & 16 & 39 & 45 & 3 & 54 & 47 & 11 & 72 & 2 & 50 & 47 & 5 & 17 \\
\hline Nesbitt \& Aubry & 1969 & 30 & 39 & 31 & 3 & 43 & 31 & 4 & 2 & 1 & 31 & 31 & 1 & ns \\
\hline Rantakal lio & 1969 & 14 & - & 86 & 2 & 30 & 87 & 5 & 3 & & & & & \\
\hline Haeri et al. & 1974 & 12 & - & 88 & 3 & 28 & 89 & 6 & 3 & & & & & \\
\hline Coburn et al. & 1982 & 7 & 81 & 12 & 1 & 23 & 12 & 4 & 8 & 0.4 & 21 & 12 & 1 & 6 \\
\hline Apgar & 1953 & 24 & - & 76 & $\cdots \cdots$ & ant mo & rtali & only & 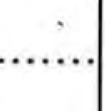 & 1 & 92 & $\pi$ & 4 & 34 \\
\hline Kessler et al. & 1973 & 54 & $\cdot$ & 46 & 2 & 75 & 46 & 3 & 2 & 2 & 81 & 46 & 3 & 4 \\
\hline Halliday et al. & 1980 & 26 & 36 & 38 & & & & & & 1 & 67 & 38 & 4 & 17 \\
\hline Donahue \& Wan & 1973 & 25 & 50 & 25 & & & & & & 33 & 43 & 29 & 58 & 3 \\
\hline McCarthy et ol. & 1981 & 12 & - & 88 & Perinat & tal 8 & infan & norta & ity & 1 & 38 & 89 & 4 & 5 \\
\hline Stembera et al. & 1975 & 14 & $?$ & $?$ & & 73 & & & ne & & & & & \\
\hline
\end{tabular}

Rate in population $=$ percent of births with the specified condition in the population studied.

sens $=$ sensitivity in highest-risk group

PV+ = predictive value positive

spec = specificity in lowest-risk group

inf = infinity

R.R. = relative risk

nc $=$ not calculated

ns = not statistically significant

? = information not provided

Table adapted from B. Selwyn, "The accuracy of obstetric risk assessment instruments for predicting mortality, low birthweight, and preterm birth," in New Perspectives on Prenatal Care, eds. I.R. Merkatz and J.E. Thompson (New York: Elsevier, 1990), p. 47. 


\section{TABLE 3.3}

\section{Sensitivity, Specificity and Predictive Value of Published Risk Assessment Systems with Regard to Low Birthweight and Preterm Birth (ordered by level of sensitivity for preterm birth)}

\begin{tabular}{|c|c|c|c|c|c|c|c|c|c|c|c|c|c|c|}
\hline \multicolumn{2}{|l|}{ Publication } & \multicolumn{3}{|c|}{$x$ in Each Risk } & \multicolumn{5}{|c|}{ Preterm Birth" } & \multicolumn{5}{|c|}{ Low Birthweight tw } \\
\hline Author & Date & high & med. & low & $\begin{array}{l}\text { Rate } \\
\text { in } \\
\text { pop. }\end{array}$ & $\begin{array}{c}\text { sens } \\
x \\
\end{array}$ & $\begin{array}{l}\text { spec } \\
\underline{x} \\
\end{array}$ & $\begin{array}{l}\text { PV+ } \\
\underline{x}\end{array}$ & $R \cdot R \cdot$ & $\begin{array}{l}\text { Rete } \\
\text { in } \\
\text { pop. }\end{array}$ & $\begin{array}{l}\text { sens } \\
x \\
\end{array}$ & $\begin{array}{l}\text { spee } \\
x \\
\end{array}$ & $\begin{array}{l}\mathrm{PV}+ \\
\underline{x} \\
\end{array}$ & R.R. \\
\hline Hebb et al. & 1980 & 10 & 75 & 15 & 7 & $\pi$ & 16 & 54 & 63 & & & & & \\
\hline Creasy et al. & 1980 & 15 & $\begin{array}{l}25 \\
16\end{array}$ & 66 & 6 & 39 & 68 & 21 & 35 & primi & $\begin{array}{l}\text { jparas } \\
\text { iparas }\end{array}$ & & & \\
\hline Fedrick & 1976 & $\begin{array}{l}40 \\
26\end{array}$ & $=$ & $\begin{array}{l}60 \\
74\end{array}$ & $\frac{2}{2}$ & 70 & $\frac{60}{75}$ & $\begin{array}{l}3 \\
5\end{array}$ & 4 & $\begin{array}{l}\text { primi } \\
\text { multi }\end{array}$ & $\begin{array}{l}\text { iparas } \\
\text { iparas }\end{array}$ & & & \\
\hline Whitehorne & 1982 & 38 & - & 62 & 12 & 62 & 62 & 18 & 2 & & & & & \\
\hline Ross et ol. & 1986 & 33 & - & 67 & 6 & 56 & 68 & 10 & 2 & & & & & \\
\hline Aubry \& ${ }_{\text {Pennington }}$ & 1973 & 21 & - & 79 & 8 & 53 & 82 & 21 & 4 & 8 & 63 & 83 & 26 & 6 \\
\hline Main et al. & 1985 & 35 & $\cdot$ & 65 & 16 & 48 & 68 & 23 & 2 & & & & & \\
\hline Nesbitt \& Aubry & 1969 & 30 & 39 & 31 & 6 & 47 & 32 & 10 & 2 & 13 & 43 & 33 & 20 & 2 \\
\hline Herron et al. & 1982 & 15 & - & 85 & 2 & 43 & 85 & 7 & 4 & & & & & \\
\hline Holbrook et ol. & 1989 & 16 & $\cdot$ & 84 & 5 & 40 & 86 & 13 & 4 & & & & & \\
\hline Kaminski et al. & 1973 & 16 & 22 & 62 & B & 30 & 68 & 17 & 3 & 4 & 39 & 63 & 10 & 4 \\
\hline Main et al. & 1987 & 21 & $\cdot$ & 79 & 15 & 26 & 80 & 18 & ns & & & & & \\
\hline $\begin{array}{l}\text { Wennergren \& } \\
\text { Karisson }\end{array}$ & 1982 & 7 & $\cdot$ & 93 & & & & & & 2 & 100 & 95 & 34 & inf \\
\hline Mielson et al. & 1980 & 18 & - & 82 & & & & & & 8 & 94 & 88 & 39 & 76 \\
\hline Belizan et al. & 1978 & 34 & $\cdot$ & 66 & & & & & & 32 & 86 & 90 & 79 & 12 \\
\hline Giffei \& Saling & 1974 & 42 & - & 58 & & & & & & 6 & 84 & 60 & 11 & 7 \\
\hline Quarante et al. & 1981 & 39 & $\cdot$ & 61 & & & & & & 32 & 73 & $\pi$ & 60 & 4 \\
\hline Kessler et al. & 1973 & 54 & $\cdot$ & 46 & & & & & & 12 & 72 & 48 & 15 & 2 \\
\hline $\begin{array}{c}\text { Xaminski } \\
\text { Papiernik }\end{array}$ & 1974 & $?$ & $?$ & $?$ & & & & & & & $\begin{array}{l}66 \\
54\end{array}$ & $\begin{array}{l}67 \\
64\end{array}$ & & $\begin{array}{l}\mathrm{nc} \\
\mathrm{nc}\end{array}$ \\
\hline $\begin{array}{l}\text { Tinguely } \\
\text { Burgener }\end{array}$ & 1981 & 23 & 17 & 60 & & & & & & 8 & 58 & 63 & 19 & 10 \\
\hline Rantakallio & 1969 & 14 & $\cdot$ & 86 & & & & & & 4 & 41 & 87 & 12 & 4 \\
\hline $\begin{array}{l}\text { Coburn et al. } \\
\text {.............. }\end{array}$ & 1982 & 7 & $\begin{array}{l}81 \\
\ldots \ldots\end{array}$ & 12 & & & & & & 4. & 22. & $\begin{array}{c}12 \\
\ldots .\end{array}$ & 13 & $\begin{array}{l}7 \\
\cdots\end{array}$ \\
\hline Sokol et al. & 1983 & $?$ & $\cdot$ & $?$ & & & & $\begin{array}{l}\text { rimipe } \\
\text { ultipe }\end{array}$ & ras & 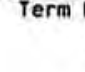 & $\begin{array}{l}\text { Lon } 81 \\
50 \\
76\end{array}$ & rth & $\begin{array}{l}9 h t \\
34 \\
47\end{array}$ & $\begin{array}{l}\text { ne } \\
\text { ne }\end{array}$ \\
\hline $\begin{array}{l}\text { Adelstein } \\
\text { Fedrick }\end{array}$ & 1978 & $\begin{array}{l}19 \\
12 \\
12 .\end{array}$ & : & $\begin{array}{l}81 \\
88\end{array}$ & & & & $\begin{array}{l}\text { rimipa } \\
\text { ultipal }\end{array}$ & $\begin{array}{l}\text { res } \\
\text { ires }\end{array}$ & $\frac{3}{2}$ & $\begin{array}{l}46 \\
58\end{array}$ & $\begin{array}{l}82 \\
89\end{array}$ & 15 & $10^{4}$ \\
\hline & & & & & piëi & $\ddot{e r m} \ddot{i}$ & öвir & n̈iègh & & & & & & * \\
\hline et al. & 1976 & 24 & $\cdot$ & 76 & 5 & 71 & 78 & 14 & 8 & & & & & \\
\hline Guzick et al. & 1984 & 24 & $\cdot$ & 76 & 9 & 62 & 79 & 23 & 5 & & & & & \\
\hline
\end{tabular}

Rate in pop. = percent in the population with the condition sens = sensitivity (in highest-risk group) PV $+=$ predictive value positive inf $=$ infinity nc $=$ not calculated

spec $=$ specificity (in lowest-risk group)

R.R. = relative risk

ns $=$ not statistically significant

$?=$ information not provided

*Includes all preterm births (regardless of birthweight) except studies by Thalhammer et al. and by Guzick et al. which included only preterm low birthweight.

*includes all low birthweight births (regardless of length of gestation) except studies by Sokol et al. and by Adelstein and Fedrick, which included anly term low birthweight.

Table adapted from B. Selwyn, "The accuracy of obstetric risk assessment instruments for predicting mortality, low birthwoight, and preterm birth," in New Perspectives on Prenatal Care, ods. I.R. Merkatz and J.E. Thompson (New York: Elsevier, 1990), p. 47. 
TABLE 3.4

Sensitivity, Specificity and Predictive Value of Published Risk Assessment Systems with regard to Neonatal or Maternal Complications (ordered by level of sensitivity for perinatal mortality)

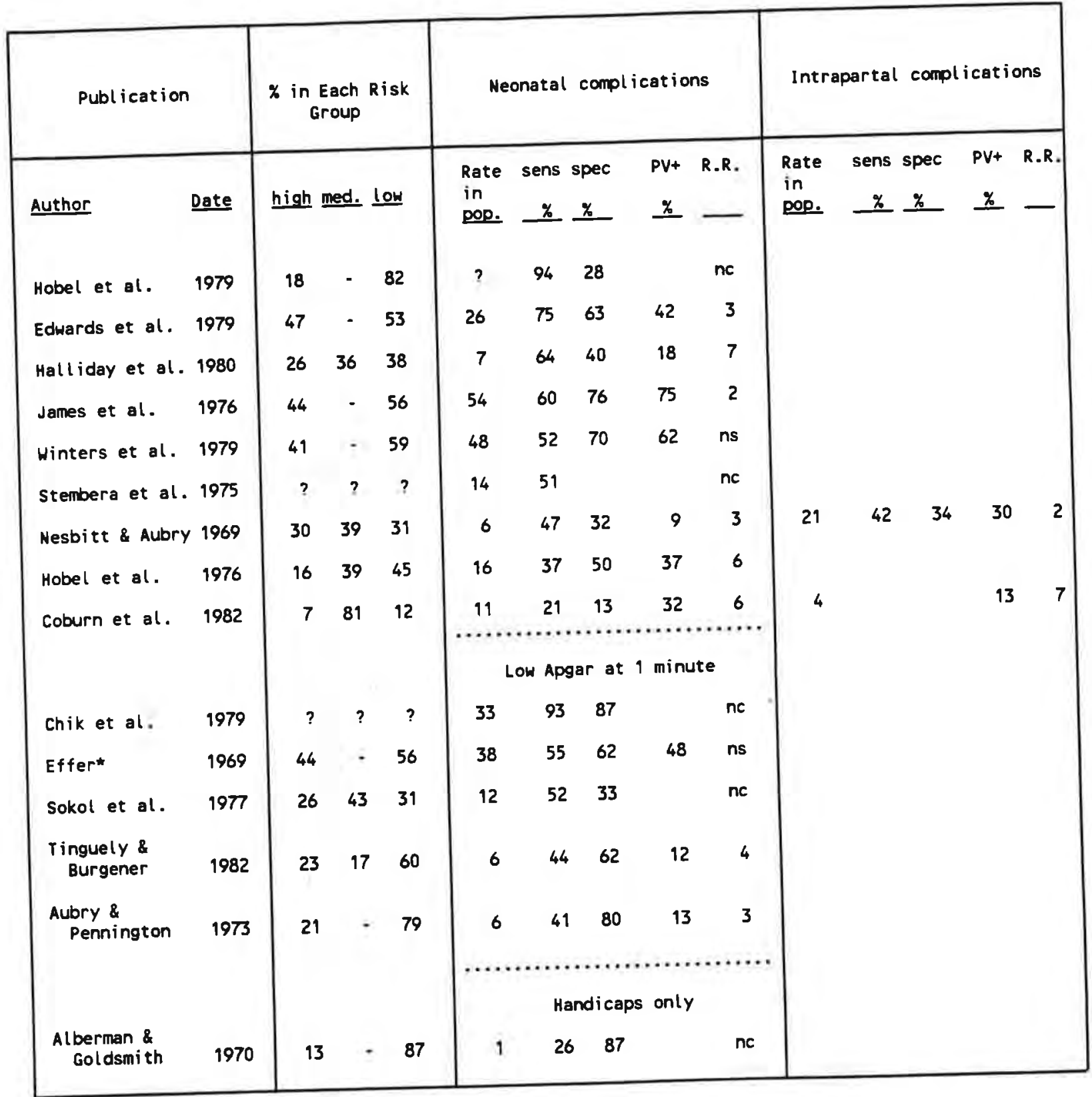

Rate in pop. = percent in the population with the specified condition in the population studied sens = sensitivity (in highest-risk group) spec = specificity (in lowest-risk group)

PV + = predictive value positive A.R. = relative risk inf $=$ infinity ns = not statistically significant nc $=$ not calculated ? = information not provided

"Effers population was clinically judged high-risk

Table adapted from B. Selwyn. "The accuracy of obstetric risk assessment instruments for predicting mortality, low birthweight, and preterm birth," in New Perspectives on Prenatal Care, eds. I.R. Merkatz and J.E. Thompson (New York: Elsevier, 1990), p. 47 
Sensitivity ranges from a low of 23 percent to a high of 94 percent, with different ranges depending on the outcome that is being predicted. Note that most of these studies focus on perinatal mortality, neonatal mortality, preterm birth, low birthweight, and neonatal complications. Very few focus on intrapartal complications (during labor and delivery) and none focuses on maternal complications, which are the outcomes of greatest importance in many developing country situations.

Since risk assessment can provide only a statement of probability, misclassification is inevitable. Consideration must be given to the expected rates of error and the consequences of misclassification. Decisions must be made as to the most acceptable type of misclassification. Different costs and benefits are associated with overdiagnosis (false positives) and with underdiagnosis (false negatives). High rates of false positives appear in most of the risk assessment systems summarized in Tables 3.2, 3.3, and 3.4, probably due to the emphasis on avoiding missed diagnosis. Concern about missing even a small number of cases leads to decisions that increase the sensitivity of the risk assessment system. However, overdiagnosis increases the cost of services, since it results in the use of facilities and care that were actually not needed.

Table 3.5 demonstrates how sensitivity and specificity can be altered by changing the threshold (in this case the numeric score) above which a woman is defined as high-risk. In this example, Davies and Harlap used a single set of data to demonstrate the effect that placement of a numeric "cut-off point" for high-risk has on sensitivity and specificity. The higher the threshold, the lower the sensitivity and the higher the specificity; the lower the threshold, the higher the sensitivity and the lower the specificity. In this example, a cut-point of 20 maximized sensitivity and specificity, making both 62 percent. The sensitivity can be increased (to 95 percent) by lowering the cut-point to 10; however, this is accompanied by lowering the specificity (to 12 percent). Conversely, the specificity increases (to 91 percent) by setting the cut-off point at 40, but this decreases the sensitivity (to 32 percent) (Selwyn, 1990). 
TABLE 3.5

The Effect of Different Cut-off Points on Sensitivity and Specificity

\begin{tabular}{lrr}
\hline Cut-off point & Sensitivity & Specificity \\
\hline $40+$ & 32 percent & 91 percent \\
$20+$ & 62 percent & 62 percent \\
$10+$ & 95 percent & 12 percent
\end{tabular}

Based on data from A.M. Davies and S. Harlap, "Antenatal prediction of peri- and neonatal mortality risk," unpublished working paper prepared for a consultation, MCH/WP/HR/741 (Geneva: World Health Organization, 1974).

Positive predictive value increases as the frequency of the condition increases in the population. Conditions that are more frequent in a population will usually result in higher positive predictive value rates; prevalence rates of less than 15-20 percent generally result in low predictive values. However, the frequency of any complication should always be higher in the high-risk group than in the low-risk group; otherwise, the risk assessment system is not identifying a group at increased risk of the problem.

Table 3.6 provides an example: The very different rates shown here were measures of the predictive power of a single risk assessment instrument as used to predict two different outcomes among women in the same population. The association between the positive predictive value and the frequency of the condition in the population occurs whether the assessment is examining different outcomes in the same population (as in this example) or is being applied to two different populations with different rates of the same outcome. 
TABLE 3.6

Positive Predictive Value Increases as the Frequency of the Condition Increases in the Population

Outcome

Frequency of the condition in the population

Positive predictive value (rate of condition in selected risk group

\begin{tabular}{lrr} 
Perinatal mortality & 1 percent & 4 percent \\
Low birthweight & 4 percent & 13 percent \\
\hline $\begin{array}{l}\text { From: A.F. Coburn, J.N. Bennert, H. Bennert, Jr., "The Maine Fetal Risk Project: Final Report" The Maine Department } \\
\text { of Human Services, 1982). }\end{array}$
\end{tabular}

Increasing the proportion of women assigned to the high-risk group (that is, increasing sensitivity) decreases the number of false negatives, but the positive predictive value also decreases, as seen in Tables 3.2, 3.3, and 3.4. As one gets closer to including 100 percent of the total population in the high-risk classification, the system "finds" almost all of the actual cases, but the rate of the complication in the high-risk group becomes progressively more like the rate in the total community. The effect of having a "special group" disappears and the system becomes inefficient. An example of this situation is shown in Figure 3.1. 


\section{FIGURE 3.1}

\section{Effect of Increasing the Size of High-Risk Groupings on Sensitivity and Cases of Perinatal Death}
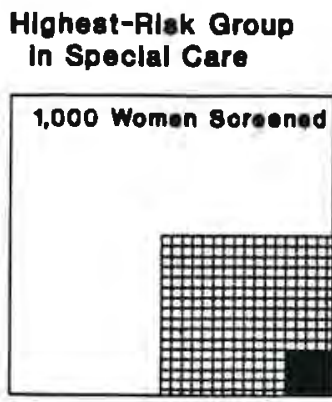

18 perinatal doathe

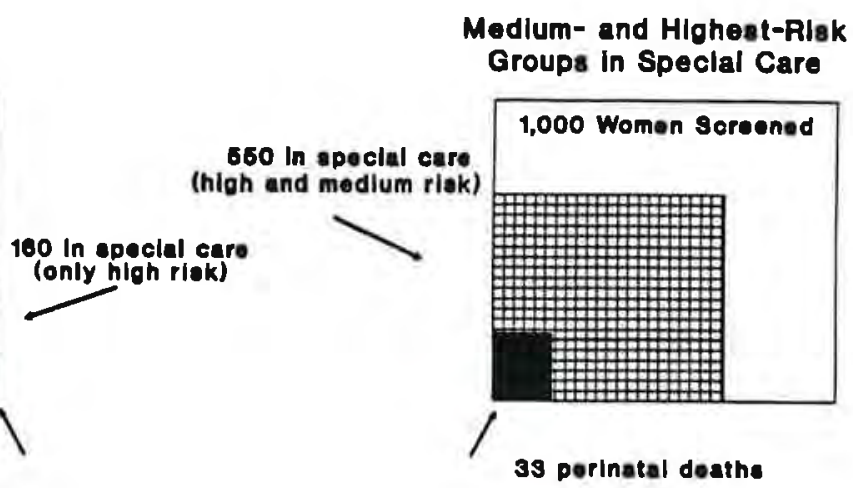

33 perinatal deathe

Based on Figure 4.1 in B. Selwyn, "The accuracy of obstetric risk assessment instruments for predicting mortality, low birthweight, and preterm birth," in New Perspectives on Prenatal Care, eds. I.R. Merkatz and J.E. Thompson (New York: Elsevier, 1990), p. 55. Selwyn's figure was based on C.J. Hobel, "Recognition of the high-risk pregnant woman," in Management of the High-risk Pregnancy, ed. W.N. Spellacy (Baltimore, MD: University Park Press, 1976), chapter 1.

In the example shown in Figure 3.1, 1,000 women were assessed; 450 were classified as low-risk, 390 as medium-risk, and 160 as high-risk. Among a total of 33 perinatal deaths 18 occurred among the 160 high-risk women and 15 occurred among the 390 medium-risk women. In the scenario depicted in the box at the left side of the figure, only the high-risk women were provided with special care. Since 18 of the 33 perinatal deaths occurred among these 160 women, the sensitivity of the screening procedure was 54 percent and the predictive value was 11 percent. (That is, 54 percent of the deaths came from cases identified as high-risk, and 11 percent of the women classified as high-risk ended up having a perinatal death.) When the medium-risk group is also classified as high-risk (that is, the scenario depicted in the box on the right side of the figure), the sensitivity is increased to 100 percent but the predictive value decreases to only 6 percent (only 6 percent of those identified as being in need of special care had a bad outcome). In this example, it was necessary to increase the size of the high-risk group (and workload) by 344 percent in order to increase the sensitivity by 46 percent.

\section{Relative Risk, Attributable Risk, and Absolute Risk}

Can risk assessment systems identify a substantially higher-risk group? The last columns in Tables 3.2, 3.3, and 3.4 show the risk of poor outcomes in the high-risk group 
relative to the risk in the low-risk group - that is, the relative risk (RR). The relative risk can be used to judge a risk assessment system's success in separating a population of pregnant women into a high-risk group and a low-risk group. The higher the RR, the better the system functions at forming two distinct groups. The RR measures the strength of the association between high-risk assignment and outcome. Even though the predictive positive values vary, most of the systems summarized in Tables 3.2, 3.3, and 3.4 result in the identification of two groups with reasonably different rates of the outcome being measured.

Some conditions associated with risk can be treated or managed so as to prevent the anticipated bad outcome; such treatment or management lowers the relative risk associated with the condition. For example, in the United States hypertensive disease of pregnancy is associated with a twofold increase in the risk of perinatal and infant mortality (a relative risk of 2), whereas in the West Bank of Jordan hypertension in pregnancy is associated with a relative risk of 4, and in the Peoples Republic of China it is associated with a relative risk of 8 , using the same definition for a case. The relative risk varies, in part, because of differences in the way the disease is treated in these countries.

Attributable risk indicates the proportion of all cases in a population that can be accounted for by the presence of the risk factor. The utility of risk assessment is directly related to attributable risk. For example, while it is true that older women have a higher relative risk of maternal death, in absolute numbers they often make up a minority of the women who die. Because most babies are born to younger women, the attributable risk of death associated with higher maternal age is relatively low. A rare factor with a high relative risk accounts for fewer problems than a common factor with a lower relative risk. Attributable risk is more important than relative risk for assessing the public health importance of a risk factor.

Absolute risk is the risk (or chance) of experiencing a poor outcome. Relative risk refers to the probability of having a poor outcome given the presence of a risk factor as compared with the probability of having a poor outcome in the absence of the risk factor. In fact, a highrisk woman may be unlikely to have problems, even though her risk may be several times higher than that of low-risk women.

The following example is based on data similar to those from several studies conducted in Bangladesh, in which the risk of death for women in some of the highest-risk groups was 
approximately 17 times greater than the risk of death for women in the lowest-risk groups. ${ }^{1}$ This means that in the lowest-risk group, only one woman died out of every 1,000 who gave birth, whereas in the highest-risk group, 17 maternal deaths occurred for every 1,000 births. Thus, the relative risk associated with high-risk status was 17. Figure 3.2 shows the risk of dying for women in the two extreme groups (highest-risk and lowest-risk) as a ratio. Shown this way, the difference in risk between the two groups is dramatic. However, as seen in Figure 3.3, if the same information is shown as the percent of women who died in each group, plotted on a true scale (17/1,000 women in the high-risk group died as compared with $1 / 1,000$ in the low-risk group), the difference seems less strong. Figure 3.2 illustrates relative risk; Figure 3.3 illustrates absolute risk.

\section{FIGURE 3.2}

Relative Risk of Death Per 1,000 Live Births

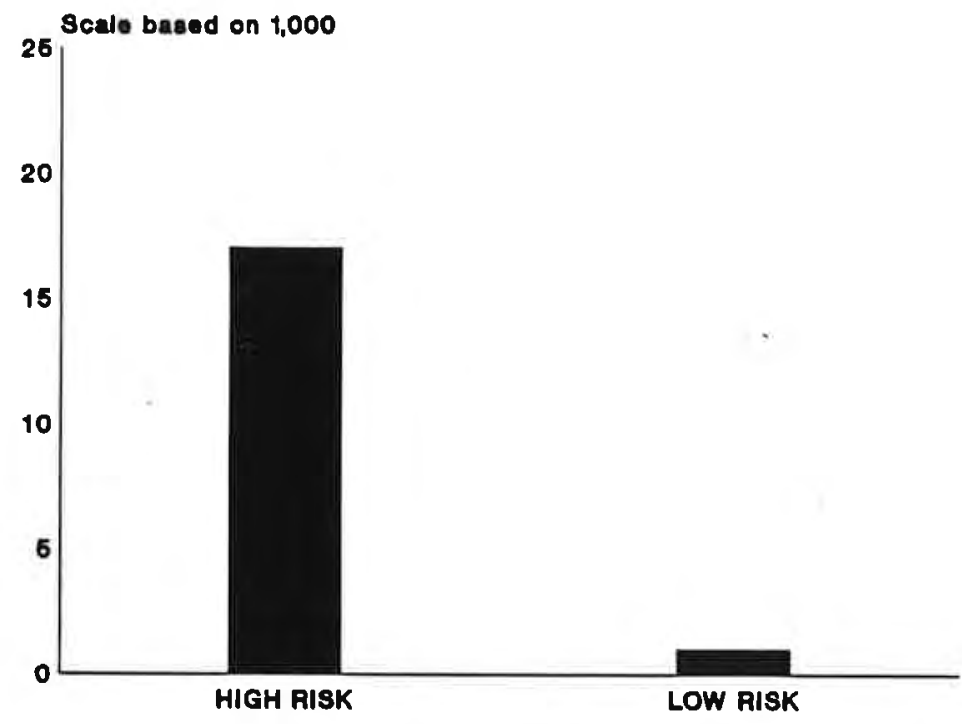

Note: When the high-risk womens risk of dying is $17 / 1,000$ pregnancies, the low-risk womens risk of dying is $1 / 1,000$ pregnancies, and the relative risk associated with high-risk status is 17. Winikoff/Population Council

1 Data from the following studies demonstrate relative risks of this order of maternal death between different age/parity subgroups: Alauddin (1986), Chen et al. (1974), Khan et al. (1986). 


\section{FIGURE 3.3}

\section{Absolute Risk of Death Per 1,000 Live Births}

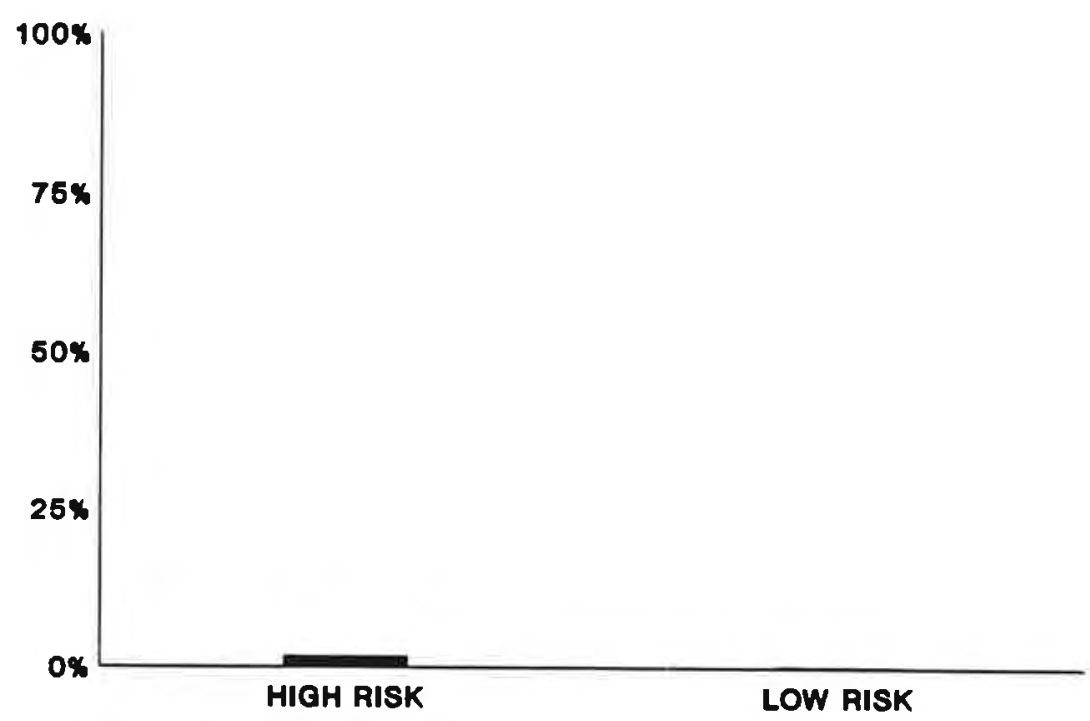

Note: When the high-risk womens risk of dying is $17 / 1,000$ pregnancies, the low-risk womens risk of dying is $1 / 1,000$ pregnancies, and the relative risk associated with high-risk status is 17.

Winikoff/Population Council

\section{Assessments of women who are pregnant for the first time are least accurate.}

Information about complications and outcomes of previous pregnancies is one of the most reliable tools for predicting future problems, and women who are pregnant for the first time have no obstetric history. As a result, virtually all maternal risk assessment scoring systerns are more accurate when applied to parous than to nulliparous women. A study conducted in Zaire found obstetric history to be the best predictor of obstructed labor in the current pregnancy (Kasongo Project Team, 1984). Women with previous complications were nine times more likely to develop obstructed labor than were women with no such history. In addition, women having their first babies have an elevated risk of complications and a somewhat elevated risk of perinatal and maternal mortality. 


\section{Problems and Limitations}

\section{Predicting Complications During Labor and Delivery: Formalized Risk Assessment Versus the Judgment of Trained Clinicians}

Although a formalized risk assessment guide may lead clinicians to observe and consider risk factors that they might otherwise overlook, clinical judgment goes beyond the application of any formal set of screening and referral rules. Despite widespread use of obstetric risk-scoring systems in the United States, their clinical value is controversial among American midwives and physicians. Two papers in the North American medical literature described findings from a study of outcomes of the singleton pregnancies of 795 women who had been cared for in a family practice that offered childbirth in local hospitals, patients' homes, or birth rooms located within the practice office suite (Acheson et al., 1990; Kelly et al., 1988). Although the practice did not use a formal risk-scoring system, the authors used retrospective data from the practice to determine which of three published risk-scoring systems would have been most accurate in predicting which women would develop complications. The doctors' own clinical judgment was more accurate than two of the risk-scoring systems and virtually as accurate as the best risk-scoring system in predicting which of the women would need to give birth in the hospital. All three systems were better at predicting the kind of care needed by parous as compared to nulliparous women. The best system (Goodwin et al., 1969) "correctly" classified 69 percent of the nulliparous women and 88 percent of the parous women as low-risk if they did not require transfer to a higher level of care and as high-risk if they did. In comparison, clinical judgment "correctly" classified 66 percent of the nulliparous women and 86 percent of the parous women with regard to the need for transfers. The Goodwin risk score was less powerful than clinical pelvimetry in predicting the need for transfers to higher-level care facilities among the nulliparous women, but was more accurate than any single risk factor in predicting the transfers of parous women.

\section{Inherent Limitations in the Usefulness of Risk Assessment}

A risk instrument cannot accurately predict the outcome for a particular woman; "risk" is a statement of probability based on data from a population. Women are assigned to a high-risk group because they have characteristics that are statistically associated with an untoward event. However, although the mortality rate for a population may be 2 percent, any given individual can only live or die. Within a given time period an individual has a mortality rate of either zero or 100 percent; it can never be 2 percent, even though the individual is part of a 
group with a 2 percent chance of dying. In other words, the outcomes predicted by "odds" apply to groups, not to a single individual, and error is inevitable when risk statements based on the experience of a group are applied to an individual.

Even so-called low-risk women are at risk. Many people use the term "at risk" rather than high-risk. However, although the opposite of "high-risk" is "low-risk," we cannot say that the opposite of "at risk" is "not at risk," since all pregnancies involve some degree of risk. The writings of even some accomplished and respected experts display an unwillingness to accept this fact. For example, one of the best-known articles on indices of high-risk pregnancies defines a "false negative" as a high-risk patient who is mistakenly classified as being at low risk. This definition implies that false negatives result from misclassification. Although misclassifications do occur, true "false negatives" are not misclassified but are individuals who develop the complication or disease despite their low-risk status. "Low-risk" implies a low probability of experiencing problems - that is, that the individual is a member of a group that experiences only a low incidence of the problem. But a low incidence is still an incidence; a low incidence means that a few members of that group will experience the problem.

Because our knowledge of the causes of complications is incomplete, all risk assessment instruments are flawed.

Predicting complications will not save any lives unless the system that makes the prediction is also able to provide effective treatment. In developing countries, medical care to treat pregnancy complications is often either inadequate or inaccessible. In a situation in which women with obvious current complications cannot get adequate treatment, it is wasteful to invest scarce resources (money and effort) in programs to identify women who do not yet have complications but are at increased risk of experiencing a complication at some point in the future. One seminar participant gave a recent example from northern Nigeria of a woman who died after spending many hours in a hospital that lacked the supplies needed to save her life. She was admitted with a diagnosed ruptured uterus, but, because of a lack of supplies, it was 18 hours before the hospital staff could do anything for her. Risk assessment without an attempt to decrease the likelihood of a poor outcome or to achieve some other benefit is not ethical. 
Problems with Using Maternal and Infant Mortality Data to Identify Risk Factors and Evaluate Risk Assessment Systems

Maternal and infant mortality data may not be accurate. Maternal and infant deaths are underreported in most societies and are very underreported in most developing countries, and the underreporting is unlikely to be random. Deaths among certain groups within the population and deaths from certain causes are much more likely than other deaths to come to the attention of the authorities and thus to be reported. Deaths that occur in hospitals are almost always reported, while deaths that occur in remote areas may not be reported. Since all cesarean sections take place in hospitals, complications that are treated by cesarean sections may appear to cause a higher proportion of the maternal deaths than may actually be the case. In contrast, deaths caused by clandestine abortions may be hidden from authorities or attributed to other causes.

If the risk assessment system improves the pregnancy outcome for high-risk women, it will eventually reduce the statistical association between risk factors and mortality. In such cases, data on morbidity would provide a more accurate base than data on mortality for determining characteristics associated with problems related to pregnancy.

\section{$\underline{\text { References }}$}

Acheson, L.S., S.E. Harris, and S.J. Zyzanski. "Patient selection and outcomes for out-of-hospital births in one family practice." Journal of Family Practice 31 (1990): 128-36.

Alauddin, Mohammed. "Maternal mortality in rural Bangladesh: The Tangail District." Studies in Family Planning 17, no. 1 (1986): 13-21.

Chen, L.C., Melita C. Gesche, Shamsa Ahmed, A.I. Chowdhury, and W.H. Mosley. "Maternal mortality in rural Bangladesh." Studies in Family Planning 5, no. 11 (1974): 334-41.

Goodwin, J.W., J.T. Dunne, and B.W. Thomas. "Antepartum identification of the fetus at risk." Canadian Medical Association Journal 101 (1969): 57-67.

Khan, A.R., F.A. Jahan, and S.F. Begum. "Maternal mortality in rural Bangladesh: The Jamalpur District." Studies in Family Planning 17, no. 1 (1986): 7-12.

Kasongo Project Team. "Antenatal screening for fetopelvic dystocias: A cost-effectiveness approach to the choice of simple indicators for use by auxiliary personnel." Journal of Tropical Medicine and Hygiene 84, no. 4 (1984): 173-83.

Kelly, R.B., L.S. Acheson, and S.J. Zyzanski. "Comparison of three prenatal risk scores in a series of low-risk pregnancies." Family Medicine 20 (1988): 122-27. 
Rooks, J.P., N.L. Weatherby, E.K.M. Ernst, S. Stapleton, D. Rosen, and A. Rosenfield. "Outcomes of care in birth centers: The National Birth Center Study." New England Journal of Medicine 321 (1989): 1804-11.

Selwyn, B.J. "The accuracy of obstetric risk assessment instruments for predicting mortality, low birthweight, and preterm birth." In New Perspectives on Prenatal Care. Ed. I.R. Merkatz and J.E. Thompson. New York: Elsevier, 1990. P. 58. 


\title{
Chapter 4:
}

\section{IMPLEMENTING THE RISK APPROACH IN MATERNITY CARE IN WESTERN COUNTRIES}

\author{
Efforts to "Regionalize" Perinatal Care in the United States \\ (from a paper by Judith Rooks, C.N.M., M.S., M.P.H.)
}

During the 1970s two large foundations, four major medical organizations, and the United States government collaborated in an expensive effort to develop a system to refer highrisk pregnant women and newborns to hospitals capable of providing the most sophisticated obstetric and neonatal care. ${ }^{2}$ The system they were trying to create, called "regionalized perinatal care," is based on maternal risk assessment. This effort was motivated in large part by concern about the U.S. infant mortality rate, which at that time was higher than the rate in 15 other industrialized countries (Robert Wood Johnson Foundation, 1978).

Techniques developed during the 1960s had made it possible to evaluate the status of fetuses during labor and to support respiration in severely distressed newborns (DeGeorge et al., 1971; Ryan, 1974). Medical journals reported large reductions in neonatal mortality in hospitals that had established neonatal intensive care units and in geographic regions that had developed systems to transport high-risk women and babies to hospitals that could provide intensive obstetric and neonatal care (Carrier et al., 1972; Merkatz and Fanaroff, 1978; Meyer et al., 1971; Thampson et al., 1977). Regionalization of perinatal care was a strategy to lower infant mortality by making these new, advanced forms of therapy available to all pregnant women and infants who might benefit from their use.

In 1972 the Robert Wood Johnson Foundation began to plan a national program to test and evaluate the effectiveness of using risk assessment and referral to concentrate the care of high-risk mothers and newborns in hospitals that could provide the new intensive care. The plan they developed called for classifying all hospitals as Level I, Level II, or Level III (Committee on Perinatal Health, 1976).

The largest and most sophisticated hospitals were to be designated as Level III (tertiary).

2 The groups were the Robert Wood Johnson Foundation, the National March of Dimes Foundation, the American Medical Association, the American Academy of Family Physicians, the American Academy of Pediatrics, and the American College of Obstetricians and Gynecologists. 
They were usually associated with medical schools, were staffed for around-the-clock emergency care, and had the staff and equipment to care for serious illnesses and childbirth complications. Level II hospitals were the intermediate-sized private and community hospitals that provide most of the care to most of the patients in most of the cities in America. All smaller hospitals were designated as Level I.

Each perinatal regional network was to be based around a single Level III hospital. In the system, Level III hospitals were expected to take care of their own clientele (many are taxsupported institutions that are responsible for providing health care to the poor) and to provide intensive care to high-risk women and infants referred to them from Level II and Level I hospitals. Level II hospitals were supposed to conduct normal deliveries and take care of most obstetric complications and some neonatal illnesses. Level I hospitals were restricted to uncomplicated deliveries and the care of healthy babies.

All maternity care providers within the region were to be trained to use a uniform risk assessment scoring system. Women were to be assessed at their first prenatal visit and at 32 weeks of pregnancy. High-risk women were to be referred from Level I to Level II or III , and from Level II to Level III, based on numeric risk assessment scores. The planners anticipated that $60-70$ percent of serious intrapartum and newborn complications would be identified during prenatal care and that women for whom complications had been predicted would go to the tertiary hospital for labor and delivery. However, since 30-40 percent of complications would not be predicted, it would be necessary to transport some women to Level III hospitals during labor and some infants following birth. Emergency transportation was designed into the system.

In 1975 the Robert Wood Johnson Foundation provided \$22 million to demonstrate this system in eight selected areas over a period of five years (Robert Wood Johnson Foundation, 1978). The eight areas covered only 6 percent of all U.S. births. The purposes of the program were to reduce neonatal mortality and morbidity, to prevent inefficient proliferation of expensive intensive care, and to create centers where there would be enough high-risk cases for the doctors and nurses to become and remain proficient at providing sophisticated care.

At the same time, the National March of Dimes Foundation convened a committee composed of representatives of the American Medical Association, the American Academy of Family Physicians, the American Academy of Pediatrics, and the American College of Obstetricians and Gynecologists to develop specific, workable guidelines to implement regional 
planning for maternal and newborn care. The committee's report, published in 1976, was a blueprint for expanding perinatal regionalization throughout the country (Committee on Perinatal Health, 1976). Their recommendations were similar to the Robert Wood Johnson Foundation plan but added a new element by specifying that Level III hospitals should have a minimum number of 8,000-12,000 deliveries per year, that Level II hospitals should have at least 2,000 deliveries per year, and that, except under special circumstances (geographic remoteness and transportation difficulties), hospitals with fewer than 2,000 deliveries per year (Level I hospitals) should close their maternity services in order to "consolidate" them into larger services. "Consolidation" meant eliminating the practice of obstetrics in as many small hospitals as possible.

In 1977 the federal government moved the process forward by incorporating recomm: dations from the March of Dimes report into proposed "National Guidelines for Health Planning" (DHEW, 1977). These were to be powerful guidelines, which could not be ignored. The final guidelines called for closing small maternity units and consolidating services in high-risk acute care settings.

As the guidelines began to be implemented in more regions of the country, a difference became evident between what happened in obstetrics and what happened in neonatal intensive care. Although "regionalized perinatal care" merged high-risk obstetrics with high-risk neonatal care, these specialties are very different.

In the first place, most of the benefit ascribed to intensive perinatal care was based on the effectiveness of neonatal intensive care. Since publication of the first papers on this subject it had been clear that this kind of care reduces low birthweight mortality. The only real question was whether many of the saved babies would be neurologically damaged. In addition, neither the lower-level hospitals nor the pediatricians who used them were opposed to transferring distressed babies to a tertiary hospital. Neonatal intensive care requires expensive equipment, 24-hour-a-day coverage by specially trained nurses, and neonatologists who are on the full-time hospital staff. Most hospitals cannot afford these units, and, since most pediatricians work out of their offices, they did not want to be responsible for this care. Also, once a baby is born, it is either sick or well; levels of risk and the possibility of high-risk pregnancies resulting in normal births are no longer the issues. If a baby weighs only three pounds or cannot breathe, it is in trouble; it is not just "high-risk." There are no false positives, and only a few babies need to be transferred. Level I and Level II hospitals were happy to transfer their sick and tiny newborns, of 
whom there are relatively few, to more intensive care. When the babies were better, they were discharged to the care of the family pediatricians. There was no danger that hospital-based neonatologists would steal patients from the private doctors.

None of this is true with regard to obstetric care. The new obstetric techniques mainly provide better information about the condition of the fetus during pregnancy and labor. Although they allow obstetricians to detect problems earlier and monitor them better, the main treatment was still to hasten delivery, by cesarean section if necessary. The benefits are not nearly as clear as the results from providing intensive neonatal care. (A recent study from the United States showed no benefit from delivery in a tertiary hospital for babies who were not low birthweight [Mayfield et al., 1990].) In addition, obstetricians did not want to refer their patients; they wanted to learn the new techniques. Intensive obstetric care did not require a new hospital unit with lots of equipment and round-the-clock special nursing care. The gradient between what could be provided in a university hospital and what could be provided in a good community hospital was not at all like the gradient between a regular nursery and a neonatal intensive care unit. Obstetricians expected to deliver the babies of their patients, and their patients expected it, too. Referring a high-risk woman to another hospital and doctor causes the local hospital and doctor to lose face; this situation is particularly unacceptable when many women who are labeled "high-risk," based on screening criteria, in fact have normal births. Thus, although there was little resistance to sending sick babies to tertiary hospitals, obstetricians were more likely to pressure their own hospitals to buy the necessary equipment and to begin to employ the new techniques themselves.

An evaluation conducted at the end of the Robert Wood Johnson Foundation's five-year program compared perinatal care and outcomes in the eight demonstration areas with those in eight similar areas that did not receive special regionalization funds (McCormick et al., 1985). During the 1970 s the percent of low birthweight deliveries, especially very low birthweight deliveries (less than 1,500 grams) had become significantly more concentrated in tertiary centers. During the project the percent of very low birthweight infants born in tertiary centers increased from 47 to 60 percent. However, this increase was part of a national trend and was not greater in the eight project areas. There was also a decrease in long-term morbidity and disability among children who had been low-weight at birth. Nevertheless, at the end of the fiveyear project, 40 percent of the very tiniest babies were still not being born in tertiary centers, which was the level of sensitivity that the Foundation had expected. 
The evaluation supported earlier evidence that caring for babies in neonatal intensive care units reduces neonatal mortality without increasing the number of surviving infants who are burdened with lifelong impairments. However, when the Foundation reviewed its experience with perinatal regionalization, they found that many perinatologists believed that further improvement in high technology medicine could not contribute much to continued reduction in the United States' infant mortality rate. Instead they looked for progress at the "low tech" end of the spectrum, through prevention of low birthweight by family planning and higher-quality prenatal care (Robert Wood Johnson Foundation, 1978).

The United States does better than any other country at saving the lives of low birthweight babies; regionalization of perinatal care contributed to this achievement. However, regionalization did little or nothing to reduce the causes of low birthweight, and therefore its actual incidence. Because of a high proportion of low-weight births, the United States' international ranking with regard to infant mortality worsened during the 1970s and 1980s; 21 other countries now have lower infant mortality rates (Institute of Medicine, 1985, 1989; The Nation's Health, 1990). The underlying causes of preterm labor and intrauterine growth retardation (which are the immediate causes of low birthweight) must be addressed before labor begins. Despite 15 years of efforts to organize and improve care during and after labor and delivery, the United States has only recently begun to focus on prenatal care. In addition, some aspects of the effort to regionalize birth care may have impaired the United States' ability to provide prenatai care:

- The closure of some small obstetric units drove obstetricians out of many small towns and discouraged family physicians from practicing obstetrics. This trend, in combination with the stress and high financial cost of frequent malpractice suits against doctors practicing obstetrics, has resulted in a situation in which there is no one available to deliver the babies in some communities. The emphasis on closing small obstetric services was unnecessary for achieving the goals of regionalization. A growing body of evidence finds that small-volume obstetric care is safe and less expensive (Fleck, 1977; Gray and Steele, 1981; Minor, 1989; Rooks et al., 1989; Rosenblatt et al., 1985; Rosenblatt et al., 1988).

- The idea of providing prenatal care in many dispersed clinics while centralizing deliveries in a single large hospital creates a schism between prenatal and childbirth care. Pregnant women see prenatal care as preparation for the coming birth and value it more when it is provided by the people who will be with them when they have their babies. Prenatal clinics that are dissociated from intrapartum care lose power in the eyes of their patients; pregnant women who do not value prenatal care might not bother 
to use it even when it is convenient and affordable.

- Regionalization contributed to the over-medicalization of childbirth in America and to the financial costs associated with excessive use of high-technology obstetric care. Several factors contributed to this:

--Health care professionals focused on risk assessment but knew it was imperfect. Because false negatives are inevitable, some obstetricians argued that all pregnant women should be treated as high-risk.

--When small obstetric services closed and the percent of deliveries in tertiary hospitals increased, many communities no longer had a model for normal maternity care. Medical students and obstetric residents learned a highly medicalized way to take care of women during labor, and took that model with them when they finished their training. Over time, obstetric techniques that had been developed for use in high-risk cases were applied more and more broadly; in some cases their use became routine. The United States has experienced huge increases in the use of continuous internal electronic fetal monitoring and oxytocin to induce or augment labor. Some labors were induced to avoid a lastminute rush for women who lived far from the hospital, which was more common where small obstetric services had closed. Nearly one in four American babies is now delivered by cesarean section (Taffel et al., 1991).

This kind of care is very expensive and consumes resources that could be used to improve access to prenatal care and other preventive services.

Thus, the application of maternal risk assessment in the United States yielded problems as well as benefits. Some of those problems might have been avoided if:

- a real effort had been made to focus on nutrition, to help women stop smoking, or to use other, truly preventive measures to lower risk;

- a real effort had been made to find high-risk women and provide them with prenatal care. In the United States, some of the highest-risk women do not seek prenatal care;

- criteria had been established for low-risk pregnancy, labor, and birth; attention was given to developing appropriate care for low-risk women; and a mandate was set up for tertiary hospitals to refer low-risk women to lower-level care;

- the system was not in the control of the tertiary centers and of physicians who specialize in high-risk care (aimost all of the efforts went toward developing the high-risk 
centers, and little effort was made to improve primary care).

The attempt to regionalize perinatal care was, of course, not the only factor that influenced American maternity care during the past two decades. The way that maternity care is paid for encourages the use of some forms of technology but does not reward doctors for spending more time to provide patient education, counseling, and other important aspects of prenatal care. Many pregnant women are poor and government payments for their care are relatively meager (Kenney et al., 1986). In addition, Medicaid (the government system to pay for care for the poor) pays only for the delivery, assuming that the person who manages the birth also provides and is being paid for the entire package of necessary care. Such a policy tends to discourage obstetric referrals, since the referring physician is unlikely to be paid for the early prenatal care. The threat of malpractice litigation and the high cost of professional liability insurance has also had a negative impact on maternity care in the United States, as noted above. A 1987 survey of obstetricians found 41 percent had limited their obstetric practice, including 12 percent who were no longer accepting pregnant patients (Opinion Research Corporation, 1988). In addition, as mentioned earlier, obstetric practice by general and family physicians - who provide most of the maternity care in rural areas - has declined sharply (Smucker, 1988). Although some attribute this decline primarily to concerns related to professional liability, others have identified the increasingly technological style of American obstetrics as a root cause of the problem (Rooks, 1990; Rosenblatt, 1988).

\section{Low-Risk Women Nonhospital Childbirth Care: Antepartum Assessment of Intrapartum Risk in American Birth Centers}

(from a paper by Norman Weatherby, Ph.D., Center for Health Services Research, University of Miami School of Medicine, Miami, Florida)

Birth centers are nonhospital facilities organized to provide family-centered maternity care to women who are thought to be at low risk of obstetrical complications. American birth center care is typically provided by certified nurse-midwives, although some birth centers are operated by physicians (obstetrician/gynecologists or family practitioners), and a few are operated by other kinds of midwives.

The goal of antepartum risk assessment in birth centers is to refer high-risk women to hospltal care before labor begins in order to keep them out of the birth centers. Women who 
"survive" the screening and are admitted to birth centers for intrapartum care should be at low risk for serious intrapartum complications and relatively few should need to be transferred to hospitals. Data derived from the National Birth Center Study (a prospective descriptive study of 17,856 women who enrolled for care in 84 birth centers throughout the United States during 1985 and 1987) (Rooks et al., 1989) were used to examine the nature and effectiveness of this screening. Six of the 84 birth centers in the study were owned by hospitals. Preliminary analysis showed that the birth centers owned by hospitals were more likely than the others to advise their clients during prenatal care to go to a hospital for labor and delivery. Because of that difference, the following analysis of the antenatal referral practices of birth centers is limited to the 78 birth centers that were not owned by hospitals.

More than 15,000 women enrolled for care in these 78 birth centers during the study period. Slightly more than 7 percent of them were "risked out" or for other reasons decided to discontinue birth center care at the end of their first complete prenatal visit. Another 16 percent discontinued birth center care for nonmedical reasons at some later point in their pregnancies. Of the remaining 11,910 women, 1,809 (15 percent) were referred to hospital care during the prenatal period and 10,101 (85 percent) were admitted to birth centers for intrapartum care.

\section{The Women}

This analysis and evaluation of birth center risk referral behavior is based on data from these 11,910 women. In addition to the screening that occurred during their first prenatal visits, they were self-selected to be relatively low-risk; it is unlikely that women who believe that they are high-risk would chose birth center care. Nevertheless, many of the women had one or more of the social and/or demographic characteristics that are statistically associated with a higherthan-average risk of poor pregnancy outcomes among women in the United States. As shown in Table 4.1, 3.0 percent were less than 18 years of age and 8.2 percent were more than 34 years of age; 13.6 percent of those who were old enough to have finished high school had not done so; 9.0 percent were unmarried; 15.4 percent were Hispanic; and 27.7 percent were of low socioeconomic status. The birth center clients were quite low-risk, however, in terms of their health habits and life-styles. Few of them smoked or drank during pregnancy. In addition, only 9.4 percent of those who received prenatal care at the birth centers (1.5 percent of those who were admitted to birth centers for intrapartum care) had fewer than four prenatal visits. However, although they averaged 11 prenatal visits per woman, 34.5 percent of the women waited until the second trimester to start prenatal care. Delay in starting prenatal care is statistically associated with a higher risk of poor pregnancy outcomes among women in the 
United States.

TABLE 4.1

"Risk" Characteristics of 14,310 Women Who Started Antepartum (AP) Care in Birth Centers (BCs), and of 10,175 of those Women Who Were Admitted to Birth Centers for Intrapartum (IP) Care

\begin{tabular}{lcc}
\hline Characteristic & $\begin{array}{c}\text { Women Starting } \\
\text { AP Care in BCs } \\
\text { (percent) }\end{array}$ & $\begin{array}{c}\text { Women Ádmitted } \\
\text { to BCs for IP } \\
\text { Care (percent) }\end{array}$ \\
\hline Age $\langle 18$ years & 3.0 & 2.3 \\
Age $\rangle 4$ years & 8.2 & 8.0 \\
Years of education $\left\langle 12^{\mathrm{a}}\right.$ & 13.6 & 13.0 \\
Unmarried & 9.0 & 7.4 \\
Hispanic & 15.4 & 15.3 \\
Low socioeconomic status & 27.7 & 25.4 \\
Did not smoke during pregnancy & 88.8 & 90.1 \\
Did not drink during pregnancy & 88.5 & 88.7 \\
Number of antepartum visits $\langle 4$ & 9.4 & 1.5 \\
& & \\
\hline
\end{tabular}

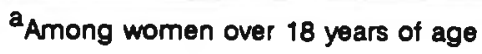

\section{Limitations of Available Risk-Screening Tools}

Most of the risk assessment data base is oriented toward prediction of neonatal or perinatal mortality, or of low birthweight, which is the main predictor of that mortality. Relatively little attention has been given to prenatal prediction of complications that occur to either the mother or the baby during or immediately after labor and delivery. In addition, most of the existing data and literature come from studies of relatively high-risk patient populations. Studies by Ross et al. (1986), Maine and Gabbe (1987), and Molfese et al. (1987) indicate that riskscoring systems tend to be applicable mainly to the sample from which they were developed, although individual items contained in various risk-scoring instruments have value for the prediction of specific complications. Thus, the ability of current risk assessment methods to anticipate intrapartum and immediate postpartum and neonatal complications among a selfselected population of relatively low-risk women was not known.

\section{Prenatal Referrals}

Fifteen percent $(1,809)$ of the women were referred to hospitals during antepartum care. There is no evidence that the birth centers referred women on the basis of the demographic, socioeconomic, or behavioral/life-style risk factor commonly mentioned in the published 
literature on risk assessment. Instead, the prenatal referrals appeared to be related to parity and the identification of medical/obstetric risk factors. As seen in Table 4.2, 53 percent of the nulliparous women and 51 percent of the parous women had at least one medical/obstetric risk factor. Of the women with one or more recognized medical/obstetric risk factor, 40 percent of those who were nulliparous and 20 percent of those who were parous were referred away from the birth center during prenatal care. Less than 1 percent of the women with no identified medical/obstetric risk factors were referred. Many of these "risk factors" actually constitute the early diagnosis of pathology. Women with diabetes mellitus, suspected intrauterine growth retardation, or multiple gestation were almost always referred. However, parity affected the likelihood that women with some diagnoses would be referred; over half of the nulliparous women but only a third of the parous women who had preterm labor, nonvertex presentation, pregnancy over 42 weeks of gestation, or premature rupture of membranes were referred. Other reasons for referral included positive Rh titre, pre-eclampsia, herpes titre or lesion, persistent anemia, hypertension, gestational diabetes, urinary tract infection, second or third trimester vaginal bleeding, and poor outcome of a previous pregnancy.

\section{TABLE 4.2}

Antepartum Referrals Among 11,910 Women Who Received Antepartum Care At Birth Centers, According To Parity And Selected Medical/Obstetric Risk Factors Recognized During Antepartum Care

\section{Number of Medical/ Obstetric Risk Factors Recognized During Antepartum Care}

Women Subject to Antepartum Referral ${ }^{a}$ number and percent of total)

\section{Nulliparous Parous Nulliparous Parous}

Women Referred (number and percent of those subject to referral)

\begin{tabular}{lrrrr}
\hline $\begin{array}{l}\text { None } \\
\text { One or more }\end{array}$ & $2,340(46.6)$ & $3,380(49.0)$ & $22(0.9)$ & $20(0.6)$ \\
& $2,678(53.4)$ & $3,512(51.0)$ & $1,078(40.3)$ & $689(19.6)$ \\
& & & \\
Total & $5,018(100.0)$ & $6,892(100.0)$ & $1,100(21.9)$ & $709(10.3)$ \\
\hline
\end{tabular}


Despite these referrals, 43 percent of the women who were ultimately admitted to the birth centers for intrapartum care had at least one recognized medical/obstetric risk factor.

\section{Outcomes for Women Admitted to Birth Centers for Intrapartum Care}

A total of 10,175 women were admitted to the birth centers for care during labor and delivery; 39 percent of them were nulliparous and 61 percent were having a second or higherorder baby. Twenty-seven percent of the nulliparous and 6 percent of the parous women (or their infants) were transferred to hospitals during or soon after labor and delivery. There were no maternal deaths, and 14 intrapartum and neonatal deaths (1.37/1,000 births); 0.65 percent of the babies had five-minute Apgar scores lower than $7 .^{3}$ The combined intrapartum and neonatal mortality rate for post-term pregnancies (more than 42 completed weeks of gestation) was $3.42 / 1,000$ births, compared with a rate of 1.15/1,000 births for pregnancies at term. These outcomes, which include results for the transferred cases as well as babies delivered in the centers, compare favorably with outcomes reported from studies of low-risk births in American hospitals (Rooks et al., 1989). The good outcomes of care in nonhospital birth centers result in part from the fact that 15 percent of the women were referred for other care, in most cases on the basis of medical or obstetric complications. The favorable comparison with outcomes of low-risk hospital births is also true for the post-term pregnancies, which are associated with poorer outcomes regardless of the place of birth.

Despite the good final outcomes, 9.4 percent of the nulliparous women and 6.4 percent of the parous women (or their infants) experienced serious emergency complications while they were in the birth centers. Serious emergency complications are those that are associated with an increased risk of death or permanent damage to the health of either the mother or the infant and that usually require immediate hospital care for optimal treatment. A major goal of antenatal screening in birth centers is to avoid the occurrence of serious, emergency complications in the centers.

\section{Should Birth Centers Use More Sensitive Screening Methods?}

Fifty-six percent of the women admitted to birth centers for labor and delivery had no known medical or obstetric risk factors; this was the case for 59 percent of the nulliparous

The Apgar score is a numeric score between 0 and 10 based on a systematic assessment of the newborn at specified times after its birth; a maximum of two points each are assigned for heart rate, respiratory effort, muscle tone, reflex, irritability, and color. 
women and 54 percent of the parous women. This group of apparently risk-free women experienced approximately one-half of the intrapartum transfers and serious emergency complications.

Nulliparous women with one or more prenatally recognized medical/obstetric risk factors were more likely than those without such factors to be transferred to hospitals during the intrapartum period (31.6 percent as compared with 23.6 percent) and to experience at least one serious emergency complication during or soon after labor and delivery (11.3 percent versus 8.1 percent). If all nulliparous women with any recognized medical risk factor had been referred during prenatal care, the overall incidence of serious complications would have declined by 9.3 percent, the need for transfers would have declined by 23.3 percent, and the number of women using the birth centers for labor and delivery would have dropped by 15.8 percent.

Parous women with a medical or obstetric risk factor were also more likely than those without such factors to be transferred to hospitals during or soon after labor and delivery $\mathbf{7 . 5}$ percent as compared with 4.8 percent) and to experience one or more serious emergency complication (7.3 percent as compared with 5.7 percent). However, if every parous woman with a recognized medical/obstetric risk factor had been referred to hospital care, the number of women using the birth centers for labor and delivery would have dropped by 27.9 percent, while the percentages of women experiencing serious complications and transfers would have increased. This paradoxical finding flows from the fact that parous women who had experienced complications during prenatal care were less likely than nulliparous women with no previous complications or other known risk factors to experience intrapartum complications or to be transferred to hospitals during or soon after labor and delivery.

Failure to progress was a factor in 62.0 percent of the intrapartum transfers and was closely associated with parity. Twenty-seven percent of the nulliparous women were transferred and 70 percent of those who were transferred experienced failure to progress. Failure to progress occurred less frequently among parous women; only 6 percent of them were transferred and 39 percent of those transfers involved failure to progress. Women with some specific prenatal diagnoses were more likely to end up with a transfer related to failure to progress. Of the nulliparous women who were admitted to birth centers for intrapartum care despite prenatal diagnoses of premature rupture of membranes, nonvertex presentation, pregnancy over 42 weeks of gestation, urinary tract infection, or being overweight (by more than 20 pounds) prior to pregnancy, 45-65 percent were ultimately transferred from the centers during 
labor because of failure to progress. About one-third of the parous women with one or more of these prenatal diagnoses had an intrapartum transfer for failure to progress.

The birth centers could have decreased both the percentage of cases with serious emergency complications and their perinatal mortality rate if they had referred all nulliparous women with post-term pregnancies to hospitals. Twenty-one percent of such women experienced serious emergency complications in the birth centers, a rate that is much higher than the incidence among women with no prenatal complications; thick meconium during labor was the most frequent serious complication experienced by these women. However, because post-term deliveries in hospitals are also associated with increased perinatal risk (Eden et al., 1987), no evidence exists that this practice would have actually saved any babies' lives.

\section{Summary}

Prenatal referrals based on medical and obstetric risk factors, but not on social and demographic factors, resulted in safe out-of-hospital care in a large population of self-selected, behaviorally low-risk American women. In this low-risk, screened population, about half of the serious complications occurred to women for whom no medical/obstetric risk factors were identified during antepartum screening and care. More sensitive screening (that is, referring more or all of the women with any medical/obstetric risk factors) would have greatly reduced the number of women who used birth centers without significantly reducing the incidence of serious problems. It is essential, therefore, that the midwives and physicians who provide nonhospital birth care be prepared to manage complications; in many cases, this management includes transfers to hospital care.

Parous women were less likely than nulliparous women to have a serious emergency complication. That was true regardless of whether the women had any recognized medical risk factors.

In order to reduce the need for intrapartum transfers of women from birth centers to hospitals, we need to refine our ability to predict failure to progress during prenatal care and/or during the early phases of the first stage of labor.

Referring women with post-term pregnancies for hospital deliveries will reduce the incidence of complications and poor outcomes in birth centers, but it will not necessarily improve the outcomes for the individual women and their babies. 


\section{New Zealand's Regionalized Perinatal System}

(from the paper by Roger Rosenblatt, M.D., Professor and Vice-Chairman, Department of Family Medicine, University of Washington School of Medicine, Seattle, Washington)

New Zealand combines aspects of the industrialized western world with some of the problems of less developed countries. Although the people of New Zealand are primarily of European origin, the country retains an important agrarian base with a large rural population and a fragile economy. The health care system is a hybrid, with elements of a nationalized system that coexist with a vocal private sector. Largely as a consequence of national economic decline, New Zealand has had to confront severely constrained resources for all public health services. National health care expenditures have been static or have declined in real terms during recent years.

New Zealand created a formal regionalized perinatal care system in 1975 . The system requires the categorization of facilities according to their level of technical capability and the use of risk-based clinical guidelines for referral, consultation, and transfer of women who are identified as high-risk during care in community settings. Maternity care is provided by specialist obstetricians, general medical practitioners (GPs), and midwives. Obstetricians work primarily in the larger state-run hospitals, although they may also have private patients. All GPs are in private practice, although their obstetric fees are paid almost entirely by the state. Midwives are employed by state-run hospitals.

As in the United States, New Zealand's perinatal regionalization scheme is based on the designation of three levels of obstetric facilities. There are five Level III (tertiary referral) hospitals, each with a sophisticated neonatal intensive care unit. Each of the country's 19 health districts contains one hospital that has been designated as a Level II obstetric unit. The other 80 hospitals in the country, virtually all in rural areas, are designated as Level I. The Level I units are staffed primarily by midwives and GPs, provide low-technology care, are designed to be accessible to women, and must have clear referral and consultation links with a more sophisticated hospital.

Level I units in most rural towns have relatively few maternity patients. A plurality of the births actually occur in the Level II hospitals, rather than in the much more numerous and smaller Level I hospitals. This is because the district hospitals are located in population centers and because of referrals of higher-risk women from Level I units. 
During the 1980s a major national policy debate occurred over whether to close many of the small, rural obstetric units. A governmental commission issued a draft document stating that hospitals with fewer than 100 deliveries per year had poorer outcomes than those with more deliveries and should be closed to improve the quality of perinatal care. Many obstetricians believed that early risk identification was not adequate and that more births should be centralized in the large urban hospitals. However, people from rural towns who were at risk of losing their obstetric services contested this assertion vigorously. A study was conducted to find out whether the general practitioners and midwives who were delivering babies in relatively isolated rural hospitals without access to sophisticated technology were achieving acceptable outcomes through a process of risk identification and referral of high-risk women (Rosenblatt et al., 1985).

The study began by looking at what was happening to low birthweight (LBW) babies. Although many factors contribute to poor reproductive outcomes, LBW is the common final pathway for a variety of problems. In addition, LBW is easy to measure, is usually captured by the vital statistics systems, and is highly correlated with outcomes such as perinatal mortality. Where were the LBW babies being born? Were their mothers being identified in a timely fashion and referred or transported to the sophisticated facilities designed to care for them? Were perinatal outcomes roughly equivalent no matter how far women lived from the Level II or Level III hospitals, or were the benefits of advanced perinatal care available only to urban women?

Figure 4.1 demonstrates that New Zealand's system has been successful in centralizing the births of LBW infants in the hospitals designed to care for them. Only a few very lowbirthweight (NLBW) infants $(<1,500$ grams) were born at Level I hospitals. The percentage of VLBW births rises with the level of the hospital, going from 0.34 percent of births in Level I hospitals to 0.80 percent of those in Level II hospitals and 1.15 percent in Level III hospitals. Similar patterns can be seen for LBW infants at other weights less than 2,500 grams. The same relationship was also observed when the data on LBW births were examined in relationship to the total number of births at each hospital (Figure 4.2), which is not surprising since hospital volume is highly correlated with the level of the hospital. Only 0.34 percent of the babies born in the 57 hospitals with fewer than 200 births per year were VLBW, an incidence of only one in every 300 births. Because the actual rate of LBW and VLBW births did not differ significantly from one part of the country to another, this finding demonstrated that most of the women who would ultimately deliver LBW infants had been identified during prenatal care or early labor and were referred or transferred to more sophisticated facilities before the baby was born. 


\section{FIGURE 4.1}

Distribution of Low-Weight Births by Hospital Level, New Zealand, 1978-1981 (147,238 births)

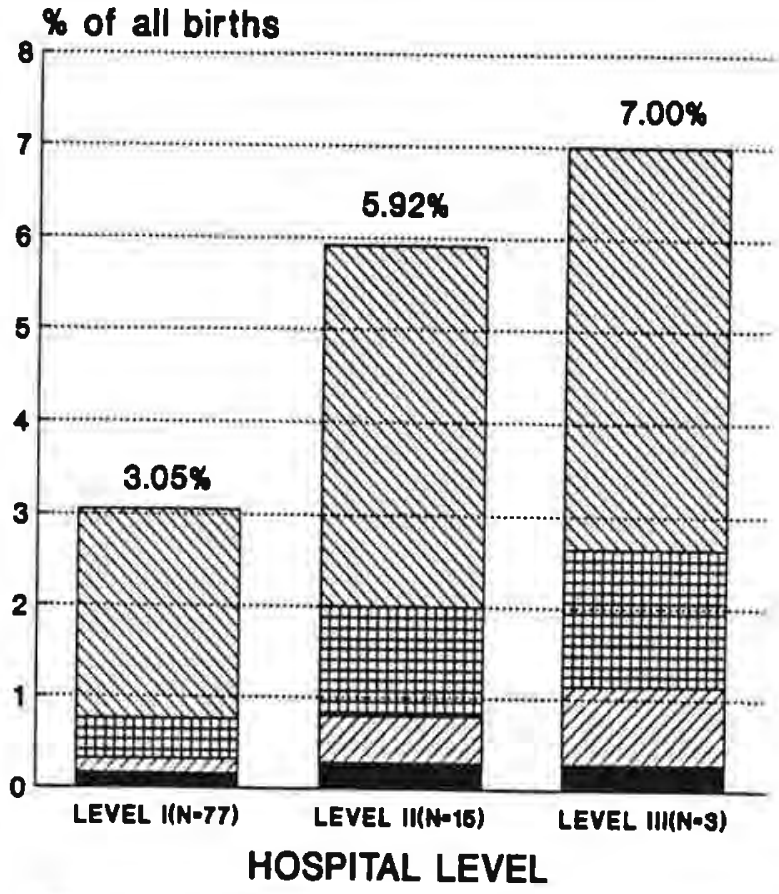

$$
\begin{array}{ll}
\text { 1,000 ORAMS } & \text { DD 1,000-1,400 ORAMS } \\
\text { 1,600-1,000 GRAMS DS } 2,000-2,400 \text { GRAM8 }
\end{array}
$$

Rosenblatt/University of Washington 
Distribution of Low-Weight Births by Hospital Volume, New Zealand, 1978-1981 (147,328 births)

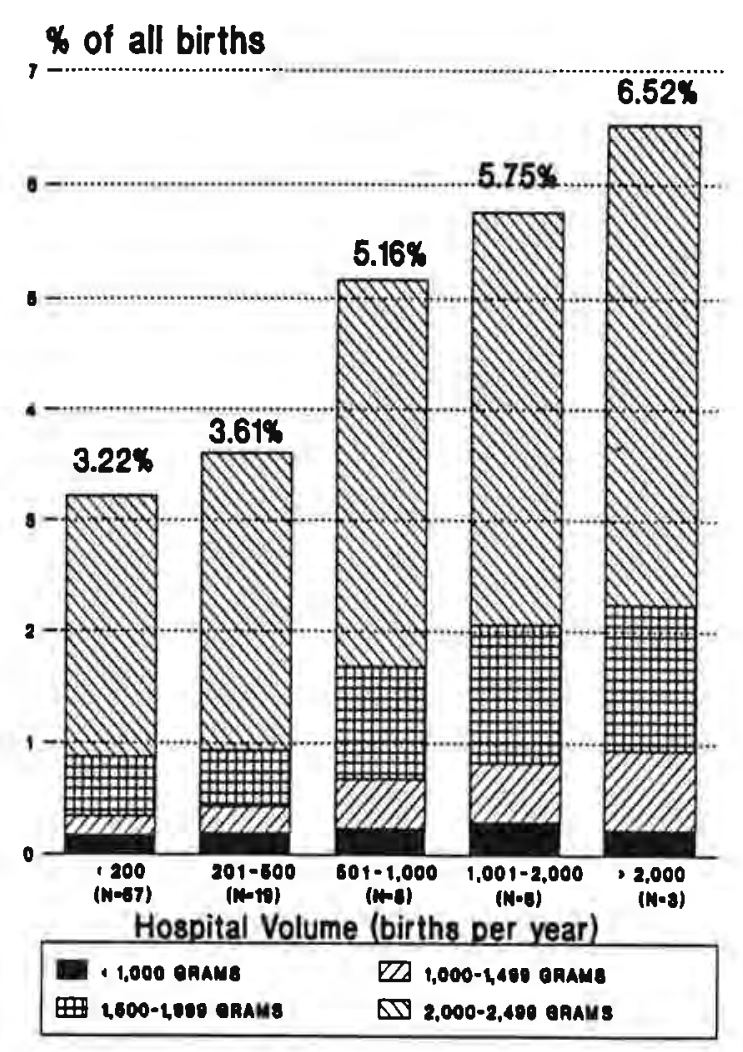

Rosenblatt/University of Washington

Perinatal mortality rates declined substantially during the period when regionalization was introduced, and the disparity in perinatal mortality rates among various hospital districts narrowed. In addition, the crude mortality rates were lowest in the smallest (Level I) hospitals and were highest in the higher-volume Level II and Level III hospitals. This pattern is what would be expected in a system that succeeds in referring the highest-risk women to the largest and most sophisticated hospitals.

However, because crude mortality rates are highly correlated with the distribution of LBW births, birthweight-specific perinatal mortality rates were examined to compare the outcomes achieved by different individual hospitals or hospital levels. The results of that 
examination contradicted the obstetricians' assertions regarding care in small, low-volume maternity units. In New Zealand, outcomes for LBW births were worst if the baby was delivered in an intermediate-sized Level II hospital and were significantly better for LBW infants born in hospitals with less than 100 deliveries per year (Figures 4.3 and 4.4). Because New Zealand has

a model vital statistics system, the data from this study are thought to be very reliable. For instance, all components of the system complied with the same rules for defining stillbirths as compared with neonatal deaths.

\section{FIGURE 4.3}

Birth-Weight Specific Perinatal Mortality Rate by Hospital Level, New Zealand, 1978-1981

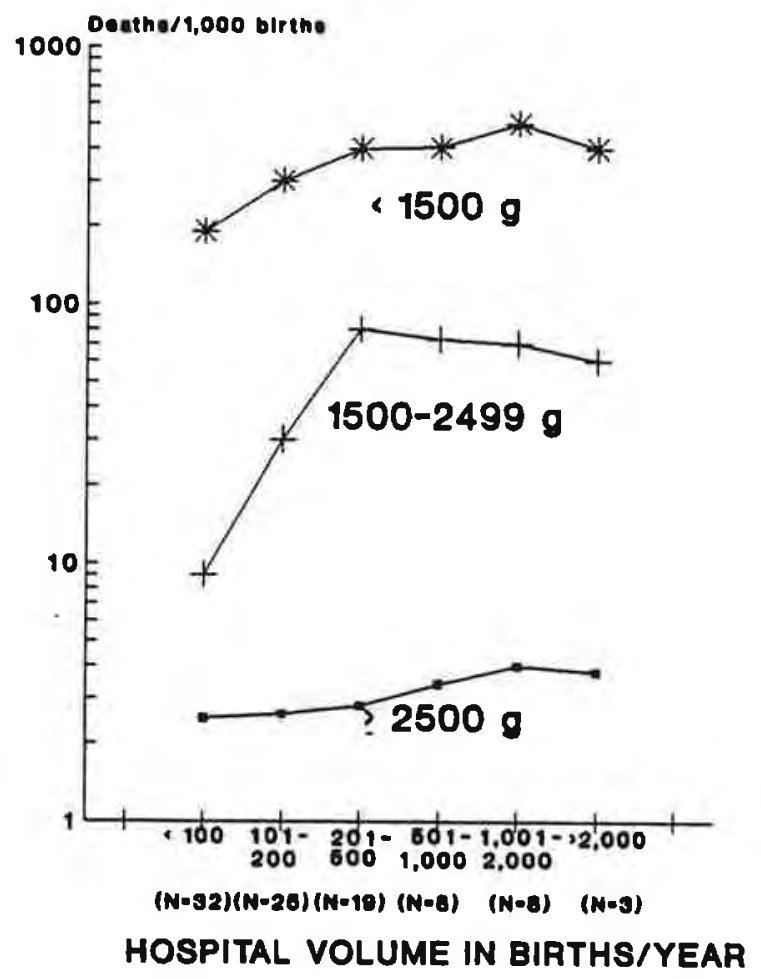

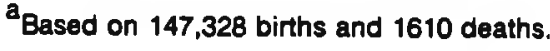

Rosenblatt/University of Washington 


\section{FIGURE 4.4}

Birth-Weight Specific Perinatal Mortality Rates by Hospital Volume, New Zealand, 1978.1981 ${ }^{\mathrm{a}}$

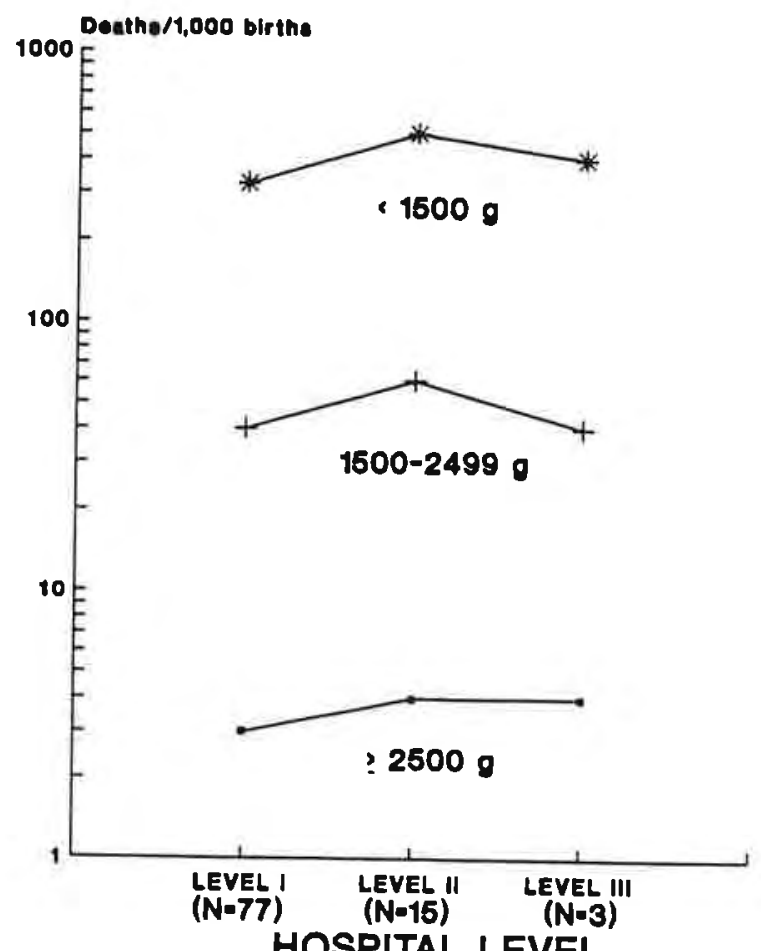

HOSPITAL LEVEL

${ }^{a}$ Based on 147,328 births and 1610 deaths. Rosenblatt/University of Washington

These data were used to determine where suboptimal outcomes were occurring. Using birthweight-specific perinatal mortality rates from the Level III hospitals as the standard, it was found that the excess deaths were occurring not in the small rural units, but in the medium-sized district hospitals. In order to try to understand why this was happening, the investigator, $\mathrm{Dr}$. Roger Rosenblatt, visited several Level II obstetric units.

He found that maternity units in district hospitals were run almost entirely by pediatricians and obstetricians who had received their training in a Level III hospital. These doctors had become skilled at neonatal intensive care at the larger facilities and enjoyed the professional challenge involved in taking care of high-risk babies in their own facilities. While Level I GPs and midwives were eager to transfer high-risk mothers and babies, the medical specialists working in Level II hospitals were more likely to keep their high-risk patients.

Unfortunately, neither the medical nor the nursing staff of the Level II hospitals were always 
equal to this task. Neonatal intensive care requires specialized training and constant practice. Yet most of the Level II units had fewer than one LBW infant per month, which was not enough for the nurses and doctors to maintain their skills, even if they had acquired them at an earlier time.

These unexpected findings prompted the professor of obstetrics who was in charge of the New Zealand governments maternity care committee to repeat the study. When the replication yielded similar conclusions, the data were further explored to try to identify a specific hospital size or number of births per year below which perinatal outcomes deteriorate. Although no such threshold was found, the proportion of referrals and transfers increased as the number of deliveries in the hospital declined. The doctors and midwives who managed fewer deliveries were more cautious about which mothers they would retain in their usually isolated rural maternity facility.

Although the use of a specific screening protocol was mandated by law, it was found that the referral rules had not been followed. Instead, most physicians and midwives recalibrated the screening tool in the context of their own clinical experience and the context in which they worked. People working in busier services tended to think that the guidelines were too sensitive, whereas those in sparsely populated places tended to be more cautious than the screening protocol required. In most areas, the protocol was used as a guideline, but not as a set of absolute rules.

Rosenblatt replicated this study in the state of Washington (United States) with similar results. There, he and his colleagues found that Level III facilities are more effective in saving the lives of infants with birthweights of less than 2000 grams but that care in these technologically intense settings provides no benefit for normal-weight births. They also found that differences in nursery care (that is, the degree of sophistication of the neonatal unit) have more influence than does obstetric volume on a hospital's perinatal mortality rate (Mayfield et al., 1990).

Although it can be expensive to maintain numerous, small, often underutilized maternity units, the cost of care may be lower in these less technologically intensive settings. In addition, in places such as New Zealand and the United States, closing small rural hospitals has a negative impact not only on the rural health care system, but also on the towns themselves. Another study from Washington state found a worsening of perinatal outcomes for women who 
live in small towns that lost their local obstetric facility (Newbitt et al., 1990).

\section{Conclusions}

Regionalization of perinatal care (identifying and referring or transferring higher-risk women from community hospitals to larger, more sophisticated hospitals) can be an effective way to make high-quality obstetric and neonatal care available to a dispersed population and thus to achieve roughly equivalent outcomes for urban and rural women. It is possible to implement such a system on a national basis, especially in places, such as New Zealand, that offer universal access to maternity care. Within such systems, no harm is associated with the management of normal childbirth in low-volume, peripheral units.

The suboptimal outcomes observed in the Level II obstetric units in New Zealand point to a strong association between volume (number of deliveries) and the quality of care provided to LBW infants. Even when doctors are trained to provide a sophisticated service, the outcome depends on the performance of an entire team of people; outcomes deteriorate if the team doesn't get enough practice. By contrast, the quality of obstetric care for low-risk women does not appear to be sensitive to volume.

Even in a nationalized health care system, specialist physicians get their professional satisfaction from their clinical prowess at treating individual patients. They tend to want to retain patients who require the use of their highly honed technical skills and believe that all babies would do better if delivered in the most technologically sophisticated facilities. For this reason, it may not be best to put the specialist physicians in charge of designing a population-based system. Given that opportunity, they are likely to design a system that relies heavily on the hightechnology care that they have been trained to provide. 


\section{Is Western Experience Applicable in Less Developed Countries?}

(from a panel discussion by a panel of four persons: Jose Luis Bobadilla, Ph.D., Director, Research Center in Public Health, the National Institute of Public Health, Mexico; A.B.N. Maggwa, M.D., Lecturer, Department of Obstetrics and Gynecology, the University of Nairobi, Kenya; Chinyelu Okafor, Ph.D., Department of Nursing Sciences, University of Nigeria, Enugu Campus; and Pramilla Senanayake, M.D., Assistant Secretary General, International Planned

Parenthood Federation, London. The discussion was moderated by Anne Tinker, Ph.D., Population and Nutrition Division, The World Bank.)

Western countries' experience with risk assessment systems has not been adequately assessed. Although some scoring systems have been evaluated, no one has conducted a thorough cost-benefit analysis or compared results from the application of alternative approaches. Furthermore, the literature shows a bias in favor of successful experiences; unsuccessful applications of the concept are usually not reported.

Developing countries are very heterogeneous, with great differences existing among countries and even among subpopulations within many countries. It does not make sense to generalize about developing countries or to try to devise a "recipe" for applying the maternal risk assessment concept in all LDCs. Instead, it is most valuable to think in terms of experimenting with implementation of the concept in a variety of different settings.

\section{Developing Country Needs}

The most "successful" risk-scoring systems include factors that cannot be detected until the onset of labor, or even until after the baby has been born. These late-occurring factors make up the most powerful aspect of the scoring systems, and are essentially responsible for the system's apparent predictive ability. But LDCs need risk-scoring systems that can in fact predict problems during labor and delivery. The relative success of scoring systems that include problems during labor and delivery as part of the score confuse the issue.

Most developing countries need to focus primarily on reducing maternal mortality and promoting family planning, whereas most of the risk assessment systems used in Western countries have focused on the prevention of low birthweight and perinatal mortality. Riskscoring instruments that were designed to predict the outcomes that are of concern to Western countries may not identify women who are at high risk for maternal mortality. Little research has been directed toward predicting complications during labor and delivery or evaluating the utility of screening for improving maternal health. The few instruments that have been developed to measure reproductive risk for women (compared with risk for infants) have not been validated 
and have many problems. The scoring systems do not work from the clinicians' point of view. A woman might have several social and demographic factors that add up to a higher score than a single but very serious medical factor, even though the nonmedical factors may not really put the woman at great risk. Clinicians take into consideration many factors that are not included in the risk-scoring systems. As discussed in chapter 3 of this monograph, an American study that compared the accuracy of the clinical judgment exercised by a group of family physicians with the predictive ability of three published risk-scoring systems found that the doctors did better than two of the scoring systems and aimost as well as the most accurate scoring system at predicting which patients would need to be hospitalized for childbirth care (Acheson et al., 1990).

Technical, cultural, and economic differences between Western countries and LDCs also affect screening, referral, treatment, and the utilization of health services. The influence of social and economic factors on pregnancy outcomes differs from one society to another; for instance, lack of a high school education is a risk factor in Western countries but is the norm in LDCs. Even the definition and measurement of social and economic factors differ widely. How these factors influence pregnancy outcomes is not well understood; many of them do not have a direct impact, but are proxies for other, less measurable factors. In addition, because of differences in the social response to health problems during pregnancy and childbirth, women in different societies may have different thresholds for reacting to the same condition or situation; therefore, their ability to communicate symptoms might vary. An individual woman's risk factors cannot be measured without creating a yardstick to measure the conditions in her community.

Finally, developing countries have an even greater need than do Western countries for a rational way to distinguish between women who will and women who will not need medical care during childbirth. In most Western countries, health care is generally available, and there are enough physicians and midwives to take care of all the pregnant women. In contrast, most developing countries have relatively few health professionals, high rates of fertility, and are unable to provide professional care during every birth. Tertiary hospitals in the large cities of many developing countries are being pressed to take care of large numbers of low-risk maternity patients. Kenyatta Hospital in Nairobi has up to 90,000 deliveries per year. Kenyan health authorities need some way to decide who should use the hospital for birthing. As it is, a scarce and very expensive resource is being misused. Obstetric residents at Kenyatta National Hospital are expected to see between 15 and 20 women during a two- to three-hour prenatal clinic session. If there is no system to distinguish which patients need to be seen by a doctor, the 
time given to each patient will be so small that pregnant women who really need expert help will not get it. This situation suggests the use of risk assessment to facilitate optimal utilization of each category of personnel. If it works, the risk assessment concept provides a way to organize the flow of patients in order to provide adequate time for the doctors to see the patients who really noed them.

\section{Applicability of Western Experience to Developing Countries}

Despite the differences discussed above, some similarities make the experiences of Western countries at least partially relevant to the situation of developing countries. First, some of the associations between risk factors and poor pregnancy outcomes are biologic, causal, and therefore universal relationships which pertain regardless of setting, race, and socioeconomic conditions. Second, medical thinking in developing countries is similar to that in Western countries. Developing countries tend to copy what is practiced in other countries, with some good and some bad results. Strategies that have been tested elsewhere are more credible and thus more likely to garner the necessary political, professional, and financial support.

Some models developed in Western countries may be particularly appropriate for developing countries, especially birth centers. In many countries, the secondary and tertiary levels of care are being used for primary care by urban women who can afford to pay the hospital fees, and some doctors encourage this. However, as the number of births increases (for example, Mexico expects the absolute number of births to increase by 30 percent during the next few years), it will be impossible for most developing countries to build enough additional hospitals to meet the growing demand. Instead, such countries need to develop an attractive alternative form of childbirth care - like birth centers - that is appropriate to the needs of lowrisk women.

Human labor is less expensive and technology is more expensive in developing countries than in Western countries. Risk assessment systems are labor-intensive and, if used in conjunction with the development of nonhospital childbirth services for low-risk women, could help to prevent the overuse of expensive technological care. Such benefits require that the risk assessment systems are reasonably accurate in distinguishing between women who will and women who will not need hospital care; this requirement is feasible for assessments made at the onset of labor, but accuracy diminishes the earlier the assessment is made.

Finally, differences in population characteristics affect the sensitivity and specificity of the 
scoring systems. For instance, differences in the prevalence of a risk factor affect the underlying rates, strength of associations, and, most important, attributable risk. Because many risk factors and poor outcomes are more prevalent in developing countries than in Western countries, the predictive value of some scoring systems may be greater in developing countries. Risk-scoring works best among parous women, and because of high fertility rates in many developing countries, a relatively large proportion of births there occur among such women.

\section{Chapter Summary}

Maternal risk assessment has been used in Western countries primarily for two purposes: (1) to predict which women will need high-technology perinatal care in order to provide it to them, and (2) to predict which women are likely to have normal, uncomplicated births so that they can receive care in less expensive, community-based facilities (including nonhospital birth centers in the United States and small, rural obstetric units in New Zealand).

Maternal mortality rates are already low in the industrialized countries, and low birthweight is the leading cause of perinatal death. Thus, systems designed to identify high-risk women in Western countries have focused on risk factors associated with preterm labor and intrauterine growth retardation, which are the immediate causes of low birthweight. Because most Western communities have relatively good access to rapid transport, Western perinatologists have not needed risk assessment systems that could make predictions early during pregnancy. In fact, the most accurate risk-scoring systems derive much of their power from factors that cannot be assessed until the onset of labor (such as preterm labor) or even after the baby has been born (such as low birthweight).

In contrast, the interest in maternal risk assessment in developing countries arises primarily from concern about maternal mortality and the need to use scarce medical resources in the most productive way. Although low birthweight is also an important cause of perinatal mortality in developing countries, preterm labor and intrauterine growth retardation do not lead to maternal mortality. In addition, because developing countries cannot afford to devote resources to the sophisticated and expensive care needed to save the lives of very low birthweight newborns, there is little reason to develop systems to predict these problems. Instead, doctors in developing countries want to be able to predict, before the onset of labor, 
which women are most likely to experience life-threatening complications during labor and delivery. The most common of these problems are hemorrhage and the need for surgical assistance during delivery. The maternal characteristics associated with these problems are not the same as those associated with preterm labor and intrauterine growth retardation. For these and other reasons, risk assessment systems developed for use in Western countries cannot be effectively applied in developing countries.

Risk assessment methods developed for the purpose of identifying low-risk women who can be cared for safely in birth centers or small, rural obstetric facilities may have greater applicability for use in less developed countries. The purpose of these assessments is similar to the purpose of the assessments needed in developing countries - to predict problems (or the absence of problems) during labor and delivery.

Even within the relatively resource-rich health care environments of New Zealand and the United States, the success of reproductive risk assessment has been limited:

- An expensive five-year program to establish perinatal regionalization in eight demonstration areas in the United States increased the proportion of very low birthweight babies born in tertiary medical centers from 47 percent to 60 percent. Although this was a large increase, it did not get close to 100 percent. In addition, the increase was part of a national trend and was not greater in the eight demonstration areas than in the rest of the country. The program did nothing to reduce the incidence of low birthweight and consumed resources and attention that might othenwise have been used to develop more effective preventive care.

- Many physicians in both the United States and New Zealand resisted efforts to make them conform to a centrally defined, formalized risk-scoring and referral system. American pediatricians proved to be much more willing than American obstetricians to refer their high-risk patients. In New Zealand, general practitioners and midwives who worked in the smallest hospitals were willing to refer women according to guidelines, while doctors who worked in Level II hospitals were more likely to keep their high-risk patients.

- Approximately 15 percent of the women who are admitted to American birth centers for intrapartum care are transferred to hospitals during or immediately after labor and delivery because of complications. The midwives and physicians who work in birth centers deem these transfers to be necessary even though only women who are thought to be at low risk for intrapartum complications are admitted to the birth centers for labor 
and delivery.

Some negative consequences have occurred as a result of implementing programs intended to identify high-risk women and send them to facilities capable of the most sophisticated care. In the United Sates, regionalization contributed to closure of some small obstetric units, resulting in a situation in which no one is now available to deliver the babies in some rural communities. Also, by directing resources and attention away from communitybased, prevention-oriented, low-technology maternity care in favor of care provided in large, sophisticated urban medical centers, it contributed to over-medicalization of childbirth and excessive financial costs.

\section{References}

Acheson, L.D., S.E. Harris, and S.J. Zyzanski. "Patient selection and outcomes for out-of-hospital births in one family practice." Journal of Family Practice 31 (1990): 126-36.

Carrier, D., B. Doray, L. Stern, and R. Usher. "Effect of neonatal intensive care on mortality rates in the province of Quebec." Pediatric Research 6 (1972): 408.

Committee on Perinatal Health. Toward Improving the Outcome of Pregnancy: Recommendations for the Regional Development of Maternal and Perinatal Health Services. White Plains, NY: National Foundation --March of Dimes, 1976.

DeGeorge, F.V., R.L. Nesbitt, and R.H. Aubry. "High-risk obstetrics. VI. An evaluation of the effects of intensified care on pregnancy outcome." American Journal of Obstetrics and Gynecology 111 (1971): 650-57.

Eden, R.D., L.S. Seifert, A. Winegar, and W.N. Spellacy. "Perinatal characteristics of uncomplicated postdate pregnancies." Obstetrical Gynecology 69 (1987): 296-99.

Fleck, A.C. Hospital Sizes and Outcomes of Pregnancy. Office of the Assistant Commissioner for Child Health, New York State Department of Public Health, February 23, 1977

Gray, A.M. and R. Steele. "The economics of specialist and general practitioner maternity units." Journal of the Royal College of General Practitioners 31 (1981): 586-92.

Institute of Medicine. Medical Professional Liability and the Delivery of Obstetrical Care. Vols. 1 and 2. Washington, DC: National Academy Press, 1989.

Institute of Medicine Committee to Study the Prevention of Low Birthweight. Preventing Low Birthweight. Washington, DC: National Academy Press, 1985.

Kenney, A.M., A. Torres, N. Dittes, and J. Macias. "Medicaid expenditures for maternity and newborn care in America." Family Planning Perspectives 18 (1986): 103-10.

Maine, D.M. and S.G. Gabbe. "Risk scoring for preterm labor: Where do we go from here?" American Journal of Obstetrics and Gynecology 157 (1987): 789-93. 
Mayfield, J.A., R.A. Rosenblatt, L.M. Baldwin, J. Chu, and J.P. Logerfo. "The relation of obstetrical volume and nursery level to perinatal mortality." American Journal of Public Health 80 (1990): 819-23.

McCormick, M.C., S. Shapiro, and B.H. Starfield. "The regionalization of perinatal services." JAMA 253 (1985): 799-804.

Merkatz, I. and A. Fanaroff. "The regional perinatal network." In Advances in Obstetrics and Gynecology. Ed. W.J. Sweeney and R.M. Caplan. Baltimore: Williams and Wilkins, 1978.

Meyer, H.B.P., L. Wagner, and W.J. Dorsen. "A regional system for the transport of sick neonates in Arizona." Pediatric Research 5 (1971): 376.

Minor, A.F. "The cost of maternity care and childbirth in the United States, 1989." Health Insurance Association of American Research Bulletin (December 1989).

Molfese, V.J., B.K. Thomson, B. Beadnell, M.C. Cricker, and L.G. Manion. "Perinatal risk screening and infant outcome: Can predictions be improved with composite scales?" Journal of Reproductive Medicine 32 (1987): 569-675.

The Nation's Health, May/June 1990, p. 1.

Newbitt, T.S., F.A. Connell, L.G. Hart, and R.A. Rosenblatt. "Access to obstetric care in rural areas: Effect on birth outcomes." American Journal of Public Health 80 (1990): 814-18.

Opinion Research Corporation. Professional Liability and Its Effects: Report of a 1987 Survey of ACOG's Membership. Prepared for the American College of Obstetricians and Gynecologists. Washington, DC, 1988.

Robert Wood Johnson Foundation. Special Report: Regionalized Perinatal Services. Princeton, NJ, 1978.

Rooks, J. "Low-intervention maternity care." Journal of Family Practice 31 (1990): 125-27.

Rooks, J.P., N.L. Weatherby, E.K.M. Ernst, S. Stapleton, D. Rosen, and A. Rosenfield. "Outcomes of care in birth centers: The national birth center study." New England Journal of Medicine 321 (1989): 1804-11.

Rosenblatt, R.A. "The future of obstetrics in family practice: Time for a new direction." Journal of Family Practice 26 (1988): 127-29.

Rosenblatt, R.A., J.A. Mayfield, L.G. Hart, and L.M. Baldwin. "Outcomes of regionalized perinatal care in Washington State." West Journal of Medicine 149 (1988): 98-102.

Rosenblatt, R.A., J. Reinken, and P. Shoemack. "Is obstetrics safe in small hospitals? Evidence from New Zealand's regionalized perinatal system." Lancet 2 (1985): 429-32.

Ross, M.G., C.J. Hobel, J.P. Bragonier, M.B. Bear, and R.L. Bemis. "A simplified risk-scoring system for prematurity." American Journal of Perinatology 3 (1986): 339-44.

Ryan, G.M. "Improving pregnancy outcome via regionalization of prenatal care." JOGN 3 (1974): 38-40. 
Smucker, D.R. "Obstetrics in family practice in the State of Ohio." Journal of Family Practice 26 (1988): $165-68$.

Thampson, T., et al. "The results of intensive care therapy for neonates." Journal of Perinatal Medicine 5 (1977): 59-75.

United States Department of Health, Education and Welfare (DHEW). Guidelines Concerning the Development of Health-Systems Plans and Annual Implementation Plans, issued under PF 93-641, National Health Planning and Resources Development Act of 1974. December 23, 1977. 


\title{
Chapter 5:
}

\section{IMPLEMENTATION IN POORER COUNTRIES}

\author{
Shunyi County, People's Republic of China \\ (based on a presentation by Brian J. McCarthy, M.D., Division of Reproductive Health, Centers \\ for Disease Control, U.S. Public Health Service, and World Health Organization consultant for \\ the Shunyi County project)
}

The Shunyi Risk Approach Project in Perinatal Health was started in 1983, after an initial assessment indicated that the World Health Organization (WHO) Risk Approach would be a functional tool for China. ${ }^{4}$ The Chinese Ministry of Health asked WHO to help them design a project that could serve as a model for maternal and child health $(\mathrm{MCH})$ services throughout China. Responsibility for the project was shared by a group including Beijing Medical University, the People's Liberation Army General Hospital, Beijing Military Hospital, the Navy Hospital, the Air Force Hospital, the Beijing Municipal Maternal Health Institute, Shunyi County Hospital, and Shunyi Maternal and Child Health Station.

The Chinese wanted WHO to help them answer a single question - whether they had chosen the right things to do. WHO added a second question - whether the things the Chinese had chosen to do were being periormed correctly. WHO proposed a dynamic process to define the most important health problems in the province, to solve the problems, and to identify the appropriate technology and necessary training for implementing the solutions.

\section{Identification of Major Perinatal Health Problems}

The first step was to develop a surveillance system to collect data on every pregnancy in Shunyi County. Particularly because of the one-child-per-family policy in China, it is very important that every child be born with optimal health. Since every child counts, the Chinese wanted to count, and focus on, every single pregnancy. In order to accomplish this goal, they

A full report on this project, The Risk Approach in Perinatal Health: Shunyi County, People's Republic of China, is available in a publication from the Centers for Disease Control, Atlanta, GA 30333.

WHO defines its risk approach as "a method for measuring the need of individuals and groups for care (and thus for assisting them to determine their priorities) and a tool for the reappraisal and reorganization of health and other services to meet that need." See Appendix 2 for a discussion of the WHO Risk Approach. 
had to begin to collect, on every birth, information that had not been collected previously, such as birthweight. Analysis of the initial data revealed a perinatal mortality rate of $25.9 / 1,000$ births.

The following were identified as the five most important perinatal health problems in Shunyi County:

- The incidence of asphyxia at birth was higher than expected.

- Hypertensive disorders of pregnancy were contributing significantly to maternal and perinatal morbidity.

- Many babies with breech presentations were dying or were being born with birth injuries.

- One-third of perinatal mortality was due to neural tube defects.

- A significant proportion of perinatal mortality was among babies who weighed 1,500 2,499 grams at birth.

\section{Assessing Performance Problems Within the Health Care System}

The performance of the health care delivery system was assessed by reviewing 50 cases of perinatal mortality in order to determine whether the skill, knowledge, attitudes, and resources existed to solve the five identified perinatal health problems. In addition, a quantitative assessment was made of access to and utilization of health care, including the number of prenatal care visits made by pregnant women and the site and mode of deliveries. An in-depth review of perinatal practices at health care facilities throughout the county was also conducted, first to determine whether the right things were being done (for example, measuring the blood pressure of all pregnant women) and then to determine whether the planned activities were being conducted effectively (for example, assessing whether the blood pressure cuffs were available and the measurements were being taken and recorded accurately). Six major deficiencies were identified:

- Individuals and families exhibited poor knowledge of the signs and symptoms associated with pregnancy complications.

- Most women were unaware that they should begin prenatal care before 12 weeks of pregnancy. 
- Care givers in the organized health care delivery system lacked the skills and knowledge to treat high-risk pregnancies: Much of their knowledge was obsolete.

- Although there were enough personnel, delivery rooms did not have qualified staff available 24 hours per day.

- No educational programs were provided for the patients.

- Transportation and telephone service were inadequate for handling emergencies, even though the basic equipment and facilities were available.

\section{Planning and Implementing the Intervention Strategies}

The intervention strategies focused on modifying risk factors for perinatal deaths (hypertension during pregnancy, low birthweight, birth defects, breech presentation, and asphyxia) and improving the performance of the health care system to reduce perinatal deaths among pregnancies with one or more of these risk factors. A massive public education program was launched to teach pregnant women and their families about prenatal care and when to seek help for potential complications.

A referral system was established based on three levels of health care: the village health station, the township hospital, and the county hospital. Practitioners at each level learned how to assess risk and make appropriate referrals. Village doctors were given the skills, resources and motivation to conduct prenatal examinations; township hospital staff were trained to manage pregnancy complications. The screening and referral criteria were revised; some additional screening measures were added and others were restated to clarify which women should be referred. The protocols for managing high-risk pregnancies were updated and improved (for example, introducing the use of magnesium sulfate to treat pre-eclampsia). The county hospital staff were assisted so that they could increase their skills in neonatal care and management of serious pregnancy and childbirth complications.

Every pregnant woman was assessed at three different times for the presence of 12 
specific medical and obstetric risk factors ${ }^{5}$ - during her initial prenatal visit, between 28 and 36 weeks of gestation, and at or after the thirty-seventh week of gestation. Each womans score was determined by summing the relative risks associated with each of the risk factors she was found to have.

Shunyi is one of the wealthier counties in China, and new resources were becoming available because of an economic upsurge. Therefore, it was not necessary to reallocate support from other activities in order to direct resources to the new efforts. It was, however, necessary to determine what facilities and skills were needed at the county hospital to enable it to give effective care to high-risk women. The county hospital was supposed to provide care to all women who resided in a defined area near the hospital and to accept referrals from hospitals in the surrounding towns. In addition, however, women throughout the county had been told that they could go to the county hospital. In fact, women who lived in the furthest reaches of the county were traveling to the county hospital for childbirth. As a result, more than $\mathbf{5 5}$ percent of the deliveries were to low-risk women. Recognizing this problem, the director of Maternal and Child Health for the county limited deliveries at the county hospital to women who lived within the specified geographic area and those referred through one of the township hospitals. Implementation of that policy freed resources that the county hospital needed to take care of high-risk women and exerted pressure on the township hospitals to improve their performance.

\section{Objectives and Evaluation}

The targets established for the project were to decrease the perinatal mortality rate from 26/1,000 births (for October 1983 through September 1984) to $22 / 1,000$ by 1985 and to reduce the proportion of perinatal deaths associated with low birthweight, birth defects, asphyxia, preeclampsia, eclampsia, and breech presentation.

The evaluation was based on prospective, continuous before-after comparisons, data

(1) township of residence; (2) mother's age (younger than 21 years or older than 35); (3) history of dystocia; (4) medical complications (hypertension, tuberculosis, heart or kidney disease, hepatitis, birth defect, or mental retardation); (5) non-vertex presentation; (6) complication of pregnancy (hypertensive disease of pregnancy, preeclampsia, eclampsia, placenta previa, premature rupture of the membranes, polyhydramnios, and preterm labor); (7) abnormal fetal heart rate ( $<120$ or $>160$ beats/minute); (8) alphafetoprotein; (9) albuminuria; (10) estimated delivery date during the months of July through August (during which women participate in harvesting); (11) multiple gestations; and (12) suspected intrauterine growth retardation. 
from the ongoing surveillance system, and selected indices of improvement in outcome measures, risk factors, and process, including community education, staff training, and the use of appropriate technology. During a two-year period (1985-1986), the county experienced the following changes:

- a 34 percent reduction in perinatal mortality (after no reduction during the previous five years),

- an 84 percent reduction in asphyxia,

- elimination of eclampsia,

- an increase from 36 to 59 percent in the percent of women starting prenatal care during the first trimester of pregnancy,

- a decrease from 14 to 6 percent in the percent of breech presentations delivered at home, and

- a 10 percent reduction in low birthweight.

The improvements exceeded several of the project's specific targeted objectives. The perinatal mortality rate reached the target of 22 deaths per 1,000 births by 1985 . By 1986 it had been reduced to $17 / 1,000$ - a 34 percent reduction in less than three years. The screening done at 37 weeks gestation or later identified a group of highest-risk women who accounted for 10 percent of the births but 21 percent of the perinatal deaths.

\section{Conclusions and Plans for the Future}

Implementation of the WHO Risk Approach led to lower rates of perinatal mortality without taxing the pre-existing health care system in Shunyi County, China. Although the project was implemented with technical assistance from WHO, the Chinese believe that it can be replicated in other provinces with limited epidemiologic expertise. WHO is now considering how to simplify the process for developing the risk assessment tool, perhaps by relying only on calculations such as cross-tabulations, simple frequencies, relative risks, and subpopulationspecific attributable risks.

Although the Shunyi County project was conducted over a five-year period, WHO officials think that this length of time is not an absolute requirement. It takes only one year to 
establish a perinatal health care service and surveillance system. One cycle of data collection, analysis, implementation of intervention strategies, and evaluation requires three years. Based on the Shunyi County experience, they conclude that four years is probably an optimal period over which to carny out the method. The time period can be shorter in areas with existing perinatal care and surveillance systems.

During the pilot study in Shunyi County, the perinatal mortality rate was reduced to an even greater degree than expected. The risk factors associated with perinatal mortality, especially hypertensive disorders of pregnancy and asphyxia, were for the most part successfully modified. Between 1985 and 1987, staff of the Shunyi County Project conducted three national workshops to train more than 300 people from 29 other provinces in this methodology. Seven other projects have resulted. In addition to training more personnel, the Chinese plan to simplify the method so that it can be used independently at the county level, develop additional training, install a computerized management information system, and expand the risk approach to every county in China by the year 2000 .

\section{Mexico City, Mexico}

(based on a presentation by Raul Lopez Garcia, M.D., Medical Director, National Institute of Perinatology, Mexico City)

In Mexico City, even low-risk women go to tertiary hospitals to deliver their babies. Dr. Lopez Garcia reported on a small study conducted to evaluate the effectiveness of the criteria used to select patients for delivery at the hospital associated with the National Institute of Perinatology in Mexico City. The National Institute of Perinatology is a resource-rich, tertiary, research-oriented hospital in Mexico City - the largest city in the world, with a population of 20 million. A unique resource in Mexico, the National Institute can be most effective if it is reserved for cases that need special care.

In general, directors of the National Institute of Perinatology say that they do not believe in using complicated risk-scoring schemes, and that Mexican medical students, nurses, midwives, and traditional birth attendants (TBAs) are not willing to use complicated instruments, because they feel that they are too busy seeing patients. If such a system is imposed upon them, they tend to ignore the necessary paperwork while giving care, waiting until the end of the day to fill out any required forms. 
The obstetricians who designed the risk assessment system used at the National Institute of Perinatology know that even low-risk pregnancies can become problematic. However, because their purpose for using risk assessment is to reduce the number of low-risk women receiving care in the tertiary hospital, their wish is to emphasize specificity at the expense of sensitivity. They do not believe that such an emphasis will result in bad outcomes for low-risk women who experience complications, because facilities to deal with complicated cases are available throughout Mexico.

\section{The Risk Assessment Instrument}

The method of risk assessment is very simple: Any woman who has any of the specified risk factors is classified as "not normal." That does not mean that she is sick. The sole objective of the risk assessment is to differentiate between those pregnant women who are "normal" and those who are not. The risk assessment tool asks about age and other types of risk factors:

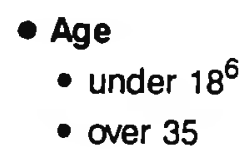

\section{- Family History}

- genetic problems

- diabetes

- autoimmune diseases

- Obstetric History

- two or more cesarean sections

- Rh problems

- preterm delivery

- intrauterine growth retardation

- repeated abortions

- macrosomia plus diabetes

- genetic malformations (in a previous infant)

- stillbirth

6 This will be changed to 15 , due to the results of a recent study of adolescents. 


\section{- Medical History}

- epilepsy (because of a special research study)

- endocrine disease (diabetes, thyroid, etc.)

- renal disease

- cardiovascular disease

- autoimmune disease

- more than 10 cigarettes smoked per day

\section{- Current Pregnancy}

- multiple gestation

- vaginal bleeding

- hypertension

- infectious disease

- intrauterine growth retardation

- threatened preterm labor

- other

\section{A Study to Evaluate the Risk Assessment Process}

The National Institute of Perinatology has about 9,000 deliveries per year. A sample of 575 patients was selected, 500 who were classified as high-risk and 75 who were "normal" (from a special study). Most of the high-risk patients had only one or two risk factors: $\mathbf{7 4}$ percent had only one high-risk factor and 21 percent had two risk factors. A retrospective analysis of data on the pregnancies of these women was conducted to determine which risk factors were associated with poor outcomes (maternal, neonatal, postpartum, and/or perinatal) at a statistically significant level $(p<0.05)$.

The incidence of complications in the normal group (those with no risk factors) was 31 percent and was most often associated with obstructed labor. The "high-risk" women experienced complications at a slightly higher rate (47 percent). Yet, most had healthy babies and there was no significant difference between the outcomes of the high-risk as compared with the normal group. The investigators believe that this finding demonstrates that pregnancy outcomes for high-risk women who receive excellent medical care during pregnancy actually can be better than the outcomes for low-risk women who receive no care or poor care.

The risk factors found to be significantly associated with maternal complications (such as toxemia, urinary tract infections, and obstetric complications) were endocrine diseases (mainly diabetes), macrosomia in the present pregnancy, bleeding, hypertension, and age 35 or higher. 
The risk factors found to be significantly associated with perinatal complications (such as fetal distress, fetal death, low birthweight, and prematurity) included multiple gestation, hypertension, and intrauterine growth retardation.

The risk factors found to be significantly associated with neonatal complications (such as low Apgar score, respiratory distress, and admission to neonatal care unit) were maternal age 35 or greater, multiple gestation (often confounded by preterm delivery and other medical complications), vaginal bleeding, and intrauterine growth retardation.

The risk factors found to be significantly associated with complications to women during the postpartum period (including sepsis, toxemia, and mastitis) included multiple gestation, intrauterine growth retardation, and threatened preterm labor. These associations may be related to iatrogenic problems caused by the many invasive interventions (for example, amniotic fluid sampling, ultrasound, cesarean section, etc.) used during pregnancy and childbirth for women with these conditions.

\section{Conclusions}

It is much easier to identify healthy patients who will go through pregnancy with no serious problems than to predict which women will experience poor pregnancy outcomes. For example, in this study the high risk designation still implied a greater than 50 percent chance of no complications during pregnancy. The risk assessment instrument does not predict all complications; the model explains only a small percent of total variance.

The "high-risk" group in this study was very heterogeneous, partly due to the wide definition of risk factors. The probability of complications is not only associated with risk factors that can be identified at 20 weeks of pregnancy; it is modified by factors that become apparent later in the pregnancy. With good medical care, women with some high-risk characteristics can have good pregnancy outcomes. However, women with multiple gestations, intrauterine growth retardation, or those age 35 or older had a higher incidence of poor outcomes even when they received expert care.

It is relatively easy to reduce perinatal mortality from a very high level to an intermediate level when high quality prenatal care is provided; to reduce it to a low level, however, is much more difficult. Using a risk assessment instrument cannot substitute for the benefits that come from excellent care during pregnancy. 
(based on a presentation by Duale Sambe, M.D., M.P.H., Director, Basic Rural Health Project, Karawa, northwestern Zaire)

Zaire is divided into 306 health zones, each of which is supposed to have one referral hospital and a number of satellite health centers. The medical director of the health zone is responsible for designing the primary health care program for the entire zone. The Karawa Health Zone has approximately 300,000 inhabitants living in 244 villages. There are no paved roads or public transport system; most people travel by foot, bicycle, or motorcycle. Most of the women have no formal education, and most births occur at home, attended by traditional birth attendants (TBAs) and family members. The 170-bed Communauté Evangelique d'UbangiMongala (C.E.U.M.) Hospital has a 35-bed maternity center and is the referral and coordination center for the entire health zone. It has three to six staff physicians, one of whom is in charge of the maternity. Thirty health centers and dispensaries are dispersed throughout the zone.

\section{Rationale for the Use of the Risk Approach at Karawa}

In 1979 Family Health International (FHI) began to collect data on women who delivered at the C.E.U.M. Hospital. Those data showed that about 18 percent of the women who went to the C.E.U.M. Hospital for care during childbirth were experiencing abnormal, prolonged, or obstructed labor. Those with obstructed labor were younger and much more likely to have a history of adverse reproductive outcomes (spontaneous abortions and/or stillbirths) as compared with pregnant women who did not have obstructed labor. About 20 percent of the women with obstructed labor were cretins (a syndrome including short stature and mental retardation that occurs in children of mothers with iodine deficiencies), compared with only 1 percent of the patients who did not have obstructed labor. A greater proportion of the women with obstructed labor had not received prenatal care.

Approximately 15 percent of the patients with obstructed labor had premature rupture of membranes, compared with 3 percent of those who did not experience obstructed labor. Because of the greater risk of infection associated with prolonged rupture of the membranes, women with obstructed labor were more likely to experience fever and infection during labor and delivery. They were also more likely to have malpresentations, especially transverse lies and abnormal vertex presentations. Mortality among women with obstructed labor was much higher than for the other women $-187.1 / 1,000$ births versus $53.3 / 1,000$. Morbidity was also higher. 
Obstructed labor can be managed successfully when it is recognized early and where emergency obstetric services are available, accessible and effective. Since most women in Karawa were delivering at home, there was a need to identify women who were likely to experience this complication and to refer them to sources of adequate medical and obstetric care.

\section{The TBA Training Program}

In 1982 a program was initiated by C.E.U.M. Hospital in collaboration with the Basic Rural Health Project (SANRU), the American College of Nurse-Midwives (ACNM), and the Program for International Training in Health (INTRAH) to train TBAs to conduct risk assessments of pregnant women and to refer high-risk women to the hospital and health centers.

A TBA in Karawa is usually a middle-aged mother or grandmother. Although most TBAs are illiterate, they are experienced as local midwives and are trusted by their communities. The Karawa TBA training program emphasized the role of the TBA in providing maternal and child health care. The TBAs were taught to encourage all women to attend a prenatal clinic, to identify selected risk factors, and to refer high-risk women to the nearest health center or to the hospital for prenatal care and delivery. They were also taught to attend normal deliveries at home, to identify and refer complications that occur during labor and delivery, to give first aid for obstetric emergencies, and to encourage women to attend well-baby and family planning clinics. 
The list of risk factors and the training were designed with assistance from the ACNM (Table 5.1):

\section{TABLE 5.1}

\section{Risks During Pregnancy}

\section{Antecedent Risk Factors}

Related to previous pregnancies:

- parity $\geq 5$

- previous cesarean section and/or symphysiotomy

- last delivery < 20 months ago

- history of long and difficult labor

- history of hemorrhage

Related to the present pregnancy:

-age $<16$ or $\geq 35$

- parity 0

- short stature of primipara

- cretinism

\section{Obstetric or Medical Problems of the Current Pregnancy \\ - antepartum bleeding}

- woman expecting twins

- malposition

- swollen legs, frequent headaches

-woman who has malaria

- weak, pale, anemic

-various underlying diseases (TB, STDs, diabetes, etc.)

\section{Six Danger Signs of Labor and Delivery}

- prolonged labor (more than one full day or night)

- malposition (breech, transverse, prolapse of limb)

- severe hemorrhage at beginning of labor

- convulsions

- premature rupture of membranes

- cord prolapse

\section{Four Danger Signs of the Immediate Postpartum Period \\ - retained placenta and membranes \\ - postpartum hemorrhage \\ - extensive lacerations \\ - infection (uterus or breast)}

Source: Manual for the Training of Traditional Birth Attendants Mashington, DC: The American College of Nurse-
Midwives, 1984). 
The TBAs are presented with a delivery kit to certify that they have completed their training. Their work is monitored during monthly supervisory visits, as well as by a data collection system. To obtain information on home births, the TBAs are trained to report their deliveries to a literate man in the community, usually the village health worker. Since most TBAs attend only three to four births per month, it is quite easy for them to remember and report the facts of each case to a birth registrar (a local person who is responsible for recording information on all births). Maternal deaths that are reported are investigated by nurse supervisors.

\section{Evaluation of the TBAs' Learning and Actual Referrals}

A 1988 survey of 90 TBAs showed that they remembered much of the content from their training program and that they did refer some high-risk women to the hospital or health centers prior to the onset of labor. The prenatal risk factors they were most likely to cite as reasons for such referrals were hemorrhage, premature rupture of the membranes, edema, malpresentation, weakness, high fever, and previous cesarean section. They mentioned malpresentation, cord prolapse, hemorrhage, meconium, nonprogressive labor, "abnormality of the abdomen" (thought to mean Brandl's ring ${ }^{7}$ ), weak or absent fetal heart beat, placenta previa, hydramnios, anemia, and weakness as the most important risks for women during labor and delivery, and retained products of conception, hemorrhage, genital lacerations, and infections as the most important risks to a woman during the postpartum period.

The TBAs also reported that they had advised some high-risk women to go the maternity waiting dormitory at C.E.U.M. Hospital to await labor. In addition, nearly half of the TBAs said that they had told women who experienced problems during labor and delivery to go to the nearest health center or the hospital. Most of them also recalled having referred clients to family planning and well-baby clinics.

Data collected by the birth registrars corroborated these findings to some degree. However, while the TBAs had referred some women for professional intrapartum care, many high-risk women had not gone to a health center or to the hospital for delivery. Although the

7 Brandl's ring is a ridge of uterine tissue that can be felt at the boundary between the lower uterine segment, which becomes very thin during obstructed labor, and the upper uterine segment, which becomes very thick. It is a sign associated with extreme cases of obstructed labor, which can lead to uterine rupture. 
TBAs could recognize and report on the complications about which they had been taught, the training did not result in the expected number of referrals. The reasons for that are discussed in the following section.

\section{Problems With Application of the Risk Approach}

The Karawa health officials conducted focus groups as a way to find out why the TBAs were not referring all the high-risk women. Through this process they identified four problems:

Inadequate capacity of the hospital maternity service: Although the TBAs were taught to encourage women to attend prenatal clinics, the hospital held only one prenatal clinic per week. In addition, the hospital did not have an adequate capacity to handle emergency obstetric cases. As a result, the TBAs lacked confidence that the hospital would provide good care to the women they referred. The constraint for solving these problems was a shortage of qualified nurses and midwives and an extreme shortage of physicians. The action taken by the health official was to train selected staff nurses to perform the majority of necessary maternity care services, including prenatal care and emergency procedures (for example, starting intravenous infusions of blood and other fluids, cesarean sections, symphysiotomies, vacuum extractions, manual removal of retained placentas, and laparotomies for repair of a ruptured uterus). The number of prenatal clinics held each week was increased from one to four.

Inadequate capacity of the health centers: The satellite health centers, which are relatively accessible to the villages, are theoretically the most appropriate place to manage many of the high-risk women. However, most of the health centers did not have the staff, facilities, or equipment to handle complicated obstetric cases. At the beginning of the project, none of the health centers had equipment and facilities for blood transfusions or any kind of surgical intervention. In addition, the staff of most of the centers had limited obstetric experience. Because of those conditions, the TBAs and pregnant women's families lacked confidence in the centers. The TBAs were more likely to refer women to the hospital, or not to refer them at all, even when a health center was much closer. In order to use the risk approach effectively, it was necessary to upgrade the capacity of the health centers by training their nurses and providing the needed equipment.

Inability to predict when labor will start or to know how early high-risk women should go to the hospital: To make it more feasible for women to comply with advice to go to 
the hospital "early," the project built a maternity waiting dormitory where women who had been referred by TBAs could stay while they awaited labor. However, the project staff discovered that the maternity dormitories were rarely being used. During the focus groups they found that many women felt that the risk associated with going to the dormitory, where there was no food and no one to help them, was greater than the risk from staying home until their labor started. To solve this problem, the Karawa health officials would need to mobilize other resources to provide food and assistance for women who are at a maternity waiting dormitory.

Social, cultural, and economic problems: Among the people in Karawa, women who deliver in a hospital, especially with surgical intervention, are considered to be less brave than women who deliver at home without assistance. This attitude has resulted in fear of the hospital among some of the women, who are afraid that they will have a cesarean section or symphysiotomy if they go to the hospital, and that the other women will laugh at them. $A$ woman's ability to comply with the TBAs referral also depends on how many children would be left in her home unattended if she went to the hospital, how long she would be away from her work, the costs involved in delivering at the hospital, and the distance she would have to travel. The amount of money that has to be spent to go to the hospital may be so great that it has an impact on the financial well-being of the entire family. Women and their families sometimes do not perceive that the risks explained to them by TBAs or by health center nurses are very dangerous, compared with the inconvenience and expense of going to the hospital.

\section{Conclusions and Lessons Learned}

A risk assessment-based maternity care program is working in Karawa, despite the Spartan communication and transportation systems in the area. But improvement is needed. Such programs must reflect local conditions, such as the capacity of the health care system to manage referrals and the ability of at-risk individuals to comply with referral guidelines. In addition, it is necessary to take many financial and sociocultural factors into account when designing such programs, especially to understand what kinds of risks are most important from the viewpoint of the women to be served and of the community as a whole. Cultural differences between service providers and community members should be taken into account; the involvement of community leaders is needed.

Community education efforts are needed to heighten awareness of the need for timely referral of high-risk women. Community education can also help to overcome some of the 
sociocultural barriers in the system. In the case of Karawa, substantial improvement in the capacity of the referral health care facilities was also needed.

\section{Sources of Additional Information on this Program}

Janowitz, B., J.A. Lewis, N. Burton, and P. Lamptey (eds). Reproductive Health in Africa: Issues and Options. Research Triangle Park, NC: Family Health International, 1984. [A copy of this document can be obtained from Family Health International, P.O. Box 13950, Research Triangle Park, NC 27709.]

Manual for the Training of Traditional Birth Attendants. Washington, DC: The American College of Nurse-Midwives, 1984. [A copy of this document can be obtained from The American College of Nurse-Midwives, 1522 J St NW, Suite 1000, Washington, DC 20005.]

Sambe, D., G. Nelson, C. Hermann, and S. Wright. Pregnancy Care Monitoring: Karawa Health Zone, Zaire. Research Triangle Park, NC: Family Health International, 1988. [A copy of this document can be obtained from Family Health International, P.O. Box 13950, Research Triangle Park, NC 27709.]

\section{Northeastern Brazil}

(based on a paper by Dr. Barbara Janowit, Evaluation Specialist, Family Health International, Research Triangle Park, North Carolina)

In 1975 a pilot program to improve maternal and infant health care was implemented in the rural areas surrounding the city of Fortaleza, in northeastern Brazil. Traditional birth attendants (TBAs) were trained in basic midwifery. Although some of them were expected to deliver babies in the mothers' homes, the best TBAs were chosen to conduct deliveries in small maternity units that were set up in the communities. Later the program expanded into more rural areas, in which it was not practical to have obstetric units except for ones that could be added to the TBAs' own homes.

The program was started by Dr. Galba Araujo, who directed the Assis Chauteaubriand Teaching Maternity Hospital (MEAC) in Fortaleza. Dr. Araujo noticed that seven or eight women from the area surrounding the village of Guaiuba had died during childbirth at the hospital. $\mathrm{He}$ felt that some of this mortality could have been prevented if improved maternity care had been provided in the area, and he went to the village of Guaiuba to meet with the community leaders about it. Dr. Araujo convinced them of the need to start a program to train TBAs and to allow him to develop facilities in the communities as places where women could go to have their babies. By the mid-1980s, about 40 of these units were in operation. The largest units have 810 beds; the smallest units, in the most remote areas, have only one room attached to the home 
of a TBA.

Family Health International (FHI) worked with Dr. Araujo and his wife, Lorena Araujo, to try to evaluate the referral process used by the TBAs. Initially they looked at the adequacy of the referral process for TBAs who worked at four of the larger units; later they helped to assess the referral system in a more remote area, where they examined referrals of TBAs who worked out of one-bed maternity units attached to their own homes, as well as some TBAs who attended deliveries in the mothers' homes.

The questions addressed in this sequence of studies were:

(1) What factors affect the TBA's decision to refer a patient to the hospital? Should TBAs be referring different types of patients, or more or fewer patients?

(2) What are the rates of perinatal and neonatal mortality among infants of women who were delivered by a TBA and among infants of the women who were referred to the hospital for delivery? (Although the impetus for the study was to improve maternal health, too few maternal deaths occurred to be used as an outcome measure.)

(3) In the second study, they also looked at the impact of hospital intervention on the outcomes of high-risk pregnancies.

\section{TBA Training}

Figures 5.1 and 5.2 show pictorially the criteria that the TBAs were trained to consider in deciding whether to transfer women to hospital care - transverse lie, bleeding, prolapsed limb or cord, and eclampsia. Written material in the training manual also mentions prolonged labor as a reason for referral. In addition, the TBAs are told to refer any woman who they feel is at high risk. Thus, if a TBA thinks that she cannot handle the delivery, she is encouraged to refer the woman. Breech presentation is not on the list; conversations with TBAs indicated that they feel capable of managing uncomplicated breech deliveries and would refer women with breech presentations only if they have other complications. In fact, the manual given to the TBAs includes a series of pictures that show how to deliver a baby in breech presentation. The list of risks also does not include criteria related to age and parity. TBAs are told to consider age and parity in making referrals, but are not told to refer all women of a certain age and/or parity. However, age and parity are among the factors included in the risk-scoring system, which is used to determine which women should see a doctor or nurse during prenatal care. 


\section{FIGURE 5.1}

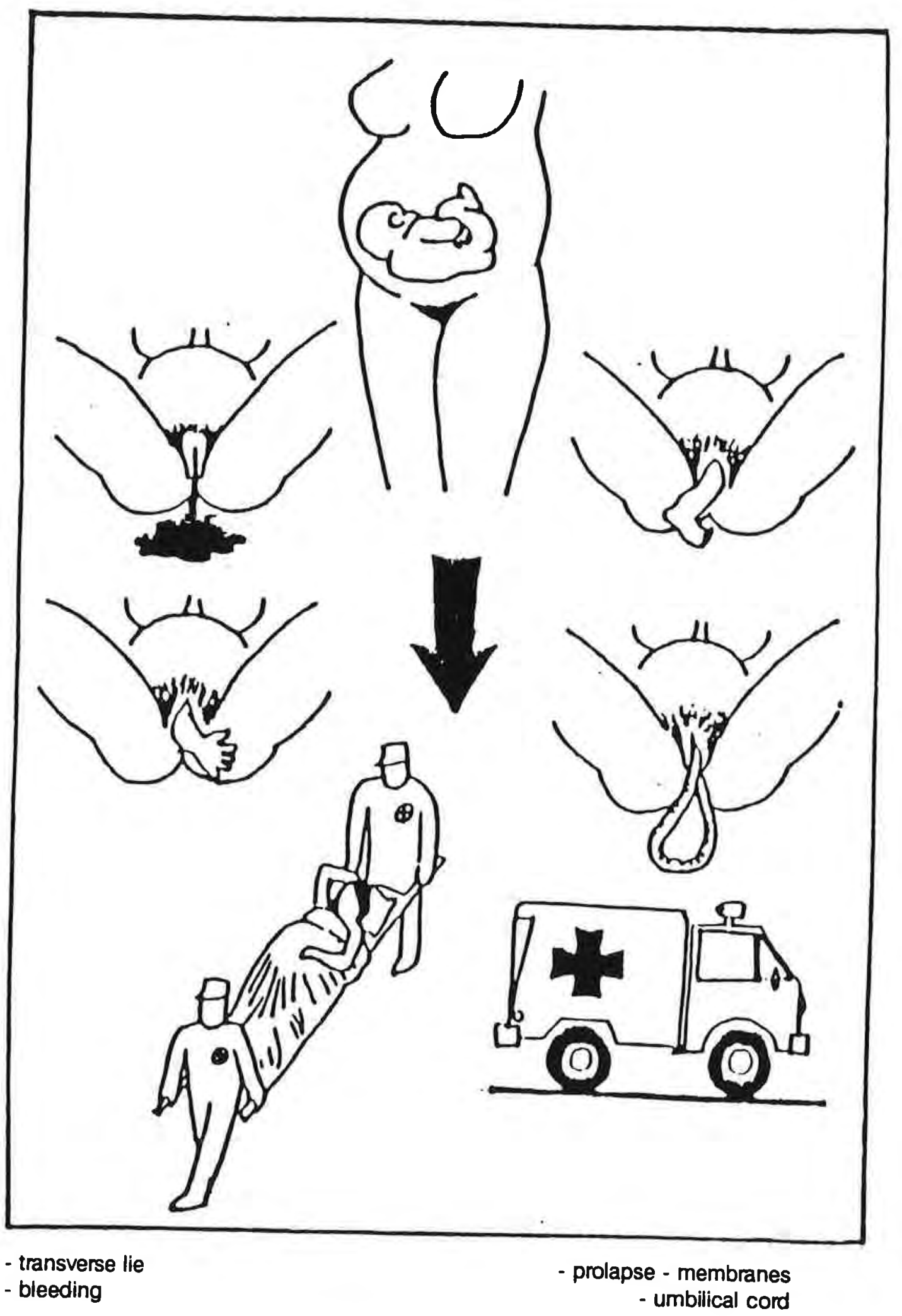




\section{FIGURE 5.2}

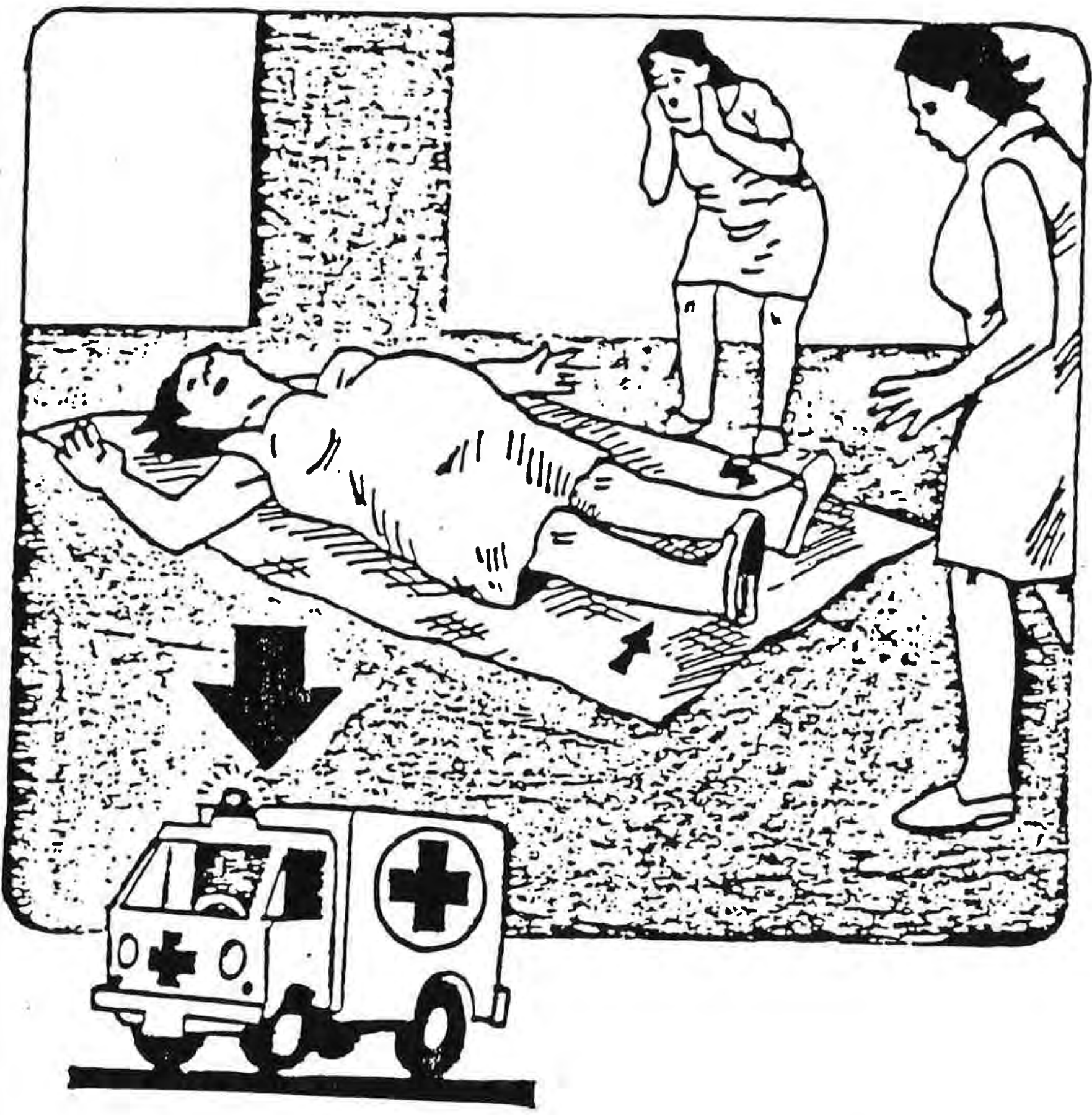

Convulsions of eclampsia 
The First Study: Care at Four Maternity Centers Run by TBAs

The first study covered a 10-month period from October 1980 to July 1981 and focused on women who delivered at four of the larger maternity units. These units are open every day of the week, 24 hours per day. A community vehicle and driver are available at all times to transport women with delivery complications to the MEAC, the teaching hospital in Fortaleza. Records were obtained from all 1,878 pregnant women who presented themselves at one of these four units during that period of time; 1,646 of the women delivered at the units and 232 (12.4 percent) were transferred to the MEAC. Women transferred to the MEAC also had a transfer slip that indicated the reason(s) for the referral. The most common reasons were the existence of some problem occurring before the onset of labor (generally hemorrhage, eclampsia, or premature rupture of the membranes), malpresentation, or a complication during labor.

Six percent $(N=117)$ of the 1,878 women had experienced one or more of the prenatal conditions for which the TBAs had been instructed to refer women to the hospital. Ninety-seven percent of the women who had experienced these prenatal conditions were in fact transferred to the MEAC for delivery. (Some of these women also had malpresentations and/or experienced problems during labor.)

Of the remaining 1,761 women (who had not experienced any of the specified prenatal conditions), 3.2 percent experienced a complication of labor (alone or in addition to a malpresentation) and 2.0 percent had malpresentations but did not have another type of complication during labor. Twenty-six percent of those with malpresentations but no other complications were transferred, compared with 79 percent of those who experienced other kinds of labor complications. In addition, 4 percent of the women who did not have prenatal conditions, malpresentations, or any other labor complication were ultimately transferred to the hospital.

Table 5.2 divides the women into four groups according to their "risk status" and whether they were referred or transferred to the MEAC. In this case, women with any of the specified prenatal conditions, a complication of labor, or a malpresentation are included in the high-risk group. All other women are classified as low-risk. The neonatal death rates presented here are based on the infants' condition at discharge from the maternity unit or hospital. Infants were not followed up at the end of the 28-day neonatal period. Outcomes differed dramatically among the four groups. The worst outcomes were found among high-risk referrals and the best 
among low-risk women who were not referred. Low-risk women who were referred and high-risk women who were not referred had intermediate outcomes.

\section{TABLE 5.2}

Outcome of Pregnancy by Risk and Referral Status

\begin{tabular}{|c|c|c|c|c|}
\hline \multirow[b]{2}{*}{ Outcome } & \multicolumn{2}{|c|}{ Low-Risk } & \multicolumn{2}{|c|}{ High-Risk } \\
\hline & $\begin{array}{l}\text { Not Referred } \\
(N=1,604)\end{array}$ & $\begin{array}{l}\text { Referred } \\
(N=65)\end{array}$ & $\begin{array}{l}\text { Not Referred } \\
\qquad(\mathrm{N}=\mathbf{4 2})\end{array}$ & $\begin{array}{l}\text { Referred } \\
(N=167)\end{array}$ \\
\hline Fetal Death Rate ${ }^{a}$ & 2 & 15 & 24 & 42 \\
\hline percent $<2,500$ grams & 3.8 & 13.9 & 21.4 & 16.8 \\
\hline $\begin{array}{l}\text { percent Apgar score } \\
<7 \text { at } 5 \text { min. }\end{array}$ & 1.1 & 6.7 & 14.3 & 18.7 \\
\hline Neonatal death rate ${ }^{b}$ & 4 & 62 & 71 & 114 \\
\hline
\end{tabular}

\footnotetext{
${ }^{a}$ Per 1,000 pregnancies.

${ }^{b}$ Per 1,000 deaths. Based on infants condition at discharge from the maternity unit or hospital; infants were not followed up at the end of the neonatal period.
}

Of the 65 low-risk women who were referred to the MEAC, 16 were referred so that they could get a voluntary sterilization operation. In another 25 cases, the referral slip indicated that the TBA thought the woman had one of the risk conditions, but the doctors at the hospital did not agree. Although TBA errors resulted in referral of some problem-free women, it is difficult to know how many.

Some of the $\mathbf{4 2}$ high-risk women who were not referred were high-risk on the basis of malpresentations (breech, brow, or face). Some of these women had been told to go the hospital but did not.

The cesarean section rate for women referred to the hospital by TBAs was 21 percent. This rate compares with a cesarean section rate of 10 percent for nonprivate patients who delivered at the MEAC but were not referred by TBAs. 
Perhaps the most important finding from this study is that the total perinatal mortality rate for the women who received care from the trained TBAs, including those who were referred or transferred to the hospital, was much lower than the mortality rate for nonprivate patients who delivered at the MEAC but did not go to the hospital via TBA referral.

\section{The Second Study: All Births in Trairi, May 1984-April 1985}

The second study was carried out in a more remote area, Trairi, which is located about three hours by car from Fortaleza. Although the road between Fortaleza and Trairi is paved and in good condition, the roads within Trairi County are unpaved and sometimes impassable for months at a time during seasonal rains.

Four of the TBAs in Trairi were selected to have one-bed maternity units built onto their homes. The units had cement floors, allowing the TBAs to maintain a clean environment. A TBA in this area can refer a woman to the hospital in the town of Trairi or to hospitals in two adjacent counties. The hospital in Trairi is staffed by two auxiliary nurses. A physician is available at times but does not attend obstetric patients. No cesarean sections are done at Trairi Hospital. A woman who needs a cesarean section must be driven to Fortaleza or to a hospital outside the county.

The research team obtained information on all deliveries in Trairi County (and/or for women who live in Trairi County but delivered elsewhere) over a one-year period (May 1984-April 1985), including deliveries attended by TBAs, deliveries at any hospital (whether or not the mother was referred by a TBA), and deliveries that were completely unattended. Babies were followed up by the TBAs at six weeks of age and again at later intervals. This analysis, however, is limited to data on the babies delivered by TBAs $(\mathrm{N}=906)$ and those that were delivered in a hospital after being referred by a TBA $(\mathrm{N}=136)$.

The 78 trained TBAs in Trairi took care of an average of 14 women each during the oneyear period. One TBA delivered only one baby during this period; the most active TBA delivered 95 babies. Half of the TBAs attended or referred eight or fewer women. Four of them (including three of the TBAs with one-bed units attached to their houses) were responsible for almost onethird of the deliveries.

About one in eight women was referred to a hospital for delivery. The major reasons for these referrals are shown in Table 5.3. The most frequent reasons were prolonged or obstructed 
labor (40 percent), first pregnancy (12 percent) and suspected abnormal presentation ( 9 percent).

TABLE 5.3

Reason for Referral by Women Referred for Hospital Deliveries

Reason for Referral

Percent

Prolonged/obstructed labor

Nulliparous

Suspected abnormal presentation

Hemorrhage

Weak, dizzy, high blood pressure

Premature rupture of membranes

Maternal anxiety

Poor obstetric history

Suspected stillbirth

Previous cesarean section

Multiple birth

Other

TOTAL

(Number of cases)

Tables 5.4 and 5.5 show the percent referred by sociodemographic and obstetric risk factors. Only variables that had a significant association with referral are included in the tables. Referral was associated with older age, first birth, antenatal pathology, malpresentation, multiple gestation, previous cesarean section, and the size of the TBA's caseload. TBAs with smaller caseloads were more likely than TBAs with higher caseloads to make referrals; however, caseload was important only with respect to nulliparous women (Janowitz et al., 1988). The TBAs who were most experienced probably thought that they could manage women having a first birth; less experienced TBAs were more likely to make referrals. 
TABLE 5.4

Percentage Reterred, by Selected Demographic Characteristics

\begin{tabular}{lcc}
\hline Characteristic & Number of deliveries & Percentage referred \\
\hline Total & 1,042 & 13.1 \\
& & \\
Years of age & 161 & 18.6 \\
$<20$ & 721 & 10.8 \\
$20-34$ & 160 & 17.5 \\
$>34$ & & \\
& & \\
Parity & 180 & 28.9 \\
0 & 517 & 8.9 \\
$1-4$ & 345 & 11.0 \\
$>4$ & & \\
\hline
\end{tabular}

TABLE 5.5

Percentage Referred and Odds of Being Referred by Selected Characteristics

\begin{tabular}{lllll}
\hline Characteristics & $\begin{array}{l}\text { Number of } \\
\text { deliveries }\end{array}$ & $\begin{array}{l}\text { Percent } \\
\text { referred }\end{array}$ & $\begin{array}{l}\text { Odds } \\
\text { Ratio }\end{array}$ & $\begin{array}{l}\text { 95\% Confidence } \\
\text { Interval }\end{array}$
\end{tabular}

Antenatal pathology

Yes

No

38

1,004

Presentation

Malpresentation

Cephalic

\section{2}

1,010

Multiple birth

Yes

No

11

1,031

Previous cesarean section

Yes

No

12

850

240

470

332

Traditional birth

attendants caseload

(in 12-month period)
1-10

$11-29$

$>29$
31.6

12.4

34.4

12.4

72.7

12.4

58.3

9.1
3.0

1.0

3.3

1.0

20.3

1.0

15.6

1.0

4.2-58.0

-.-

1.3-6.5

…

1.4-7.7

-.-

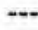

$+\cdots$
14.2
14.5

10.2
1.9

1.9

1.0
4.9-83.7

adjusted odds ratios for antenatal pathology, presentation, and multiple birth were calculated using a multiple linear logistic regression model. Other variables in the model included education, antenatal care, and previous stillbirth. Odds ratios for previous cesarean section were calculated from a second model, that excluded nulliparous women. 
TBAs reported a wide range of problems as antenatal pathology. However, they were more likely to refer women with the strictly defined pathologies than those with less serious conditions, indicating that they were able to distinguish the severity of conditions. For example, 10 of 15 women with hemorrhage or hypertension were referred, compared with only one of the 12 women for whom TBAs reported fatigue, nausea, dizziness, or vomiting as antenatal conditions.

The researchers tried to examine the impact of hospital intervention on birth outcomes. Thirteen of the 136 referred women (9.5 percent) had cesarean sections. The cesarean rate for the entire group of women cared for or referred by the TBAs was only 1.2 percent $(13 / 1,042)$. Eleven cesareans were performed at the MEAC and two at hospitals in counties adjacent to Trairi.

The researchers also attempted to examine the impact of hospital intervention on birth outcomes by calculating odds ratios for TBA versus hospital births using four multiple linear logistic regression models. In addition to parity, age, the presence of antenatal pathology, and/or an obstetric complication, each model included an interaction effect for whether the delivery occurred at home or in a hospital. No reduction in perinatal mortality could be attributed to hospital deliveries for women having a second or higher-order birth. In fact, when all other variables were controlled, the relative risk for parous women of perinatal mortality associated with home as compared with hospital delivery was 0.5 (95 percent confidence interval $=0.2-1.2$. In contrast, the babies of nulliparous women were 3.6 times more likely to die if the birth occurred at home instead of in a hospital (95 percent confidence interval $=0.8$ 16.0). Although this study did not find a statistically significant association between place of birth and perinatal mortality among either nulliparous or parous women (for both groups the confidence limits of the relative risk include 1), the findings suggest the possibility of an advantage of hospital births for low-risk nulliparous women, and no advantage, or even a disadvantage, to hospital births for low-risk parous women (Janowitz et al., 1988). However, the study was not able to control adequately for differences in the severity of problems experienced by the women. Therefore, it is likely that the data underestimate the impact of hospital delivery on infant survival. The principal investigator thinks that hospital delivery may be protective for women undergoing their first delivery.

To understand these data better, especially the lack of benefit associated with hospital deliveries for parous women, the researchers tried to determine the timing of the deaths, 
especially to learn whether the mothers had reached the hospitals early enough for the hospital care to have had a chance to make a difference in saving the babies' lives. Fourteen deaths were associated with singleton deliveries in the hospitals; 12 of them were classified as antepartum deaths (prior to the onset of labor). TBAs reported that they had referred four of these 12 cases because the fetus was already dead. In seven of the other eight singleton antepartum deaths with hospital deliveries, the mothers were referred during labor and reached the hospital too late for any intervention to have saved the baby. Antepartum deaths could not be excluded from the analysis because the TBAs had not been asked to differentiate between antepartum and intrapartum stillbirths, and hospitals may not always make the distinction correctly.

The inclusion of the 12 antepartum deaths in the calculation of the odds ratios probably resulted in an underestimation of the positive impact of hospital intervention. An alternative explanation may be that the risk factors recorded by the TBAs did not adequately reflect the severity of the referred women's conditions. Although the TBAs may have identified and selectively referred women with the most threatening complications, the data collected by the TBAs were not specific enough to distinguish the higher-risk women who were referred from lower-risk women who were not referred. This would result in noncomparable groups; the women who had antenatal pathology but were delivered by TBAs may not have had as serious problems as the women who were referred. This type of bias would not have functioned in regard to parity, which is the only factor for which the data suggest a possible benefit of hospital delivery.

\section{Conclusions}

The TBAs do a good job of referring women to the hospital. The referral rates are high for women who have problems during labor but lower for women with an antenatal condition. This is probably because many of the antenatal conditions were not severe. However, even if the referral system works adequately (that is, the woman does not wait too long to call the TBA and the TBA realizes that she needs to get the woman to a hospital), the woman still must travel to the hospital. In the first study, an emergency vehicle was constantly available. However, TBAs in Trairi have to find a vehicle to take the woman to the hospital (with luck, not in the rainy season!). Even if a woman reaches the hospital in Trairi promptly, if she needs a cesarean section she must then be sent by ambulance to the hospital in Fortaleza, a three-hour trip. Many women arrive too late for the interventions available at the hospital to have an impact on their babies. As Winikoff has pointed out, services at the facilities that receive obstetric 
emergencies should include at least surgical delivery, blood transfusion, antibiotic treatment and fluid replacement (Winikoff et al., 1987). Upgrading the resources at the hospital in Trairi may be the best solution for lowering mortality rates in this rural area.

\section{Problems}

\section{The Need For Local Data}

It is necessary to conduct research on local reproductive health problems and to use the data from that research as the basis for developing a risk assessment instrument and scoring system. No valid "generic" risk-scoring systems exist that can be applied accurately in a variety of situations. Since relative risk and prevalence (and thus attributable risk) vary in different populations, risk assessment systems must be based on data from the community in which the system will be used. In most cases, the same risk assessment tool should not be used even for an entire country. Because of the paucity of data in most developing countries, it is usually necessary to collect new data in order to develop a locally appropriate risk-screening tool. This process provides an excellent basis for planning local health care and thus is valuable in itself. Nevertheless, it requires skilled leadership and consumes resources, either or both of which may not be available. It is not always necessary to collect completely new data, however. Much information can be gained by retrospective analysis of pre-existing hospital and health center records, and local health professionals can be taught to conduct such analyses. Since most risk-scoring systems have been based primarily on readily available data, some of the more relevant and powerful predictors of risk have not been used because the data are not available from existing records.

\section{The "Inverse Care Law"}

Some women, often those most at risk, do not come for care and thus are not screened. This paradox is known as "the inverse care law." In almost all countries, some percentage of pregnant women do not come to the attention of the persons responsible for providing prenatal screening and care. Although in many developing countries more than half of the women have at least one prenatal visit, a large proportion do not get any prenatal care. Poor women living in rural areas and urban slums are least likely to get prenatal care (Maine, 1991). The World Health Organization (WHO) monograph on the risk approach refers to threshold and acceptability as factors that influence people's willingness to use a health care service: "For some families ... the threshold is high and the need for health care is not recognized" (WHO). When the quality of care provided in the health facilities is low, this 
problem is worse because people do not think it is worthwhile to go to the hospital or clinic. However, it is possible, but very costly, to improve coverage by active outreach.

\section{Inability to Conduct Accurate Assessments}

Because many women do not begin to receive care until late in their pregnancies or make only one or two prenatal visits, it is often not possible to complete important screening procedures or to learn the results of screening tests in time to use the information as a basis for treatment and referral. A study of women who obtained prenatal care in Nairobi and delivered at Kenyatta National Hospital found that more than half of the women did not start care until after the twenty-seventh week of gestation. This delay in prenatal care made it impossible to obtain a baseline blood pressure measurement for 12 percent of the women; blood grouping was done for only 52 percent; and hemoglobin was measured for only 48 percent. In Swaziland, some women with positive prenatal blood screening tests for syphilis do not get treated because they do not return to the clinic or, in some cases, because their babies are born before the test results are known (Ausherman et al., 1990).

Inability to Obtain Accurate Histories. Accurate assessments are also hindered because some women cannot provide reliable information on their age, parity, date of last menstrual period, family medical history, or the history of their previous pregnancies, and/or they do not perceive current symptoms as abnormal and thus do not report them. Less accurate data cause the riskscoring system to be less sensitive.

Some people try to forget babies that die and thus do not mention those pregnancies that resulted in stillbirths or neonatal deaths. With understanding of the culture, some of these problems can be at least partially overcome. For instance, many Indian women cannot report the date of their last menstrual period, but they do remember performing customs that accompany menstrual periods - for example, washing one's hair and/or sitting apart from the rest of the family. Many women can report when these events occurred, even if they do not know the date of their last menstrual period.

Inaccurate Perceptions. In many societies, women's perception of what is normal and what is abnormal during pregnancy is very poor. For instance, because it is common for pregnant women to have slightly swollen feet, many women do not recognize even severe edema as an indication of a pathologic process and thus do not bring their condition to the attention of a 
trained health worker. The paleness associated with severe anemia is also often considered to be normal and thus may not be reported.

Lack of Equipment and Supplies. LDC health care systems may not have the equipment or supplies to conduct even simple medical tests; that is, many hospitals do not have the reagents needed to test urine or the equipment to measure blood pressure. In Nigeria, women classified as high-risk are told to go to the clinic for weekly visits from the time they register for prenatal care until they deliver their babies. However, the midwives who run the clinics often lack the means to conduct blood tests or urine tests, have no iron supplements to give, and run out of the medicine for treatment of malaria. ${ }^{8}$

Need for Simple Risk Assessment Tools. Developing country programs need assessment tools that are both valid and simple to use; however, the most accurate scoring systems are the least simple to apply. Risk factors rarely occur in isolation. Rather, they occur in multiple combinations, and specific combinations of factors may be associated with certain poor outcomes. Although most risk-scoring systems provide a way to weigh the cumulative effect of several factors, the validity of the weighting systems is not known. In some systems, women with several demographic risk factors end up with higher scores than are given to women with a single but very powerful medical risk factor. Yet simplicity is needed if TBAs and other minimally trained workers are to perform risk assessments.

\section{Unwillingness of Providers to Comply with Referral Guidelines}

If the screening systems are oversensitive, some care providers (physicians and midwives, as well as TBAs) ignore or bend the program rules and use their own judgment regarding which women should be referred. Persons who provide prenatal care have ample motivation to disregard the referral guidelines, including the fear that they will lose respect if they are perceived as being unable to handle complicated cases, financial loss, and sympathy for their patients - who may not be able to afford hospital fees or may not want to leave their communities or their familiar care provider to go to a hospital where strangers will be caring for them. A study of referral practices in one physician group practice in the United States attributed inconsistent screening practices to concerns regarding financial hardship for patients and elements within the physician-patient relationship; the doctors were more likely to make Sciences, University of Nigeria, Enugu Campus. 
exceptions to their own referral rules for patients who had been coming to their practice for a long time (Noorhoeve et al., 1984). In some developing country situations, care providers are reluctant to refer many women for fear of overwhelming the resources of the higher-level center.

\section{Lack of Transportation and Financial, Cultural, and Social Factors}

Factors that determine whether women will follow advice to go to a hospital for labor and delivery include cultural norms and practices, the feasibility of transfer (distance, terrain, and transportation), and a variety of other influences on not only the woman but also her husband or other persons who advise her or control what she does. Risk avoidance is just one aspect of human behavior; there are many other kinds of motivation.

Many women cannot afford to act on the advice they are given - for example, to minimize their workloads or to go to live close to the hospital during the last few weeks of pregnancy. Who will take care of their children? A study in Kenya found that six of 10 women who intended to deliver in the hospital actually delivered at home, not because they had changed their minds but because of the distance to the hospital and the cost of transportation (Acheson et al., 1990). The distance between the woman's place of residence and the referral hospital may be very great in a developing country. Women may be unable or unwilling to travel many hours or, in some cases days, to obtain childbirth care.

Developing country women have much work to do and must make their own judgments regarding whether the actions they are advised to take are worth the time and effort it takes, from their own perspective. For instance, many Indian women will not comply with a schedule of frequent prenatal visits unless they can see that something of value is being done. ${ }^{9}$

Some women are frightened by the prospect of leaving the care provider and system that are familiar to them; others are concerned about being looked upon as inadequate if they need assistance in something as straightforward as having a baby; still others are afraid that if they go to a hospital they will have a cesarean section. Women in Nigeria who are told that they are at risk of needing a cesarean section may avoid the hospital for that exact reason.

The behavior of all persons involved is heavily influenced by their perceptions of what is

$9 \quad$ Based on comments made by Dr. Usha Shah during the seminar. 
and is not normal during pregnancy and by their own risk/benefit assessment of the situation, and their view of what is appropriate care under specific circumstances. Many women who attend prenatal clinics also go to traditional birth attendants, traditional healers, and/or prayer houses and may get opposing advice from them. ${ }^{10}$ Some women who have already had one cesarean section refuse completely to go to a hospital for their future deliveries.

Going to the hospital almost always entails significant financial cost to the family; because of that, in many societies the decision that a woman should go to the hospital can be made only by the husband. Even when the woman ultimately follows the advice to go to a hospital, it may take many hours or days for the family to come to this decision. (See, also, chapter 9, "Women's Personal Risk-Benefit Calculations.")

\section{Summary}

Five projects involving the implementation of maternal risk assessment projects in four developing countries were described in this chapter. The projects varied greatly in scope, highlighting the lack of consensus regarding the meaning of the "risk assessment approach."

The WHO project in China developed an extensive data base on perinatal health and health care in Shunyi County and used that information to plan many significant interventions. The information-gathering phase of this complex project included (1) development of a surveillance system to collect data on every pregnancy; (2) an in-depth study of 50 cases of perinatal mortality; (3) assessment of access to and utilization of prenatal and intrapartum health care; and (4) an in-depth review of the quantitative and qualitative adequacy of care provided to pregnant women at all levels of the health care system.

Many interventions were implemented during the project, including the following:

- a massive public education program to teach pregnant women and their families about prenatal care and when to seek help for potential complications;

- a formalized risk-assessment and referral system that called for every pregnant woman to be assessed for the presence of 12 risk factors at three specified times during her pregnancy; practitioners at each level of the system were taught to conduct these assessments and to care for or refer women based on their risk assessment score.

Based on comments made by Dr. Chinyelu Okafor, during the seminar. 
- interventions to improve identified deficiencies in the performance of the health care system.

As a result of these extensive interventions, perinatal mortality in Shunyi County was reduced by one-third, eclampsia was eliminated, and the incidence of neonatal asphyxia decreased by 84 percent. Although this success has been attributed to "the risk approach," risk assessment and referral were only one component of this multifaceted program.

The National Institute of Perinatology in Mexico City used a very different risk assessment tool; it assessed each pregnant woman for twice as many factors as the China program did, but used the resulting information in a much less complicated way: If a woman had any of the approximately 25 risk factors, she was designated "high risk." And while the WHO and Chinese officials used risk assessment as part of a comprehensive overhaul of perinatal care in Shunyi County, the major purpose of the Mexico City project was to reduce the number of low-risk women delivering their babies at Mexico's premier tertiary hospital. Keeping low-risk women out of Shunyi County's one higher-level hospital was also an important part of the success of the Chinese project.

The project in Zaire and one of the two projects in Brazil were implemented in rural areas with poor or unreliable transportation. Both programs focused on preventing maternal mortality by training traditional birth attendants (TBAs) to advise women who were likely to experience serious problems during childbirth to go to a hospital for labor and delivery. Although the other project in Brazil had the same objectives, it was located in an area that is much closer to the referral hospital; most of the TBAs in that area conduct deliveries in 8-10bed birth centers, and community vehicles and drivers were available to transport women with complications to the hospital in Fortaleza. An important objective of the project was to transfer women who were experiencing labor complications to the hospital as early as possible.

During the first phase of the project in Karawa, Zaire, obstructed labor was identified as the most significant problem. The Zairian TBAs were taught to refer women to the hospital based on characteristics that had been found to be more frequent among women who experienced obstructed labor. Some of these factors can be assessed during the prenatal period; other factors do not occur or cannot be recognized until near or after the onset of labor. The TBAs in Brazil were taught to send women to the hospital if they had a transverse lie, bleeding, a prolapsed limb or cord, eclampsia, or prolonged labor. 
Three of the projects had difficulty convincing referred women to go to the hospital as directed or found that health care workers bent the program guidelines to conform to their own opinions regarding suitable care.

- Staff of the National Institute of Perinatology in Mexico City were not willing to use complicated risk-scoring instruments. If forced to do so, they would not fill out the forms while providing clinical services but put it off to do all of the paper work at the end of each day, a system that does not produce the most accurate information.

- In Zaire, fewer women than expected went to the hospital. Neither the satellite health centers nor the hospital were able to provide adequate care to women referred by the TBAs. The TBAs lacked confidence in those facilities and were hesitant to tell women to go to them. Some of the women who were referred to the hospital did not go for various logistical, social, cultural, and economic reasons.

- The TBAs near Fortaleza, Brazil did not refer some of the high-risk women, and some whom they did refer did not go to the hospital.

- Among the trained TBAs in Trairi, Brazil, those with smaller case loads made more referrals, especially of nulliparous women, than the TABs with more experience.

The "lessons learned" from the experience in Zaire include the need for community education and for substantial improvement in the capability of the health care facilities to which high-risk women are supposed to be referred. Both lessons were important components of the successful Chinese project.

Evaluation of the project near Fortaleza, Brazil found that the TBAs referred (during prenatal care) or transferred (during labor) 97 percent of the women who experienced the conditions they had been taught to consider as reasons for referrals. The perinatal mortality rate for women who received care from the trained TBAs, including those referred or transferred to the hospital, was much lower than the rate for nonprivate patients who delivered at the hospital but had not been referred by the TBAs.

Evaluation of the project in Trairi, Brazil suggested a benefit of hospital delivery for nulliparous women, regardless of their predetermined risk status, but no reduction in perinatal mortality associated with hospital deliveries for parous women. Eight potentially preventable stillbirths occurred to women with singleton pregnancies who had been referred to the hospital by the TBAs. In seven of these eight cases the mothers reached the hospital too late for any 
intervention to have saved their babies. The evaluators concluded that upgrading the resources at the hospital in Trairi may be the best way to lower perinatal mortality in this rural area.

It is difficult to develop and implement a successful risk assessment and referral program:

- It is necessary to conduct local research to identify factors associated with a high incidence of poor pregnancy outcomes in a specific area. Risk assessment forms developed elsewhere are inappropriate.

- Many pregnant women do not utilize prenatal care services, even when they are available, or do not come until late in their pregnancies. The women who are most likely to need special care are often least likely to participate in the program.

- It may be difficult to obtain accurate information on risk factors.

- If the risk assessments are to be done by persons with relatively little training, they must be easy to do. It may not be feasible to collect and use some potentially useful types of information.

The most successful of the five developing country projects discussed during the seminar was a very complex project that included extensive community education and substantial improvement of the health care system at every level. Evaluation of less complex projects in Zaire and Brazil concluded that similar basic improvements in the health care systems of the areas served by those projects are needed for the risk assessment programs to achieve their goals.

\section{$\underline{\text { References }}$}

Acheson, L.S., S.E. Harris, and S.J. Zyzanski. "Patient selection and outcomes for out-of-hospital births in one family practice." Journal of Family Practice 31 (1990): 126-36.

Ausherman, C., S. Bertoli, R.L. Kolehmainen-Aitken, J. Rooks. "Swaziland Primary Health Care Project End-of-Project Evaluation." Arlington, VA: Medical Services Corporation International, 1990.

Janowitz, B., P.D. Bailey, R.C. Dominik, and L. Araujo. "TBAs in rural Northeast Brazil: Referral patterns and perinatal mortality." Health Policy and Planning 3 (1988): 48-58.

Maine, D., Safe Motherhood Programs: Options and Issues. New York: Center for Population and Family Health, Columbia University, 1991. 
Voorhoeve, A.M., C. Kars, and J.K. Van Ginneken. "Modern and traditional antenatal and delivery care." In Modern and Traditional Obstetrics. Ed. J.K. Van Ginneken and A.S. Muller. London: Croom Helm, 1984. Pp. 309-22.

Winikoff, B., C. Carignan, E. Bernardik, and P. Semeraro. "Medical services to save mothers' lives: Feasible approaches to reducing maternal mortality." Population Council paper prepared for the Safe Motherhood Initiative Meeting, Nairobi, Kenya, February 1987.

World Health Organization (WHO). The Risk Approach in Health Care, With Special Reference to Maternal and Child Health, Including Family Planning. Geneva: World Health

Organization. p. 49. 


\section{Chapter 6:}

\section{POSSIBLE EFFECTS ON THE HEALTH CARE SYSTEM}

If the efficiency of risk screening is poor (too many false positives, too many false negatives), people may lose faith in the screening system and in the people and institutions who promote it. Other public health programs, such as immunization, could be negatively affected. What is the impact on the community when a woman who has been told that she is high-risk and must go to a hospital for a safe delivery does not go and has an easy birth and healthy baby? It is hard to explain false positives, false negatives, and sensitivity and specificity. Unlike curative care, for which most people perceive a need, the value of preventive care (such as family planning, prenatal care, immunizations, and well-child care) is difficult for people to appreciate. It is costly to them, in terms of their time and attention, and in some cases in terms of their money and their dignity. To encourage the habit of using preventive health care, it is necessary not only to make these services as attractive and inexpensive as possible, but also to help people understand that the services are beneficial. Participation in a maternal health care program based on risk assessment will be "costly" to many women and their families; therefore, it is essential that the program be perceived as valuable - that is, as being effective in preventing scary problems and bad outcomes. If the screening methods are not very specific, many women will be told that they need to go for special care, and some of them may not be willing or able to do so but will go on to have uncomplicated births. If the screening methods are not very sensitive, some women who had been told that they were normal or low-risk will go on to develop serious problems. In either case, the people and institutions who do the screening may lose respect, and there is a risk that the society will begin to doubt the importance and value of participating in preventive health care programs. Such doubt could have a negative long-term effect on other public health programs.

On the other hand, risk assessment may increase the number of low-risk women who go to hospitals for childbirth, making it even more difficult for the limited hospital staff to give adequate care to those women who experience actual complications. If scoring systems are not specific enough, large numbers of women will be advised to go to the hospital for labor and delivery. In addition, there is a danger that many people will think that if the hospital is the best place for high-risk women to deliver, it must really be the best place for all women to have their babies. Then those who live close enough and can afford it will begin to demand hospital intrapartum care, even though they are low-risk and have no complications. 


\section{Effects on Traditional Birth Attendants}

Some have hypothesized that risk assessment systems may make it possible to use relatively inexperienced, brieffy trained care providers in prenatal care programs and make it easier to structure, control, and evaluate the care that they provide.

In many developing countries, risk assessment programs (or shorter-term projects) are training traditional birth attendants (TBAs) to conduct normal births more safely and to carry out prenatal risk assessments and refer high-risk women for hospital deliveries. The effects of these activities on the TBAs themselves should be considered along with other consequences of such programs. Such effects could include positive or negative impacts on their status in the community, their expectation of payment, and their willingness to continue to provide free or very low-cost services after the special (but, too often, short-term project) has been discontinued. TBAs may lose status (and thus motivation to continue their work) if they must accept training from young, inexperienced nurses, or if they are required to refer to hospitals large numbers of women who end up having normal births. TBAs involved in these programs often ask for training and supplies to help them deal with common but serious complications, such as postpartum hemorrhage and breech births, which cannot be entirely avoided by risk assessment and referral. It should be remembered that most TBAs participate in risk assessment programs without payment, although not without costs in time and effort to themselves. If they are to continue to cooperate in these programs, that participation must be made satisfying to them.

Need for Education and Counseling. Women who are told that they are high-risk will need information and counseling; their husbands may need it, too. Counseling needs bring additional demands to the service system and raise ethical dilemmas (see chapter 12). 


\section{Chapter 7:}

\section{REPRODUCTIVE RISK ASSESSMENT IN FAMILY PLANNING}

\section{Delivery of Family Planning Services at the Mexican Social Security Institute (IMSS) on the Basis of Reproductive Risk \\ (based on a paper by Dr. Aurora Rábago, Ph.D., Chief, Studies and Statistics Models Applied to Population Department, Mexican Institute of Social Security)}

The Mexican Social Security Institute (IMSS) has been a major provider of family planning services in Mexico since the early 1970s. Approximately 36 million urban and 11 million rural Mexican citizens have the right to receive health services through the IMSS. In order to qualify for IMSS services, an individual must be employed in, or must be a dependent of someone employed in, the formal sector; must be retired; or must be a student. The IMSS does not cover people who are unemployed or are not salaried employees, such as domestics, street vendors, or agricultural workers; thus, its population is not representative of all Mexican people. Those who live in rural areas are particularly under-represented. In addition, many people who qualify for IMSS health services utilize the private sector for routine medical care while using the IMSS for more expensive services, such as childbirth, surgery, and emergency care. Since 1979 the IMSS has provided family planning services, including sterilization procedures, without charge to any eligible person who requests them.

People who want to obtain medical attention through the IMSS enter the system by enrolling in one of 1,230 IMSS family medicine clinics. Secondary care is available through 215 general hospitals. The system also has 32 specialized hospitals; it employs about 32,000 physicians. The IMSS uses reproductive risk assessment in order to assign individual women to the appropriate level of care.

The IMSS's decision to utilize reproductive risk assessment was based in part on their finding that, among their own clientele, 83 percent of the perinatal deaths involved women with high-risk characteristics. In addition, 70 percent of maternal deaths in Mexico occur to women with high-risk characteristics (AMIDEM, 1987).

In 1983 the Family Medicine Division of the IMSS developed a form to structure uniform risk assessment of every pregnant woman. Women found to be at normal risk were referred to IMSS clinics for prenatal care. Women with elevated risk factors were sent to IMSS hospitals for 
a more thorough evaluation. If the hospital physician felt that the risk factor could be monitored adequately at a clinic, the woman was referred back to the primary care level. However, women whose risk factors required close monitoring were encouraged to obtain prenatal care at the hospital. While this condition required some women to obtain prenatal care at inconvenient locations, it directed those most likely to need it to a higher level of medical attention.

More recently, the IMSS has begun to apply reproductive risk assessment not only to pregnant women but also to women who are not pregnant, including those who have never conceived. By evaluating women who are not pregnant, the IMSS hopes to promote the use of effective family planning methods, especially to women with risk factors, and thus to reduce the number of pregnancies that result in poor outcomes.

\section{Development and Evaluation of the Risk Assessment Form}

Reproductive risk evaluation at the IMSS is guided by a two-page form that groups potential risk characteristics into three categories: sociodemographic risk factors (nine questions), obstetric risk factors (nine questions), and personal medical history (five questions). A risk score is associated with each variable. A total risk score up to 3.5 is classified as normal; scores of 4.0 and higher indicate high-risk. The form also includes sections for information on the woman's next pregnancy, including prenatal care, diagnoses and treatment of illnesses that occur during the pregnancy, laboratory results, information on the delivery, and family planning referral.

The specialists who designed the risk assessment form drew upon their clinical experience to decide which risk factors to include and how much weight to assign to each factor; epidemiologic data were not considered. The form was created in this manner because the risk factors suggested by the physicians' clinical experience were similar to those mentioned in published reports, and the IMSS did not want to undertake a long and expensive study.

During the past six years, two versions of the IMSS risk assessment form have been developed. The original form, created in 1983, was used to channel women to hospitals for prenatal care and to track the progress of their pregnancies. A second version, developed in 1985 , is more frequently used to promote acceptance of family planning methods. The latter version of the form includes risk factors from previous pregnancies and can be used to evaluate the risk level of women who are not pregnant, as well as those who are. 
Two studies were conducted to evaluate the ability of these forms (based on risk factors found in the literature) to predict perinatal mortality in the IMSS population Nelasco, 1985; Aparicio, 1987). Using these criteria for risk, 57 percent of the women screened through the IMSS were classified as high-risk; the sensitivity of the risk assessment was 83 percent, and the pregnancies of women predicted to be high-risk were 3.9 times more likely than those of normalrisk women to result in perinatal death (Gribble and Rábago, 1989).

\section{Program Strategy and Objectives}

As a result of this research and experience, the staff of the IMSS believed that the strategy of identifying women with certain characteristics and urging them to use effective family planning methods would improve the quality of care and reduce adverse pregnancy outcomes for women as well as babies. They planned to train IMSS personnel in risk assessment and management, to develop an educational program to make women more aware of risk factors, to screen as many women as possible, to inform large numbers of prenatal patients and other (nonpregnant) women about the availability of family planning services, and to provide special counseling and treatment, including contraception, for those at greatest risk. The IMSS offers family planning services to all women, regardless of risk status, but women identified as high-risk were to be given greater access to higher levels of obstetric and gynecologic care and more motivation to practice contraception. The IMSS risk assessment strategy has three major objectives:

(1) Incorporate family planning into the IMSS strategy for reducing high-risk pregnancies and perinatal mortality.

(2) Reduce high-risk pregnancies among the IMSS population.

(3) Increase contraceptive use by IMSS-eligible women, particularly those at greatest risk of morbidity and mortality associated with reproduction.

A complementary goal of the strategy is to maintain the reproductive health of women judged to be low-risk.

\section{Methodology for Evaluating the Risk Assessment Program}

A quasi-experimental evaluation was conducted. IMSS surveyed both an experimental and a nonequivalent control group before and 17 months after the risk assessment strategy was started in the experimental area. This amount of time was thought to be sufficient to observe 
changes in contraceptive use by women with high reproductive risk. Patients of IMSS outpatient clinics and hospitals in Aguascalientes State were used as the experimental group; those in Queretaro State were used as the control group. When the study was being designed, these two areas were found to be quite similar with regard to the incidence of perinatal mortality and the number of postpartum women who were accepting contraception.

\section{Results of the Evaluation}

Training. Prior to the commencement of this program, the physicians, nurses, and other relevant personnel working at IMSS facilities in the experimental and control areas were found to be equivalent in their knowledge of reproductive risk. There was a significant increment in the knowledge of the health workers in the experimental area (Aguascalientes State) following five days of special training.

Health Education/Communication Program. Seventeen months after the program started, 91 percent of the women using the IMSS clinics and hospitals in Aguascalientes State had heard about reproductive risk. In contrast, only 6 percent of the control group women were aware of this concept. Among women in the experimental group, radio announcements and posters were the most common sources of this kind of information, followed by pamphlets, talks, and audiovisual presentations provided by the IMSS.

Table 8.1 presents information on the adequacy of the women's knowledge about reproductive risk. Women's understanding was considered to be "limited" if they mentioned only traditional indicators such as age, parity and birth interval, but "adequate" if, in addition to the usual risk factors, they also mentioned factors related to obstetric or medical conditions. Approximately three-fourths of the women in the experimental group were found to have either a limited or an adequate understanding of the concept. Women who used the IMSS hospitals were more likely than those who used the IMSS clinics to have adequate knowledge of the concept. However, no difference was found between high- and normal-risk women in terms of their knowledge of reproductive risk. This finding demonstrates that the same information was given to all of the women, regardless of their personal risk status. However, it also shows that high-risk women did not end up with a better understanding or greater retention of the material. 
TABLE 7.1

Adequacy of Understanding of Information about Reproductive Risk at Endline Survey

Hospitals
Experimental

$(N=1,205)$
Control

$(N=1,107)^{\star}$

\begin{tabular}{|c|c|c|}
\hline Adequate & 43.8 & 4.9 \\
\hline Limited & 33.6 & 2.0 \\
\hline Inadequate & 14.1 & 1.2 \\
\hline No information & 8.1 & 91.9 \\
\hline Family medicine clinics & $(N=1,480)$ & $(N=939)$ \\
\hline Adequate & 36.8 & 2.7 \\
\hline Limited & 37.0 & 0.6 \\
\hline Inadequate & 15.9 & 0.1 \\
\hline No information & 10.3 & 96.6 \\
\hline
\end{tabular}

Coverage and Correctness of the Risk Assessment. Table 7.2 shows the percent of women using IMSS facilities whose reproductive risk status was evaluated before, during and after implementation of the experimental program in Aguascalientes State. Even before the program started, 34 percent of the women seen in these facilities had been assessed for reproductive risk. The weighted average of completed forms during the intervention was 85.3 percent. Over the course of the study, approximately 70 percent of the forms were completed correctly - that is, all items were filled out and the woman's final risk score was totaled accurately. Although this finding does not necessarily mean that large numbers of women were classified incorrectly, it points to the need for careful training and supervision. With operational monitoring of the experimental program, the percentage of completed forms increased by about 3.3 percent per month. The percentage of forms completed correctly increased by about 2.0 percent per month during the intervention. 


\section{TABLE 7.2}

Risk Assessment of Women Who Received Outpatient Services, Experimental Group

\begin{tabular}{|c|c|c|c|}
\hline \multirow[b]{2}{*}{ Month } & \multicolumn{2}{|c|}{ Risk Assessment Status (\%) } & \multirow{2}{*}{$\begin{array}{l}\text { Sample } \\
\text { Size }\end{array}$} \\
\hline & Completed & Correct & \\
\hline \multicolumn{4}{|l|}{ Pre-intervention } \\
\hline September 1986 & 34.0 & - & 80 \\
\hline \multicolumn{4}{|l|}{ Intervention } \\
\hline February 1987 & 78.2 & 58.8 & 312 \\
\hline March & 70.7 & 57.6 & 795 \\
\hline April & 86.8 & 72.2 & 730 \\
\hline June & 77.3 & 62.6 & 1,056 \\
\hline August & 90.0 & - & 804 \\
\hline October & 94.4 & 82.9 & 886 \\
\hline November & 90.0 & 74.6 & 862 \\
\hline January 1988 & 90.7 & 70.7 & 990 \\
\hline $\begin{array}{l}\text { Weighted average } \\
\text { during intervention }\end{array}$ & $\begin{array}{c}85.3 \\
(N=5,435)\end{array}$ & $\begin{array}{c}78.1 \\
(N=5,631)\end{array}$ & \\
\hline Slope by month & 3.3 & 2.0 & \\
\hline
\end{tabular}

"Correct" indicates that all items on the MF-7 were completed and that the sum of the risk score was correctly totalled.

Proportion of Women Classified as High-Risk. Table 7.3 shows the distribution of married women of reproductive age who were classified as high-risk in both the experimental and control groups, before and after the programmatic intervention. Between 50 and 60 percent of women seen in the hospitals and between 60 and 75 percent of women seen in the outpatient clinics were classified as high-risk. These figures are high due to the high sensitivity (and correspondingly low specificity) of the classification procedure used by the IMSS. In addition, women seeking treatment at an IMSS clinic or hospital (or any other health care facility) may be at greater risk than those in the general population. 
TABLE 7.3

Outcomes of Risk Assessment: All Women in IMSS Study Before and After Intervention

\begin{tabular}{|c|c|c|c|c|}
\hline \multirow{2}{*}{$\begin{array}{l}\text { State, Site of Care, } \\
\text { and Risk Status }\end{array}$} & \multicolumn{2}{|c|}{ Baseline } & \multicolumn{2}{|c|}{ After Intervention } \\
\hline & Number & Percent & Number & Percent \\
\hline \multicolumn{5}{|l|}{ Experimental state } \\
\hline \multicolumn{5}{|l|}{ Hospitals } \\
\hline High-risk & 469 & 51.7 & 646 & 53.6 \\
\hline Normal & 438 & 48.3 & 559 & 46.4 \\
\hline All & 907 & 100.0 & 1,205 & 100.0 \\
\hline \multicolumn{5}{|c|}{ Family medicine clinics } \\
\hline High-risk & 372 & 71.7 & 583 & 75.7 \\
\hline Normal & 147 & 28.3 & 187 & 24.3 \\
\hline All & 519 & 100.0 & 770 & 100.0 \\
\hline \multicolumn{5}{|l|}{ All sites of care } \\
\hline High-risk & 841 & 59.0 & 1,229 & 62.2 \\
\hline Normal & 585 & 41.0 & 746 & 37.8 \\
\hline All & 1,426 & 100.0 & 1,975 & 100.0 \\
\hline \multicolumn{5}{|l|}{ Control state } \\
\hline \multicolumn{5}{|l|}{ Hospitals } \\
\hline High-risk & 646 & 60.1 & 607 & 54.8 \\
\hline Normal & 429 & 39.9 & 500 & 45.2 \\
\hline All & 1,075 & 100.0 & 1,107 & 100.0 \\
\hline \multicolumn{5}{|c|}{ Family medicine clinics } \\
\hline High-risk & 323 & 61.6 & 207 & 64.9 \\
\hline Normal & 201 & 38.4 & 112 & 35.1 \\
\hline All & 524 & 100.0 & 319 & 100.0 \\
\hline \multicolumn{5}{|l|}{ All sites of care } \\
\hline High-risk & 969 & 60.6 & 814 & 57.1 \\
\hline Normal & 630 & 39.4 & 612 & 42.9 \\
\hline All & 1,599 & 100.0 & 1,426 & 100.0 \\
\hline
\end{tabular}

Contraceptive Use by Women Cared for in IMSS Hospitals. Women whose risk status was assessed in a hospital were either postpartum or postabortion. IMSS Family Planning Program managers believe that IUDs and tubal ligations are the most appropriate methods of contraception for such women. Combined oral contraceptives are occasionally prescribed for a 
postabortion woman who is not willing to accept either of the other two methods. In order to promote breastfeeding. IMSS staff do not offer combined oral contraceptives to postpartum women; however, they are beginning to offer progestin-only pills to lactating women.

Acceptance of contraception during the postpartum and postabortion periods increased significantly in the experimental state, from 47.3 percent at the time of the baseline survey to 61.0 percent after the reproductive risk assessment program had been in operation for 17 months (Table 7.4). Postpartum contraceptive use was much lower in the control state at the baseline study (19.3 percent), and increased by only 2 percentage points during the study. This large initial difference was unexpected based on earlier data, which indicated similar use of postpartum contraception in the two states. Unfortunately, the extreme differences between the states as measured during the pre-intervention survey make it impossible to draw conclusions regarding the impact of the risk assessment program on overall contraceptive use. In the experimental state, women who were classified as high risk were less likely than normal-risk women to accept postpartum contraception. This was true before the risk assessment program was started and was still true after the program had been in operation for 17 months. The opposite was true in the control group. The percentage of women practicing contraception increased more in the experimental area than in the control area in absolute terms. However, if the increases are measured in relation to the baseline percentage for each group, no consistent pattern emerges. The smallest increase in contraceptive acceptance (5 percent) was among high-risk women in the control group; the highest increase (30 percent) was among normal-risk women in the control group. Both high- and normal-risk women in the experimental group experienced increases of 24-25 percent. 
TABLE 7.4

Contraceptive Prevalence Among Women Interviewed in Hospitals

\begin{tabular}{llll}
\hline Area & $\begin{array}{l}\text { Baseline } \\
\text { Survey }\end{array}$ & $\begin{array}{l}\text { Endline } \\
\text { Survey }\end{array}$ & $\begin{array}{l}\text { Absolute } \\
\text { Difference }\end{array}$ \\
\hline Experimental & $N=907$ & $N=1,205$ & \\
& $47.3 \%$ & $61.0 \%$ & $13.7 \%$ \\
& $(429)$ & $(735)$ & \\
Control & $N=1,075$ & $N=1,110$ & \\
& & & \\
& $19.3 \%$ & $21.3 \%$ & $2.0 \%$ \\
$(207)$ & $(236)$ & \\
\hline
\end{tabular}

Table 7.5 presents data on the type of contraception chosen by high- and normal-risk women in the experimental and control groups before and after implementation of the risk assessment program. No significant change in method mix occurred between the pre- and post-intervention surveys in any group. In both the experimental and the control areas, however, high-risk women were more likely than normal-risk women to have tubal ligations. In both areas, demand for tubal ligation was greater than the ability of the system to provide the method. Consequently, little opportunity existed for an increase in the use of this method. Thus, it was not possible to determine what effect, if any, the risk assessment program might have had on the desire and demand for permanent contraception. 
Contraceptive Methods Chosen by High- and Normal-Risk Women Who Received Care in IMSS Hospitals

Area Baseline Survey (\%) Endline Survey (\%)

\section{Experimental}

High-risk

IUD

Tubal ligation

Normal-risk

IUD

Tubal ligation

\section{Control}

High-risk

IUD

Tubal ligation

Normal-risk

IUD

Tubal ligation
$(\mathrm{N}=191)$

70.2

29.8

$(\mathrm{N}=237)$

96.6

3.4

$(\mathrm{N}=129)$

27.1

72.9

$(\mathrm{N}=58)$

65.5

34.5
$(\mathrm{N}=356)$

73.0

27.0

$(\mathrm{N}=379)$

95.5

4.5

There was no significant change in method mix between baseline and after intervention surveys in any group.

Rábago/Mexican Social Security Institute

Contraceptive Use among Women Who Received Care in Clinics. At the time of the baseline survey, 60 percent of the outpatient clients in Aguascalientes and 55 percent of those in Queretaro were practicing contraception (Table 7.6). By the time of the post-intervention survey, prevalence in Aguascalientes had increased to 66 percent, an increase of 6 percentage points.

Queretaro experienced a similar increase of nearly 7 percentage points, achieving a contraceptive prevalence of 62 percent. Contraceptive use by high-risk women increased during the study in both areas. It appears that the risk assessment program did not exert an effect on contraceptive prevalence. In both study areas, high-risk women were more likely than normalrisk women to have tubal ligations (Table 7.7); however, the association between risk status and sterlization did not appear to be enhanced by the risk assessment program. 
TABLE 7.6

Contraceptive Prevalence by Risk Group Among Women Receiving Care in IMSS Family Medicine Clinics

\begin{tabular}{lcclc}
\hline $\begin{array}{l}\text { Area and } \\
\text { Risk Status }\end{array}$ & Baseline & $\begin{array}{l}\text { After } \\
\text { Intervention }\end{array}$ & $\begin{array}{c}\text { Percent } \\
\text { Increase }\end{array}$ & $\begin{array}{l}\text { Increase as \% } \\
\text { of Baseline }\end{array}$ \\
\hline Experimental & $(\mathrm{N}=519)$ & $(\mathrm{N}=770)$ & & \\
High-risk & $64.5 \%$ & $70.7 \%$ & 6.2 & 9.6 \\
Normal-risk & $(240)$ & $(412)$ & & \\
All & $49.0 \%$ & $52.4 \%$ & 3.4 & 6.9 \\
& $(72)$ & $(98)$ & & 0.1 \\
Control & $60.1 \%$ & $66.2 \%$ & 6.1 & \\
High-risk & $(312)$ & $(\mathrm{N}=510)$ & & \\
Normal-risk & $(\mathrm{N}=524)$ & $(\mathrm{N}=319)$ & & \\
All & $58.2 \%$ & $68.1 \%$ & 9.9 & 17.0 \\
& $(188)$ & $(141)$ & & \\
& $58.2 \%$ & $50.0 \%$ & -8.2 & -14.1 \\
& $(117)$ & $(56)$ & 6.7 & 12.2 \\
\hline
\end{tabular}




\section{TABLE 7.7}

Contraceptive Method Chosen by High- and Normal-Risk Women Receiving Care in IMSS Clinics Before and After 17 Months of Reproductive Risk Assessment Program

\section{State and Risk \\ Status of Women By Contraceptive Method Chosen}

\section{Before Program \\ Started (\%)}

17 Months After

Program Started (\%)

Experimental state

$\begin{array}{lll}\text { High-risk } & (\mathrm{N}=240) & (\mathrm{N}=412) \\ \text { IUD } & 23.7 & 22.3 \\ \text { Tubal ligation } & 48.7 & 46.1 \\ \text { Orals/Injectables } & 16.3 & 14.1 \\ \text { Other } & 11.3 & 12.5 \\ \text { Normal-risk } & (\mathrm{N}=72) & (\mathrm{N}=98)^{\star \star} \\ \text { IUD } & 43.1 & 46.9 \\ \text { Tubal ligation } & 4.2 & 19.4 \\ \text { Orals/Injectables } & 38.8 & 19.4 \\ \text { Other* } & 13.9 & 14.3 \\ & & \\ \text { Control state } & & \\ \text { High-risk } & (\mathrm{N}=188) & (\mathrm{N}=141) \\ \text { IUD } & 25.0 & 18.4 \\ \text { Tubal ligation } & 53.7 & 56.0 \\ \text { Orals/Injectables } & 11.2 & 10.7 \\ \text { Other } & 10.1 & 14.9 \\ \text { Normal-risk } & (\mathrm{N}=117) & (\mathrm{N}=56) \\ \text { IUD } & 50.3 & 44.6 \\ \text { Tubal ligation } & 11.1 & 17.9 \\ \text { Orals/Injectables } & 22.3 & 21.5 \\ \text { Other } & 16.3 & 16.0\end{array}$

* Barrier methods, hysterectomy and vasectomy

* The distribution of methods was significantly different between the before and after surveys only for normal-risk women in the experimental group $(P<.0)$

Rábago/Mexican Social Security Institute

\section{Perinatal and Maternal Mortality and Risk Status of Pregnant Women. One of the IMSSs}

long-term objectives for use of the risk approach is to reduce morbidity and mortality associated with high-risk pregnancies. In the short term, they hoped that their public education strategy would result in fewer pregnancies among high-risk women. Table 7.8 presents data on pregnant 
women screened through the IMSS Family Medicine Clinics in the experimental and control areas before and 17 months after the risk assessment program was started in Aguascalientes State. At the time of the baseline study, 39 percent of the pregnant women in the experimental state and 27 percent of the pregnant women in the control state were classified as high-risk. In the experimental group, the proportion of pregnant women with a history of obstetric pathology declined from 26.5 to 17.0 percent between the baseline and the endline study. The opposite change occurred in the control state; in fact, in the control state the proportion of pregnant women who were classified as high-risk for any reason increased from 27.1 percent at the baseline study to 35.6 percent at the endline study. Although it is too early to attribute the improvement in the experimental area to effects of the risk assessment program, the change is encouraging. 
TABLE 7.8

Prevalence of Risk Factors Among Pregnant Women Seen in IMSS Family Medicine Clinics

\begin{tabular}{|c|c|c|c|c|}
\hline \multirow{2}{*}{$\begin{array}{l}\text { Risk } \\
\text { Factors }\end{array}$} & \multicolumn{2}{|c|}{ Experimental (\%) } & \multicolumn{2}{|c|}{ Control (\%) } \\
\hline & $\begin{array}{l}\text { Baseline } \\
(\mathbf{N}=\mathbf{3 3 0})\end{array}$ & $\begin{array}{l}\text { Endline } \\
(\mathbf{N}=354)\end{array}$ & $\begin{array}{l}\text { Baseline } \\
(\mathrm{N}=411)\end{array}$ & $\begin{array}{l}\text { Endline } \\
(N=186)\end{array}$ \\
\hline \multicolumn{5}{|l|}{ Age } \\
\hline$<19$ & 18.2 & 16.4 & 14.6 & 12.4 \\
\hline$>34$ & 9.4 & 7.1 & 4.1 & 4.9 \\
\hline \multicolumn{5}{|l|}{ Parity } \\
\hline 1 & 34.5 & 33.3 & 33.7 & 26.7 \\
\hline$>4$ & 23.0 & 16.9 & 14.6 & 16.2 \\
\hline \multicolumn{5}{|l|}{ Births } \\
\hline 0 & 15.8 & 17.2 & 10.0 & 12.8 \\
\hline$>4$ & 19.1 & 14.2 & 10.6 & 10.2 \\
\hline \multicolumn{5}{|l|}{ Abortions } \\
\hline 1 & 20.5 & 23.8 & 18.4 & 23.5 \\
\hline 2 & 5.6 & 4.6 & 3.7 & 1.0 \\
\hline$>2$ & 5.6 & 2.5 & 1.1 & 1.0 \\
\hline \multicolumn{5}{|l|}{ Previous Cesarean } \\
\hline birth & 15.8 & 18.0 & 13.1 & 17.3 \\
\hline \multicolumn{5}{|l|}{ History of obstetric } \\
\hline pathology & 26.5 & $17.0^{\star}$ & 15.4 & $27.5^{\star}$ \\
\hline Toxemia & 1.4 & 2.1 & 1.1 & 2.2 \\
\hline Bleeding & 3.2 & 0.0 & 1.1 & 2.6 \\
\hline Premature & 10.2 & 4.2 & 4.4 & 6.1 \\
\hline Low birthweight & 9.7 & 4.7 & 2.9 & 10.8 \\
\hline Congenital anomaly & 1.9 & 0.8 & 0.7 & 0.0 \\
\hline Late fetal death & 3.7 & 3.4 & 1.5 & 0.5 \\
\hline Macrosomia & 5.4 & 4.7 & 4.0 & 9.2 \\
\hline $\begin{array}{l}\text { History of personal } \\
\text { pathology }\end{array}$ & 2.5 & 3.5 & 1.2 & 3.1 \\
\hline Hypertension & 1.5 & 0.2 & 0.7 & 3.0 \\
\hline Diabetes & 0.0 & 2.5 & 0.0 & 0.0 \\
\hline Any risk factor & 39.1 & 38.6 & 27.8 & $35.6^{\star}$ \\
\hline
\end{tabular}

- Difference in distribution between baseline and endline sumeys are statistically significant (p.<01)

Rábago/Mexican Social Security Institute 
Table 7.9 presents maternal mortality rates for Aguascalientes and Queretaro states from 1985 through 1989. The rate has always been higher in Queretaro. Although reporting may have been incomplete in both states during 1986, the information for 1987-1989 is thought to be quite complete. The rate declined in both states, but the decline was proportionally greater in Aguascalientes. It should be noted, however, that these data reflect all births in each state that is, not only births to women who are eligible for care at an IMSS facility.

\section{TABLE 7.9}

Maternal Mortality Per 100,000 Live Births: Experimental and Control States, 1985-1989

\begin{tabular}{ccc}
\hline Year & $\begin{array}{c}\text { Experimental } \\
\text { State }\end{array}$ & $\begin{array}{c}\text { Control } \\
\text { State }\end{array}$ \\
\hline 1985 & 60.3 & 103.2 \\
1986 & 35.4 & 35.8 \\
1987 & 56.2 & 44.0 \\
1988 & 54.0 & 74.4 \\
$1989^{*}$ & 42.9 & 84.8 \\
\hline January-September, 1989 & SOURCE: Confidential Reports of Maternal Mortality, IMSS \\
Rábago/Mexican Social Security Institute
\end{tabular}

Effects on Family Planning in Mexico and Other Latin American Countries By focusing on the health aspects of family planning and its potential for reducing perinatal and maternal morbidity and mortality, the IMSS increased the number of IMSS physicians who are offering family planning services and improved its family planning outreach efforts. The IMSS strategy focused on educating the public as well as promoting family planning. As a result, larger numbers and percentages of both high-risk and normal-risk women are now practicing contraception.

IMSS leaders believe that their utilization of this approach has had a positive effect on family planning throughout Mexico. They believe that the emphasis on risk assessment is attractive to physicians and makes them more willing to become involved in family planning. At the end of the 1970s, only 20 percent of doctors in Mexico were providing family planning 
services; now, 75 percent of the doctors are doing so.

In addition, the risk approach encouraged the IMSS to increase its family planning outreach efforts. Because the risk program promotes family planning as a health intervention, the IMSS now provides family planning services in conjunction with a wide range of health services. This approach makes a big difference, since previously contraception was promoted only through the Family Planning Department. Under this program, when a woman brings her child to an IMSS clinic for any reason, she is exposed to posters, brochures, and audiovisual presentations that explain reproductive risk and promote contraception. If a woman comes to the clinic seeking medical attention for herself, the receptionist reviews her records to see if she has had a reproductive risk assessment. If she does not have a risk assessment form, the physician is notified and an assessment is conducted. Thus, even women who seek care for acute illnesses receive information on family planning. Prior to starting the reproductive risk program, the IMSS family planning program seemed to have reached a plateau - they were serving about one million women a year, and the number was not increasing. However, last year, using this approach, the IMSS provided contraceptive services to 1.3 million women.

The reproductive risk approach is now being implemented at IMSS facilities throughout Mexico. The IMSS has given courses on how to conduct such a program to the Family Planning Division of the Mexican Ministry of Health, the National Association of Schools and Faculties of Medicine (ANFEM), and the union for government employees (ISSSTE). Several state-level ministries of health have received the training manuals and are adapting the educational materials to suit their own circumstances. Many Mexican medical schools are beginning to integrate the risk-based approach to family planning into their curriculae.

The risk strategy is also being used in other parts of Latin America. The Honduran Social Security Institute (IHSS) is starting a similar program in Honduras, a country in which the environment for family planning is relatively hostile. The IHSS is hoping to create greater demand for family planning among its beneficiaries by promoting contraception as a health intervention. Other health institutions have also contacted the IMSS for more information on their reproductive risk assessment program. Studies that could lead to the development of similar programs are being conducted in Peru, El Salvador, Paraguay, and Ecuador. Bolivia, Guatemala, and Costa Rica are planning to conduct training courses as a way to develop risk assessment strategies. 


\section{Conclusions}

The proportion of women who accepted a method of contraception increased during the experiment. However, it increased in both the experimental and the control areas. Although the increase seemed to be greater in the experimental area, no consistent trend was evident. In addition, the underlying differences between the two states were so great that it would not have been possible to draw conclusions from the study even if there had been a consistent advantage in favor of the state in which the risk assessment program was being tried.

Despite the limitations of the study, IMSS officials believe that the risk assessment approach has resulted in a more vigorous and effective family planning program. However, the IMSS risk assessment strategy resulted in many changes in the agency's approach to family planning. In addition to screening all women and classifying them as high- or normal-risk, a major effort was made to reach out to women using a wide range of IMSS health services and to provide them with information about family planning. It is impossible to know to what extent the apparent success of the program results from its use of risk assessment as compared with changes related to outreach and providing all women with family planning information. If the main benefit of the program resulted from the risk assessment and classification, a greater increase in contraceptive acceptance would have been expected among the high-risk women compared with the normal-risk women. This was not the case. However, if the main benefit of the program resulted from outreach and patient education, a greater increase in contraceptive acceptance would be expected in the experimental group as compared with the control state. This outcome is closer to what was found. Thus, it seems likely that the benefits that may have accrued were due primarily to improved outreach and patient education.

\section{PAHO's Perspective on The Latin American Experience}

(based on a paper presented by Joảo Yunes, M.D., M.P.H., Ph.D., Coordinator, Maternal and Child Health Program, Pan American Health Organization)

Reproductive health, as defined by the World Health Organization (WHO), requires that:

- people have the ability to reproduce as well as to regulate their fertility.

- women go through pregnancy and childbirth safely,

- the outcome of pregnancy is successful in terms of maternal and infant survival and well-being, and

- sexual relations are free from fear of unwanted pregnancy and of contracting disease. 
The Pan American Health Organization (PAHO) views the risk approach as one of the most important strategies for improving reproductive health in the Americas; it is consistent with WHOs underlying philosophy of "something for all, but more for those in need - in proportion to that need." The idea of risk assessment in maternal health care and family planning service programs has gained great popularity in the Latin American region. PAHO believes that application of the risk approach has contributed to several improvements in the Latin American region, including declining incidence of maternal mortality and increased usage of family planning, prenatal care, and hospital deliveries.

Nevertheless, the risk approach has not achieved its full potential in several areas in Latin America, due mainly to three major barriers:

- The entire population is not screened for reproductive risk and those identified as high-risk are not always referred appropriately; those referred do not always receive proper treatment.

- The political decisionmakers are not fully aware of the need to reorganize the system and to redirect resources to suit new technologies and demands.

- Shortcomings in the existing referral system hamper the success of the risk approach.

In promoting and implementing the risk approach at the country level, PAHO has adopted seven strategies, with support or by request of the member states:

(1) Dissemination of information and motivation. The purpose of this strategy is to motivate the government groups, teaching institutions, nongovernmental organizations (NGOs), and health care providers to adopt or adapt the risk approach, despite some inherent limitations in the approach itself. WHO materials on the risk approach have been adapted to Latin American conditions and incorporated into an expanded manual, in Spanish, which has additional examples, exercises, and visual aids (slides). Several training workshops have been held, and most countries in the region have decided to implement the risk approach on a district or national level. 
(2) Development of norms and standards. The Latin American Center of Perinatology has developed criteria for organizing prenatal care based on the reproductive risk approach and a computerized information system that starts with standard records for data relevant to the risk approach. The computerized system uses these data to calculate absolute as well as relative and attributable risks in order to prioritize intervention programs. The system is now working in about 100 Latin American maternity centers and hospitals. Some countries (for example, Nicaragua) have considered implementation of the system at the national level. In addition to providing opportunities for improving services to their clientele, these centers have become teaching facilities for other areas and some have taken on an advisory role for national programs.

(3) Development of policies and programs. The concept of the risk approach is becoming institutionalized in Latin America. This trend is reflected in policies, programs, norms, training, and research, and stems from the fact that almost all countries have accepted family planning, integrated with maternal and child health, as a priority. However, because many health systems and bureaucracies are too rigid to accommodate the changes necessary for implementing the risk approach, the results have not always been as desired.

(4) Development of human resources. Considerable training related to the risk approach has been undertaken in many countries in the region, including 11 international workshops, two of which were in English (Mexico and Jamaica) and nine of which were in Spanish (one each in Brazil, Costa Rica, and Cuba; two in Colombia; and four in Washington, D.C.).

As the training needs of health personnel are ongoing, the responsibility has been gradually transferred to schoois of public health in the region. Other health-related teaching institutions have also been provided with technical materials and backup. Information on the risk approach has been incorporated into courses for traditional birth attendants (TBAs), auxiliary nurses, and other health care personnel through projects that are funded by the United Nations Population Fund (UNFPA) and executed by PAHO. One drawback is that the work has continued without scientific monitoring and adequate evaluation.

(5) Support of operations research. Some research on the risk approach has been conducted. The best-quality research has come from Cuba, Chile, Costa Rica, Colombia, 
Mexico, Guatemala, and Nicaragua. The results have led to the transformation of clinical services based on sophisticated methods of risk assessment. In other countries, although the risk approach is gaining in popularity, the ministries of health are still using the traditional risk factors (that is, one or several of the following factors, without weighting: maternal age less than 20 years or greater than 35 years, less than two years since the last pregnancy, nulliparity, maternal height less than $150 \mathrm{cms}$, maternal weight less than $50 \mathrm{kgs}$, history of previous abortions or stillbirths).

(6) Direct technical cooperation. PAHO, together with other national and international organizations, has provided direct technical cooperation in all of the other strategies, especially training and the preparation of manuals and teaching materials.

(7) Mobilization of national and international resources. Although countries are responsible for making their own decisions about the implementation and development of the reproductive risk approach, international collaboration can help to catalyze these efforts.

PAHO is collaborating with local health authorities in executing approximately 45 projects that are related to some aspect of the reproductive risk approach. Funding for those projects, totaling US\$16 million, has come from UNFPA, the W. Kellogg Foundation, the Carnegie Foundation, the Pew Trust, and other sources. Different kinds of projects have been conducted in different countries. Most of them deal with improving outreach in order to provide services - including screening - to a larger proportion of the population; projects have also been undertaken to improve the referral system, and in health education and training.

Despite these and other efforts, data from many Latin American countries show that large percentages of women are not practicing contraception, even though they state that they do not want more children. For example, 68 percent of currently married women of reproductive age (MWRA) in Guatemala as of 1987 (Ministerio de Salud de Guatemala, 1989), and 57 percent of MWRA in Panama in 1984-1985 (Ministerio de Salud Publica, 1986) reported that they wished to terminate childbearing, although they were not practicing contraception.

\section{The Effect of the Risk Approach on Family Planning in Latin America: PAHO's Conclusions}

Based on the experiences described above, PAHO's leaders believe that the concepts that underlie the risk approach are generally valid and have great potential in a region that is 
struggling with economic crises and has little expectation of immediate, sizable investments in health care. However, special efforts should be made to guarantee an increase in coverage of primary health care in rural and marginal urban areas. In addition, there is a great need to improve the capacity of the service points that receive referrals of high-risk pregnant women.

PAHO is concerned about inadequate scientific monitoring and evaluation of health care programs based on reproductive risk assessment. It would be advisable for the international organizations to reach some sort of consensus on the risk approach. As it is, some confusion results because different countries and communities are receiving different messages.

Potential Benefits of Risk Assessment in Family Planning Programs. Advocates of using the risk concept in family planning believe that it has the potential to achieve the following benefits:

1. It will force family planning service providers to reach out to the higher-risk women. All women and couples have the right to regulate their fertility, if they wish; to be properly informed and counseled; and to have access to a variety of contraceptive methods. These rights are independent of their health status or "risk." Even women who are in the best condition and circumstances for healthy childbearing have the right to delay or completely avoid having any or more children. However, in reality, family planning service resources are limited and all women do not have access to accurate family planning information and a variety of effective contraceptive methods. Under these circumstances, the least healthy (most high-risk) women are often least likely to receive correct and adequate information about family planning and to have access to effective contraceptive care. Without some emphasis on risk, family planning service providers may stay busy and be content taking care of the easy-to-serve, lowrisk women. The risk approach will force service providers to reach out to the higher-risk, harder-to-serve women.

\section{Risk assessment will help individual women select a contraceptive method that} has little or no probability of causing harm. Risk assessment has been used for this purpose extensively and for a long time. The Institute of Perinatology, in Mexico, is using a risk assessment scoring system to select contraceptives for individual clients; however, the program has not been evaluated yet. 


\section{Risk assessment can help people consider the risks associated with}

contraception in relation to the risks associated with pregnancy. Risk assessment, with accurate information on absolute (instead of relative) risk, may be especially helpful in hard cases of women who have contraindications to the most effective methods of contraception but are at very high risk for serious or life-threatening pregnancy-related complications.

\section{Women who are known to have permanent or persistent conditions that cause a} high absolute (not relative) risk of maternal mortality will be informed of their risk and will be offered and encouraged to use permanent or at least very highly effective methods of contraception. A woman who has serious complications during one pregnancy may be at high risk during subsequent pregnancies. Those who provide care to women who have experienced serious pregnancy complications should counsel such women and their families about such risks and offer contraceptive services. Health personnel who provide medical, surgical, and obstetric services are in a better position than those who work in family planning services to identify the women who are very high-risk for maternal morbidity and mortality.

\section{Through risk assessment, tamily planning will become more acceptable to} health care providers and politicians by focusing on the health benefits. Many health care providers do not understand the importance of family planning. They may be prejudiced against it or may consider it to be a nonessential, low-priority service. Emphasis on maternal risk assessment has encouraged some physicians who were previousiy disinterested in or even opposed to contraception to begin to think of it as a proper and important medical intervention. The reproductive risk strategy may help create a more receptive professional and political environment.

\section{Family planning can be incorporated into the wider health care system through}

risk assessment. One objective of the Mexican Social Security Institute's use of risk assessment (described earlier in this chapter) was to incorporate family planning into their overall maternal and child health program. To accomplish that goal, the IMSS trained physicians, nurses, and auxiliary nurses working at their hospitals and family medicine clinics to screen women for characteristics associated with reproductive risks, to offer family planning services to as many prenatal patients and other women as possible, and to provide special counseling and treatment, including contraception, for those at greatest risk. In addition, the IMSS developed an educational program to inform their clientele about reproductive risk factors 
and the availability of family planning services. Through these means, the IMSS was successful in expanding family planning education and counseling far beyond the reach of their family planning clinic. Service delivery systems that offer family planning only to women who go to a family planning clinic, or only to women who seek obstetric and gynecologic attention, fail to reach many women who might want to practice contraception.

\section{A risk assessment approach will ensure that higher-risk individuals are given} priority in situations where resources are limited and insufficient to satisty the needs of all women who want to practice contraception. In a situation such as that described by Dr. Sambe, in the Karawa.Health Zone in Zaire (see chapter 5), where very few physicians and facilities are available, very few sterilizations can be performed. Those few should be reserved for women who are in significant danger of dying if they become pregnant.

Problems and Potential Dangers in Risk Assessment. Efforts to focus family planning services on women with demographic risk factors such as high parity and younger or older age are associated with certain problems. These problems should be taken into account when considering the implementation of a risk assessment system.

Inefficient use of limited tamily planning program resources. The risk approach consumes energy, attention, and resources that could otherwise be used to expand services and make them more acceptable to all women. Focusing on maternal risk assessment and high-risk women may distract family planning program planners and staff from developing attractive, accessible family planning services to meet the needs of the many women who want to regulate their fertility but lack access to acceptable services. Large proportions of fertile-age women in most developing countries want either to delay their next pregnancy or to have no more births. World Fertility Surveys, Contraceptive Prevalence Surveys, and Demographic and Health Surveys conducted in 26 developing countries since the early 1980 s found that, in all but four of those countries, the majority of women intended to space or limit their births. The percent of women planning to delay or limit births ranged from 69 to 84 percent in surveys conducted in five Latin American countries, from 66 to 83 percent in surveys conducted in five Asian and North African countries, and from 29 to 78 percent in surveys conducted in sixteen sub-Saharan African countries. Yet, the same surveys found much lower proportions of women who were using a modern contraceptive method (Radloff et al., 1989). 
It is not necessary to use the threat of pregnancy complications or death to convince women to accept family planning. Lack of access to high-quality family planning services is the main constraint to greater use of family planning in many countries. Until we have made attractive, affordable family planning services accessible to all woman who do not want to get pregnant, it does not make sense to emphasize risk assessment as a way to convince women who want more children that they should practice contraception to avoid the risk of pregnancy complications.

It takes time to conduct a formalized reproductive risk assessment, to explain the concept of reproductive risk to women, and to help women who have been classified as highrisk understand what that means or could mean to them and how it relates to their potential use of contraception. The time consumed by these activities might be better used to talk about other health and reproductive issues, including whether and when the woman wants to become pregnant, if she wants to use a method of contraception, and which method or methods she wants to use. PAHO-supported studies from Latin America have documented that clientprovider interaction time in some health care systems averages less than one minute per client (Gay, 1980). Even in systems such as the IMSS, in which care providers may spend as much as ten minutes with each woman, the time that can be devoted to each client is limited and should be used as effectively as possible.

Limited focus. The risk approach causes family planning programs to focus on only a small segment of the persons who need and want their services. Many women want to stop bearing children long before they become "high-risk" based on age and parity. In developing countries, large proportions of all births are to women who do not want more children. It may be more effective and efficient to focus family planning services at meeting the needs of women who do not want to get pregnant.

Young, unmarried, sexually active women are at high risk for unwanted pregnancies but would be overlooked in programs that focus on traditional high-risk indicators. Although these young women may not be at increased risk of obstetric complications and perinatal mortality, they are at high risk of morbidity and mortality associated with illegal induced abortions, especially in countries where having a child without being married is an extremely grave social offense that can ruin a young woman's life. 
Finally, the risk assessment approach to family planning tends to ignore or deemphasize the important role of men.

The wrong emphasis. Warning women that they have an increased risk of pregnancyrelated morbidity and mortality may not be a very effective way to motivate them to practice contraception. People's decisions regarding childbearing and contraception are complex. In most cases, the risk of serious maternal morbidity or mortality is small and remote relative to the much more certain impacts of pregnancy and a new baby on the mother and the family. Family planning counseling that helps a woman to consider a broad range of factors may be much more effective than counseling that focuses primarily on the risk of infant or maternal injury and death. (See, also, chapter 9.)

Too much power to the health care provider and less autonomy for the woman. The risk assessment approach may increase the social and authority barriers between family planning providers and clients. The risk approach tends to medicalize a decision that would otherwise be simply a matter of choice for the woman. That tends to take authority away from women and give it to doctors and nurses. In situations where there are important social-level differences between the provider and the client, the risk approach may create another barrier.

In addition, the risk assessment approach endangers access to family planning by giving physicians a larger "gatekeeping" role. The risk approach defines family planning as a medical intervention - something to be prescribed by a physician or other authorized health professional. Instead, it should be seen as a means by which all people can be assisted to make and implement their own decisions regarding whether and when to have children. Family planning should be made more accessible, not less so.

Risk associated with unwanted pregnancies. As currently conceptualized, risk assessment does not attempt to measure a woman's risk of having an unwanted pregnancy. The desire to avoid having a baby is the single most important indicator of need for family planning and is a very important indicator of maternal mortality risk. In many countries, 20-25 percent of maternal mortality is due to illegal abortion. Any woman who has an unwanted pregnancy and does not have access to a safe, legal abortion may be at increased risk. Women who have already had one or more illegal induced abortions are at high risk of additional unwanted pregnancies and of the morbidity and mortality associated with illegal abortions. Not 
wanting to be pregnant is probably much more powerful than any combination of age and parity at predicting maternal risk. Family planning information, advice, and services should be offered to all women who obtain health care as a consequence of abortions, including "spontaneous abortions," many of which are actually misclassified induced procedures.

\section{Confounding tactors in the association between risk and parity or age. The} statistical associations between reproductive risk and parity and between reproductive risk and age are strongly confounded by other factors and thus do not apply to all high-parity and/or older and younger pregnant women. Consider the data regarding the association between various types of reproductive risk and maternal age:

- During the early 1970 s, Dorothy Nortman of the Population Council, conducted an extensive review and analysis of published studies and some unpublished data regarding the effects of maternal age on maternal morbidity and mortality, fetal loss, stillbirths, perinatal mortality, infant mortality, congenital malformations, and the development and performance of children (Nortman, 1974). She described the literature on this subject as "rich almost to the point of being inexhaustible," but limited her analysis to well-designed and well-executed studies with samples that were large enough to yield meaningful results. Most of the studies were based on national or regional vital statistics records or were well-designed medical investigations with control groups.

Nortman documented a maternal age of minimum reproductive risḱ and a rising incidence of poor outcomes as the mother's age departs, in either direction, from the optimal age. Poor outcome rates are high during the earliest fertile years, drop to a minimum during the twenties, and then rise continuously to the end of the childbearing age range. This pattern outlines a "J"- or " $U$ "-shaped curve, which describes the relative risk associated with maternal age for women within a particular population; whether the curve is $\mathrm{J}$ - or $\mathrm{U}$-shaped depends on which outcome is being observed and on the mother's parity.

However, Nortman also concluded that "social, cultural and economic factors largely determine the degree of absolute risk [emphasis added] regardless of the mother's age," and that the impact of age on risk is least in countries that have the highest rates of maternal mortality and other poor pregnancy outcomes (1974: 5). 
The age associated with the lowest incidence of undesirable outcomes varied by parity and depended on which reproductive outcome was being examined. For instance, among women having their first pregnancies, 18-year-old mothers experienced the lowest incidence of fetal mortality but 26-year-old women were least likely to have their live-born babies die before reaching one year of age. Nortman hypothesized that this difference was due to the socioeconomic advantages of having one's first live-born child at a later age. Women aged 22 23 were at the lowest risk of maternal mortality.

- A later review classified 104 studies conducted in the United States and published between 1917 and January 1983 by their trustworthiness based on four criteria: (1) inclusion of a comparison group of younger women in the research design if comparative statements were to be made about the pregnancy outcomes of older and younger women, (2) control of parity level between older and younger groups, either by matching or by examining only first births, (3) adequate sample size, and (4) use of statistical tests to determine differences in pregnancy performance between older and younger maternal groups (Mansfield, 1986). Most of the studies (61 percent) had serious methodological flaws, often due to confounding age with other factors. Only 10 percent of them ( 11 studies), most published after 1970, met all four criteria.

Mansfield concluded that "Many of these researchers demonstrate an awareness not apparent in earlier work that pregnancy outcomes are determined by a variety of obstetrical, maternal and social-psychological factors; thus, they recognized the importance of controlling for a wide variety of factors which might be confounded with maternal age, many employing multivariate statistics to this end" (1986: 46) Because of their better research designs, conclusions based on these 11 studies can be viewed with more confidence than those of the other 50 studies.

In the 11 best studies, cesarean section was the only undesirable outcome found to increase in association with age. Advanced maternal age was not found to be relevant "when other factors, themselves bearing an association with mother's age, were separated statistically from the age variable" (Mansfield, 1986). For example, one study found that slow deliveries among women older than 35 were due to excessive amounts of sedation (Friedman and Sachtleben, 1965). The higher incidence of fetal mortality associated with higher maternal age in another study disappeared when patients with hypertension were removed from the sample (Grimes and Gross, 1981). A study published in 1980 found that three factors previously thought to be associated with low birthweight (maternal age, parity, and height) "bore this relationship 
only because they in turn were related to maternal weight gain and pre-pregnancy weight, the two attributes actually predicting low birthweight incidence" (Rush et al., 1980). In another study, an apparent association between infant mortality and maternal age disappeared when other maternal, social, and economic factors were controlled for simultaneously; the authors concluded that age has no independent effect on neonatal mortality (Shah and Abbey, 1971).

The findings from these studies, in which the association between advanced maternal age and poor pregnancy outcomes virtually disappeared when the effects of important confounding variables were controlled for, suggests that factors that are more frequent in older women, rather than age itself, also account for associations between maternal age and poor pregnancy outcomes found in less well-designed studies. Older women have more chronic illnesses. In Western countries, pregnant women over the age of 35 are more likely to receive medical interventions, including cesarean sections, which may result in iatrogenic complications. Births to older women may also include a disproportionate number of unplanned births to poor women with large families, a situation that is associated with pregnancy complications (Mansfield, 1986).

- The consistent finding of higher cesarean section rates for older mothers deserves special attention because cesareans are presumably performed in response to complications that might otherwise result in maternal and/or perinatal mortality or serious morbidity. Thus, a maternal characteristic associated with a high incidence of cesarean deliveries in the United States might be thought of as a risk factor for maternal mortality in less developed countries. This conclusion is probably unwarranted in the case of higher maternal age. First, the extraordinarily high incidence of cesarean births in the United States must be considered; approximately one of every four babies born in the United States is delivered by cesarean section (Taffel et al., 1990). This incidence is widely acknowledged to be excessive - a recognition that many cesareans are done unnecessarily (Gleicher, 1984). In addition, the increased incidence of cesarean deliveries among older mothers is probably due in part to the fears and pessimistic expectations of American physicians responsible for the care of older pregnant women, especially women who are having their first babies (Antonovsky and Bernstein, 1977; Mansfield, 1986). "Old primiparity" was given as a reason for cesarean delivery in a classic obstetrics textbook published in 1929 (DeLee, 1929). A study of the pregnancy and labor experiences of "elderly primigravidas" published in 1950 concluded that physicians apparently performed cesareans in order to safeguard the highly valued, late-timed first-born child (Waters and Wager, 1950). This is certainly also true today, when obstetricians practice 
under the fear of malpractice suits (Pearse, 1983; Quilligan, 1983). Paradoxically, physicians' fear of bad outcomes with older mothers may contribute to the bad outcomes, which, in turn, reinforce the fear: The maternal mortality rate associated with cesarean sections is higher than the rate with vaginal births, even when the data are adjusted for the increased risk associated with conditions that are considered to be indications for cesarean section. The maternal death rate associated with cesarean sections in the state of California (U.S.A.) was more than twice as high as the rate for vaginal deliveries (data from 1960-1975) (Petitti et al., 1979). In the state of Georgia (U.S.A.), it was ten times higher when all of the women were included in the calculations and six times higher when women whose underlying illnesses may have contributed to their deaths were eliminated from calculation of the rates (Rubin et al., 1981).

Finally, the data that demonstrate an association between poor reproductive outcomes and high parity are also confounded by associations between parity and other factors associated with risk, especially poverty and pregnancies that were not planned.

Absolute versus relative risk. Although, as a group, older and/or higher parity women are at higher risk relative to younger and/or lower parity women, unless they are obese (Spellacy et al., 1986) or have chronic medical conditions or a history of serious obstetric complications, their absolute risk of having a poor outcome is still quite low, and their chance of producing a healthy baby is high. A "high-risk" 'woman may be unlikely to have problems, even though her risk may be several times higher than that of a "low-risk" woman. (See chapter 3 for a discussion of absolute as compared with relative risk.)

Maternal risk assessment programs that are based on estimates of relative rather than absolute risk overstate the likelihood that women who are "high-risk" on the basis of age or parity will experience serious problems. It is difficult to communicate risk information in a way that is both accurate and meaningful to women. Recall the example presented in chapter 3 that demonstrated the difference between absolute and relative risk: A study conducted in Bangladesh found approximately a 17-fold difference in maternal mortality between the highestand lowest-risk groups of women. That information can be communicated to women in various 
ways - as relative risk (Figure 7.1), as depictions of the absolute risk of dying as a result of pregnancy or childbirth (Figure 7.2), or as depictions of the chance of surviving pregnancy (Figure 7.3). In Figure 7.3, for example, the "high-risk" women have 983 chances out of 1,000 of surviving a pregnancy, and the low-risk women have 999 chances out of 1,000 of surviving. That is not the message transmitted in Figure 7.1. Which figure tells the "truth"? When care providers tell women about risk, they tell the truth as they understand it, but what message does the woman receive?

\section{FIGURE 7.1}

Relative Risk of Death Per 1,000 Live Births

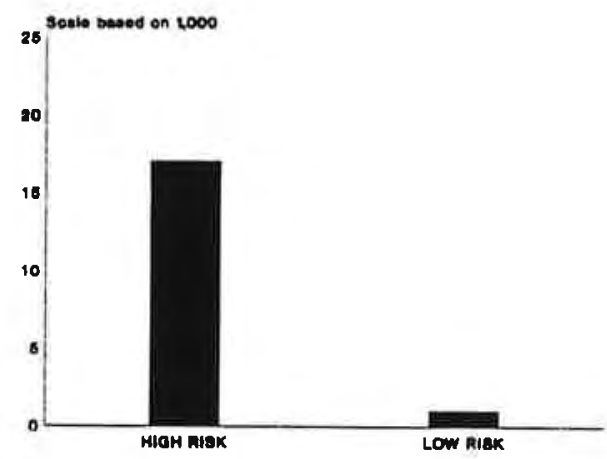

Note: When the high-risk womans risk of dying is $17 / 1,000$ pregnancies, the low-risk womans risk of dying is $1 / 1,000$ pregnancies, and the relative risk associated with high-risk status is 17. 


\section{FIGURE 7.2}

\section{Absolute Risk of Death Per 1000 Live Births}

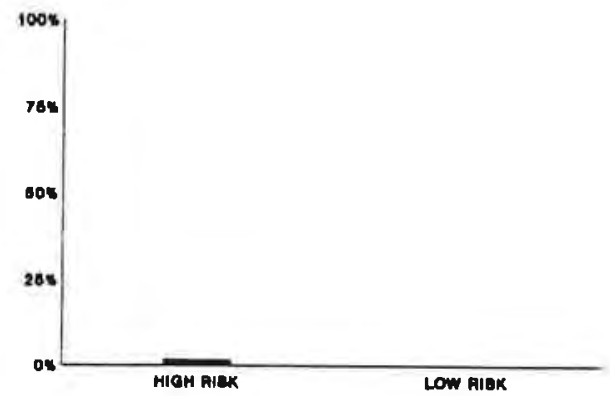

Note: When the high-risk womans risk of dying is $17 / 1,000$ pregnancies, the low-risk womans risk of dying is $1 / 1,000$ pregnancies, and the relative risk associated with high-risk status is 17 .

\section{FIGURE 7.3}

\section{Probability of Surviving Pregnancy}

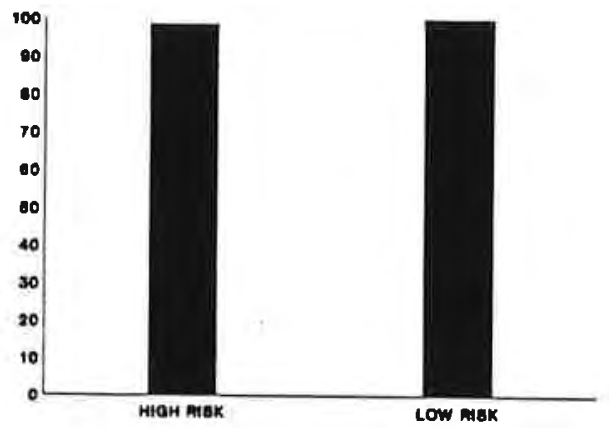

Note: When the high-risk womans risk of dying is $17 / 1,000$ pregnancies, the low-risk womans risk of dying is $1 / 1,000$ pregnancies, and the relative risk associated with high-risk status is 17. 
Ethical concerns. The difficulty of conveying risk information accurately in the context of a family planning program raises ethical concerns.

First, it is inaccurate and unethical for family planning personnel to tell women who want to become pregnant and probably would not experience serious pregnancy complications that they should practice contraception because they are high-risk. All populations include some women who want many children and some older women who want to become pregnant. Very young women who are told that they are high-risk because of age can delay childbearing until they are older. However, that is not an alternative for older or higher-parity women who want to have a(nother) child.

Second, the risk assessment approach creates the opportunity to coerce women who want more children to practice contraception because of undue concern about risk. Such use of risk information would be unethical, would diminish the rights of women and their families, and would work against the long-term goal of making family planning acceptable and available to all people.

Finally, conveying risk information can result in sexism because the concepts are unequally applied to men and women. To understand this statement, imagine a man who comes to a health care facility and is told that he is high-risk for being unable to father healthy children. Imagine further that as many as half to three-quarters of the men who use that health care facility are given this same message. (In fact, in some applications of the risk approach, half to three-quarters of the women have been told that they are high-risk for childbearing. See the data from the IMSS in Mexico.) The credibility of the family planning program may be damaged if large proportions of the women are told they are high-risk.

The goal of tamily planning. The following observations are based in part on remarks made by Judith Bruce, Senior Associate, Programs Division, the Population Council.

The real mission or goal of family planning may become twisted if risk assessment and health benefits are overemphasized. Improved maternal and infant health is but one of many benefits that flow from family planning. The health benefits are important but are not the primary purpose of family planning and are not more important than the other values. Using health as the primary rationale for family planning may make it harder for caregivers to see and respond 
to each woman as an individual. If family planning programs narrow their vision and focus in onder to concentrate on maximizing the health benefits, there is a danger that the other, primary benefits of family planning will suffer.

Whereas it is valuable for all health and family planning workers to understand that a woman's decision regarding contraception can have health consequences, the primary role of family planning service providers is to provide family planning on a voluntary basis. That is the job they should know how to do well. Using improved health as the rationale for family planning could lead to a eugenic approach to the provision of services, such as encouraging (or forcing) "mentally retarded" people to be sterilized. Such an approach is inherently dangerous to the long-term success of family planning, as well as to society itself.

Using health as the primary rationale for family planning may reinforce the idea that the health risks associated with contraception are relatively unimportant because, for most women, the risk of dying from the practice of contraception is lower than the risk of death associated with pregnancy and childbirth. That comparison is not an appropriate response to concerns about risks associated with contraception, especially since many of those risks can be reduced through improvements in family planning service delivery.

Any organization that attempts to organize family planning service delivery around the assessment of reproductive risk must be able to either provide or refer women for the permanent and/or highly effective and long-acting methods of contraception needed by women who have a high absolute risk of dying or of serious morbidity related to pregnancy.

\section{Summary}

Because the Mexican Social Security Institute is the major provider of family planning services in a very important Latin American country, their experiment with the use of reproductive risk assessment as a way to increase the practice of contraception attracted much attention, especially after it was reported that the percentage of women accepting a method of contraception increased during the experiment. However, a closer look at the study and its findings indicates that they are inconsistent and not adequate to support the conclusion that risk assessment leads to greater practice of contraception.

In the first place, the experimental state (in which the risk assessment program was 
implemented) and the control state (with no risk assessment program) were not comparable at the beginning of the study: A much higher percentage of women in the experimental state used family planning even before the experimental intervention (the risk assessment program) was started. Lacking a comparable control group, we cannot conclude that any difference in contraceptive prevalence after the risk assessment program had been in operation for 17 months was due to the experimental programs. Whatever differences occurred might have resulted from other factors - for example, those that caused the experimental state to have a higher contraceptive prevalence level initially.

Second, the findings were inconsistent. The evaluation tried to determine the effect of reproductive risk assessment by comparing the level of contraceptive prevalence before and after the risk assessment program was implemented in the experimental state among four different groups of women in each state - high- and normal-risk women who received care in IMSS clinics and high- and normal-risk women who received care in IMSS hospitals - eight groups of women altogether. The "before" and "after" differences in those eight groups of women can be viewed in two ways: (1) by comparing the absolute contraceptive prevalence rates before the intervention with those after the intervention, and (2) by measuring the change in the contraceptive prevalence rate after the intervention as a percent of increase or decrease relative to the pre-intervention rate. Among women who received care in IMSS clinics, contraceptive prevalence did not increase more in the experimental state than in the control state. Among women who received care in IMSS hospitals, use of postpartum contraception increased much more in the experimental state than in the control states.

Although there was a significantly greater increase in postpartum contraceptive use in the experimental state as compared with the control state, that difference was not due to greater acceptance of contraception by women who had been told that they were "high risk." "Highrisk" and "normal-risk" women in the experimental state increased their acceptance of postpartum contraception by about the same percentage. "High-risk" women were somewhat less likely than "normal-risk" women to accept postpartum contraception before the program started, and 17 months of risk assessment had no effect on that difference.

The IMSS evaluation produced several other interesting results:

- Fifty to 75 percent of the women were identified as being high risk. 
- Even though the IMSS physicians and nurses were given five days of special training in risk assessment, over the course of the study only 70 percent of the risk assessment forms were completed correctly.

- In both states, high-risk women were more likely than normal-risk women to have tubal ligations. The risk assessment program did not appear to have any effect on that. These findings suggest that high-risk women are more likely to seek permanent contraception for their own reasons, irrespective of whether they have been told that pregnancy may be particularly hazardous for them.

- The risk assessment program seemed to have a significant effect on the willingness of physicians to participate in family planning and resulted in important programmatic changes. Before the risk assessment program started, family planning was discussed only with patients who presented themselves at the family planning clinic. As a result of the patient education aspect of the program, women who go to IMSS facilities for any reason now are likely to be exposed to multimedia presentation of information on reproductive risk and the availability of family planning services at IMSS.

Despite the inconclusiveness of the IMSS findings, the IMSS program has been perceived as very successful and has attracted great attention throughout Latin America and within the Pan American Health Organization (PAHO). World Health Organization (WHO) materials on the risk approach have been adapted for use in Latin America, workshops to teach people how to organize and run risk assessment programs have been conducted, computer programs that use local data to identify risk factors have been developed and are being used, and research projects have been started. As of February 1990. PAHO was collaborating in the implementation of approximately 45 projects related to some of the aspect of the reproductive risk approach. Dr. Yunes, the PAHO official who participated in the seminar, expressed concern about the inadequate evaluation of these projects.

Risk assessment offers potential benefits to family planning programs, but may also bring some dangers. Risk assessment programs could push family planning service providers to reach out to the higher-risk women and, by focusing on its health benefits, may make family planning more acceptable to health care providers and politicians. On the other hand, the risk approach could impair the effectiveness of family planning programs by drawing attention and resources away from the need to expand and improve services for all women and by causing 
programs to overlook the needs of young, unmarried, sexually active women, who have a different set of special needs.

Risk assessment programs that focus on common demographic factors such as age and parity may identify the majority of women as "high risk." Over time, that could lead to disrespect or distrust of the program, especially since the actual degree of increased risk associated with those designations is extremely small. In contrast, the desire to avoid pregnancy among women who are not pregnant, and the desire to have a baby among women who have become pregnant unintentionally, pose a significant risk to the health of women in societies in which effective contraception and safe abortions are not widely available. There is a great unmet demand for family planning services among women in most countries of the developing world; these women do not need motivating, they just need services.

\section{$\underline{\text { References }}$}

AMIDEM. Riesgo Reproductivo II. IMSS Training Manuals for Reproductive Risk Strategy. Mexico City: IMSS, 1987.

Antonovsky, A. and J. Bernstein. "Social class and infant mortality." Social Science and Medicine 11 (1977): 453-70.

Aparicio, R. and A. Rábago. "Capacidad predictiva de los Factores de Riesgo reproductivo de la forma MF-7, 1987." Unpublished document. [Available from IMSS; write to Dr. Aurora Rábago, Sub-Jefe de Servicios de Salud, Reproductiva, Jefatura de Servicios de Planificación, Familiar y Salud Reproductiva, Instituto Mexicano del Seguro Social, Mier y Pesado 120, Col. de Valle, 03100 México D.F. México.]

DeLee, J.B. Principles and Practice of Obstetrics. 5th ed. Philadelphia: W.B. Saunders Co., 1929.

Friedman, E.A. and M.F. Sachtleben. "Relation of maternal age to the course of labor." American Journal of Obstetrics and Gynecology 91 (1965): 915-24.

Gay, Jill. "A Literature Review of the Client/Provider Interface in Maternal and Child Health and Family Planning Clinics in Latin America." Report for the Pan American Health Organization. Washington, D.C.:PAHO, 1980.

Gleicher, N. "Cesarean section rates in the United States: The short-term failure of the National Consensus Development conference in 1980." Journal of the American Medical Association 252 (1984): 3273-276.

Gribble, J.N. and A. Rábago. "Family planning services based on reproductive risk: A new strategy of the Mexican Social Security Institute." Background paper prepared for the NAS Working Group on the Health Consequences of Contraceptive Use and Controlled 
Fertility. Mexico City: IMSS, 1989.

Grimes, D.A. and G.K. Gross. "Pregnancy outcomes in black women aged 35 and older." Obstetrics 58 (1981): 614-19.

Mansfield, P.K. "Re-evaluating the medical risks of late childbearing." Women \& Health 11, no. 2 (1986): $37-60$.

Ministerio de Salud de Guatemala and Instituto de Nutrición de Centro América (INCAP). "Encuesta Nacional de Salud Materno Infantil 1987." 1989.

Ministerio de Salud Publica, Departamento Materno Infantil y Estadisticas. "Encuesta de Salud Materno Infantil y Planificacion Familiar, 1984-1985." Mimeograph, 1986.

Nortman, D. "Parental age as a factor in pregnancy outcome and child development." Reports on Population/Family Planning, Number 16 (August 1974).

Pearse, W.H. "To section or not to section." American Journal of Public Health 73 (1983): 843 44.

Petitti, D., R.O. Olson, and R.L. Williams. "Cesarean section in California, 1960 through 1975." American Journal of Obstetrics and Gynecology 133 (1979): 391.

Quilligan, E.J. "Making inroads against the C-section rate." Contemporary OB/GYN (January 1983): 221-25.

Radloff, S.R., B.H. Seligman, J.F. Seltzer, and R.M. Cornelius. "Reproductive risks and intentions in six countries in sub-Saharan Africa." International Family Planning Perspectives 15 (1989): 136-43.

Rubin, G.L., A.B. Peterson, R.W. Rochat, et al. "Maternal death after cesarean section in Georgia." American Journal of Obstetrics and Gynecology 139 (1981): 681.

Rush, D., A. Stein, and M. Susser. "Diet in pregnancy: A randomized controlled trial of nutritional supplements." Birth Defects 16, no. 3 (1980).

Shah, F.K. and H. Abbey. "Effects of some factors on neonatal and postneonatal mortality." The Millbank Memorial Fund Quarterly 49 (1971): 33-57.

Spellacy, W., S.J. Millar, and A. Winegar. "Pregnancy after 40 years of age." Obstetrics and Gynecology 68 (1986): 452.

Taffel, S.M., P.H. Placek, and M. Moien. "1988 U.S. cesarean section rate at 24.7 per 100 births -- a plateau?" New England Journal of Medicine 323 (1990): 199-200.

Velasco, M.V. "Valorización del riesgo reproductivo en mujeres no embarazadas en edad fértil." In Planificación Familiar y Demografía Médica: Un Enfoque Multidisciplinario. Mexico City: IMSS, 1985.

—_. "Embarazo de alto riesgo." In Planificación Familiar y Demografía Médica: Un Enfoque 
Multidisciplinario. Mexico City: IMSS, 1985.

Waters, E. and H. Wager. "Pregnancy and labor experiences of eiderly primigravidas." American Journal of Obstetrics and Gynecology 59 (1950): 296-304. 


\section{Chapter 8:}

\section{costs}

(This section incorporates information presented by Anne Tinker, M.P.H., Health Advisor, Population, Health and Nutrition Division, The World Bank, as well as discussion during the seminar.)

It is necessary to compare the probable costs and effects of a formalized risk assessment/referral system with the probable costs and effects of investing similar amounts of resources in other efforts to improve maternal health. The choice of cost-effective program strategies is especially critical in developing countries. Even in the wealthiest societies, however, health care planners need to recognize the costs of implementing a risk assessment system, which should be conceptualized as including the use of scarce resources, as well as the "lost opportunity" to invest the same time and resources in other, possibly more effective approaches to improving reproductive health. The more a strategy's cost-effectiveness and impact can be demonstrated, the more likely it is that new resources can be mobilized.

Virtually no data are available on the costs of implementing risk strategies or cost comparisons of various approaches. To date, most studies of risk assessment-based programs have focused primarily on the sensitivity and specificity of the risk assessment method. They have failed to measure the costs of starting and maintaining such programs and have not measured the effectiveness and impact of the programs as compared with the cost-effectiveness of alternative strategies. While both of the following examples provide some important insight into certain process indicators, they also demonstrate the inadequacy of data on program impact and cost-effectiveness.

\section{The reproductive risk program implemented by the IMSS in Mexico: Chapter 5} provides a full description of this project, which was intended to promote the use of effective family planning methods, especially by women with risk factors, and thus to reduce the number of pregnancies that result in poor health outcomes. IMSS personnel were trained in risk assessment and management; an educational program to make women more aware of risk factors was conducted in the community as well as within the IMSS health care facilities; and efforts were made to screen as many women as possible, to offer family planning services to all of the women who were screened, and to provide special counseling and treatment, including contraception, to those at greatest risk. The program was evaluated and is considered successful because contraceptive prevalence increased among both the high-and the low-risk 
women. This outcome was significantly affected by changes in the attitudes and behavior of the health care providers. During the first 17 months of the program, the percentage of physicians promoting family planning increased from 20 to 75 percent.

Since cost information was not provided in the report of this study, it is not possible to evaluate the cost-effectiveness of this approach. However, the program has been influential within many other Latin American countries. Particularly for that reason, it would be important to compare the costs and effects of alternative approaches, such as providing community and patient education focused on identifying women who do not want more children, and increasing the institution's currently limited capacity to provide tubal ligations. Improvement in the attitudes of health care providers was cited as an important accomplishment of the program. It would also be useful to assess alternative approaches to achieving that improvement.

\section{A risk-screening program intended to direct a more select group of higher-risk} women for hospital deliveries in Sierra Leone (Aitkin and Wallf, 1986): An important purpose of this program was to reduce the utilization of high-cost hospital obstetric services by low-risk women. Cephalopelvic disproportion (CPD) leading to obstructed labor is a major cause of maternal and perinatal morbidity and mortality in Sierra Leone. Since women who are pregnant for the first time (primigravidas) are at greatest risk of CPD, all of them were being referred for hospital deliveries, of which they accounted for about one-fourth.

A study that measured the incidence of CPD among primigravidas of different heights led to a recommendation that only those primigravidas who are 5 feet tall or less (approximately half of the total number) should be routinely referred to hospitals. Unfortunately, the study did not include any analysis of the potential impact of this change on costs, and the actual impact of this change on maternal mortality has not been assessed. In addition, analysis of the cost and effectiveness consequences of alternative cut-off thresholds for height and/or of alternative approaches would have provided a fuller informational base for this important programmatic decision.

\section{Evaluating the Cost-Effectiveness of Risk Assessment}

Efforts to evaluate the cost-effectiveness of risk assessment-based approaches to reproductive health care should include consideration of several factors. 
1. Cost-effectiveness assessments should take into account the multiple health care systems that operate almost independently of one another in many countries. Often, no unified system exists to cover all people in a defined geographic area.

2. Risk assessment cannot be cost-effective without appropriate follow-through. Risk assessment is a tool for risk management - that is, actionable interventions to reduce the likelihood of an untoward result. Appropriate follow-through requires an adequate budget, staff, transport, equipment and facilities, and patient compliance. The costs of implementing a risk assessment-based program include start-up and recurrent costs.

Start-up costs will vary greatly from country to country, depending on the infrastructure and the amount of staff time and energy already being devoted to maternal health and family planning. Planners need to budget for the collection and analysis of the local data required to design the strategy, training of staff at all levels of the health care system (including the value of the time expended by both the trainers and the trainees), and capital costs for facilities (for example, maternity waiting homes), equipment, and vehicles at both the primary and the referral levels.

Recurrent costs include ongoing training; forms; personnel time spent making the assessments; supervision costs, including the time and financial cost of the transportation necessary for effective supervision in an extended health care system; ongoing collection of data in order to monitor and manage the system; program evaluation; routine and emergency transportation of patients; maintenance and replacement of facilities and equipment; staff time used to conduct screening and provide treatments; inputs required to provide information and education to the community as well as to patients; costs of food and housing for women who have moved into or near the hospital in anticipation of parturition; and the capacity to deal with the needs of low-risk women, including their obstetric emergencies. In addition, any effective risk assessment system must include outreach efforts, which can be quite expensive.

\section{It may also be appropriate to consider the feasibility and costs of providing non-} emergency transportation for many women prior to labor (for example, with the use of maternity waiting homes) as compared with providing emergency transport for a much smaller number of women who develop complications during labor. Prenatal referrals will reduce but not eliminate the need for emergency transfers during labor. 
4. Costs and effectiveness vary depending on the sensitivity and specificity of the riskscreening process. Risk assessment programs that utilize more sensitive risk assessments increase the demands placed on the referral hospitals and the use of expensive technology. Hospital care has the highest cost, and most hospitals in developing countries are already overburdened, understaffed, and undersupplied. Without substantial increases in resources, most less developed country (LDC) hospitals could not handle the increased patient load that would result if all "high-risk" women went to them for care during childbirth. Risk assessmentbased programs should be prepared to provide, on an ongoing basis, the additional resources needed for health centers and hospitals to serve the women who will be referred to them, many or most of whom will have normal births, without compromising the ability to provide effective care to women with serious unanticipated complications. Facilities to which high-risk women are referred should be able to conduct cesarean sections and other operative deliveries and provide intravenous fluids, antibiotic therapy, and blood transfusions.

Risk assessment programs that utilize less sensitive but more specific risk assessments may optimize the cost-effectiveness of scarce hospital services by screening out women who can be handled at lower levels of the health care system.

5. Depending on local circumstances, varying proportions of women will have access to (and will choose to utilize) routine care and screening. These proportions affect the program's ability to reach the highest-risk women and determine the need for resources to be applied to outreach and "demand creation."

6. The relationship between unit costs and the number of persons screened and treated is not linear, as is often assumed. That must be taken into account in budget estimates. For example, economies of scale can be achieved by standardizing procedures. Nevertheless, it may cost twice as much to reach the last 20 percent of an eligible population as it did to reach the first 80 percent.

7. Risk assessment does not obviate the need to provide basic services to all women and to develop and maintain the capability to deal with obstetric emergencies at the local level. No screening program can identify all of the women who will need emergency treatment during or immediately following labor and delivery. Persons providing care to "low-risk" women, therefore, need to be trained and equipped to handle common obstetric emergencies, and there must be provision for emergency intrapartum transfers. Screening programs may consume 
resources (energy and interest, as well as money) needed to develop and maintain the ability of persons who manage low-risk deliveries and emergencies at the local level.

8. Costs accrue to all participants in the system, including the pregnant women, their families, and unpaid workers such as traditional birth attendants (TBAs). Expenditures of time, energy, and attention should be considered as costs, as well as monetary expenditures, such as those required for transportation. Although the health care delivery system does not have to pay these costs, people make their own, often unconscious cost-benefit assessments when they decide whether to use a preventive health service or to follow advice they have been given about health care. The psychological and social costs to women and their families must also be considered. However, it is necessary to distinguish between costs to a program, costs to individual patients, and costs to the community.

9. Any cost-effective reproductive risk strategy must include the safe management of abortions and family planning to prevent unwanted pregnancies. Unsafe abortion is a major cause of maternal mortality, responsible for up to one-half of the maternal deaths in some communities.

10. Some amount of iatrogenic disease may be among the costs if risky medical interventions are applied to women who do not really need them. Complications of cesarean sections, for example, have become a major cause of maternal mortality in the United States, where the cesarean section rate is very high and many of the cesareans are not warranted. They are a health issue in Brazil, as well. Even in developing countries, cesareans can be a problem; complications following cesarean sections have also become a major cause of maternal mortality in Swaziland. Moreover, women who have one cesarean section are at increased risk of either another cesarean or other complications during subsequent deliveries. Unnecessary cesarean sections have become an important cost to health care programs.

11. Opportunity costs must also be considered - that is, costs that will be associated with missed opportunities if implementing a risk assessment program takes the place of, delays, or dilutes other, more effective maternal/child health and family planning program efforts.

12. The value of screening is a function of the prevalence, importance, and preventability (or manageability) of the problems for which screening is conducted. Screening for rare, unpreventable/untreatable and/or unimportant problems wastes resources. 
Papers prepared in 1987 compared the costs and effectiveness of several alternative approaches to reducing maternal mortality (Herz and Measham, 1987). It was estimated that the most cost-effective ways to prevent maternal deaths are averting pregnancies through family planning programs and providing obstetric first aid at peripheral health centers. Such programs are estimated to cost less than $\$ 3,000$ for each death that is averted. The World Bank has estimated that maternal mortality rates can be halved by additional expenditures of $\$ 2$ per capita per year in countries that currently spend less than $\$ 10$ per capita on health care. More field research is needed to determine the costs, effects, and impacts of interventions and combinations of interventions in various settings.

\section{References}

Aitkin, I. W. and B. Wallf. "Maternal height and cephalopelvic disproportion in Sierra Leone." Tropical Doctor 16 (1986): 132-43.

Herz, B. and A. Measham. The Safe Motherhood Initiative. World Bank Discussion Paper for the International Safe Motherhood Conference, Nairobi, Kenya, February 1987. [Available through the World Bank.] 


\section{Chapter 9:}

\section{WOMEN'S PERSONAL RISK-BENEFIT CALCULATIONS}

(based primarily on presentations and papers by Judith Bruce, Senior Associate, the Population Council; Adrienne Germain, Vice President and Program Director, International Women's Health Coalition; and Carmen Barroso, Director, the John D. and Catherine T. MacArthur Foundation, Population Program)

The effectiveness of reproductive risk assessment, whether applied to maternity care or to family planning, depends in large part on the ability to use information about health risks to influence the behavior of women. The whole enterprise is predicated on the assumption that, given adequate information, women will usually act in ways that minimize their risk of serious health problems or death. However, health problems are not women's only or necessarily their main concern. The social, psychological, and economic risks and costs of childbearing and contraception sometimes outweigh concerns based on health. This section of the monograph synthesizes several papers that were presented during the seminar, as well as discussions throughout the seminar regarding this assumption.

Few women can completely avoid exposure to health risks resulting from their potential ability to reproduce. Childbearing, abortion, and many forms of contraception are all associated with some degree of morbidity and mortality risk. The risk of maternal mortality is highest during first pregnancies. The only way women can avoid this "riskier" birth is to have no children at all. Even that circumstance - having no children - predisposes women to a higher incidence of some diseases (breast cancer, for one).

Health risks are only one of many considerations that women factor into their decisions regarding family planning, pregnancy and childbirth. Risk avoidance is one of many objectives that motivate human behavior. Women, like men, are complex, multidimensional beings. Although most people fear and try to avoid death, serious injuries, and disease, all people take risks and many take some unnecessary risks. People who smoke, drive fast, or participate in certain dangerous sports accept known and often serious health risks in order to experience excitement or pleasure, or simply out of habit. Others accept the health risks inherent in certain occupations. Obtaining social acceptance and economic security are of preeminent importance for both men and women. These concerns also exert strong influence on the reproductive and sexual choices that women make. The frequency of dangerous illegal abortions makes it clear that women will accept substantial health risks in order to avoid an unwanted birth. They will also accept considerable risks to bear a wanted child. 
Women in most societies have relatively little freedom to determine the degree of reproductive risk to which they are exposed. The timing and circumstances of childbearing are heavily culturally determined and are directed toward social rather than health outcomes. Women in developing countries have to be sexually active and bear several children in order to have a place in society. Most of them initiate or are initiated into sexual activity before the age of 20. A measure of how little choice women have is the severe social and economic consequences that befall women who fail to bear children at the right time and in the right number and gender. In many parts of the world, women who are infertile are abandoned in marriage and socially rejected. Because of this, the risk of infertility is often more threatening than the risk of injury or death in childbirth.

Adolescent fertility should be viewed within the context of this lack of choice. It is generally not until a society passes through the demographic transition and achieves a high level of socioeconomic development that some women have, as a reasonable choice, the possibility of a viable social place and economic survival without attaching themselves to a male and having at least one child. To the extent that women have any choice about the timing and number of their children, it generally does not come into play until after the first birth. A woman who has already achieved motherhood status may be able to think about health outcomes or use health risk as a rationale to make her decision to practice contraception more acceptable to others. However, even though first pregnancies are associated with somewhat greater-thanaverage health risks, few women - at least in developing countries - can choose to avoid having their first child.

The desire to become pregnant at one time and to avoid pregnancy at another time may be equally intense. In addition to the social mandate to bear children, a woman may want to have children because of curiosity about her body's wonderful ability to make another person, the physical pleasure of nursing, the many challenges and satisfactions of raising children, the desire to have a concrete demonstration of her bond with a man, the fear of insecurity during old age, the aspiration for permanency, the fear of her own mortality, and many other reasons.

A woman's desire to avoid pregnancy is equally complex and is also a combination of personal and socially determined needs. Social, psychologic, and economic risks may be much more common, more powerful, and more real to most women than are the risks of death and disease from childbearing. In the decision to get pregnant or not to get pregnant, the abstract 
notion of relative mortality risks may have very little weight. The extent of dangerous illegal abortions is testimony to the strength of motivation other than risk-avoidance in matters of reproduction.

Discussions regarding risk should be guided by each individual woman's immediate and long-term reproductive goals. Women with wanted pregnancies are most likely to be concerned about risks that could affect their unborn babies. In contrast, women who want to avoid pregnancy are more likely to be concerned about health risks to themselves. And, until they've had all the children they want, most women are concerned about risks to their ability to conceive.

Research has shown that safety is one of the most important factors considered by women who want to avoid pregnancy when they select a specific contraceptive method (Hollerbach, 1982). This is true for women of all social classes. Once a woman has decided to practice contraception, comparisons between the risk of contraception and the risks of pregnancy are inappropriate. Instead, a woman wants and needs to know about the relative risks and advantages of different kinds of contraception. Given that information, many women will tolerate considerable discomfort with contraception in order to achieve their goal.

Use of many of the most effective types of contraception entails risk of side effects and the possibility of iatrogenic complications if the persons who provide the contraception make mistakes. Evaluation of the safety of contraceptive methods should include consideration of the adequacy of the service delivery system. Women who are deciding what risks to accept need information not only about the risks that are intrinsic to each method, but about the risks of the method as it is provided within the health care system available to them. Many studies have documented practices that are less than optimally safe. For example, a study conducted in the slums of Rio de Janeiro found that 8 percent of the women over 45 were using oral contraceptives, that over 40 percent of the oral contraceptive users were smokers, and that half of them had at least one health problem that is considered to be a relative contraindication to the use of pills. Forty-five percent of the women reported at least one health problem that they attributed to their use of contraception (Costa et al., 1988).

In addition to incurring possible health risks, women who decide to practice contraception may be exposed to a variety of inconveniences, as well as monetary and social costs. Costs are associated with the need to make several trips to a health care facility and to 
continue to make such trips in the future. Seeking care requires transportation and consumes time. In addition, it may be psychologically costly, especially if a woman is embarrassed by the interview or physical examination, if she is not treated with respect, if she is pressured to accept a contraceptive method that she does not understand or want, or if it becomes necessary for her to assert herself in an uncomfortable way. In many societies, a woman who decides to practice contraception risks violence from her husband and/or censure from her mother-in-law. Such women may also worry that they are jeopardizing their future ability to conceive.

But the fact that women are concerned about health and safety does not mean that they can always take the action that is predicted to be safest. Women accept many risks because their reasons for wanting to bear children or for not wanting to bear children are of critical importance in their lives. Many, if not most, women in developing countries probably do not feel that they really have a choice. As a result, they proceed with their reproductive lives, viewing health risks as an inherent part of that life. (See chapter 6 for a discussion of the reasons why many women cannot comply with advice to go to a hospital.)

\section{$\underline{\text { References }}$}

Costa, Sarah Hawker, Ignez Ramos Martins, Sylvia Regina da Silva Freitas, and Cristiane Schuch Pinto. Family Planning Practice in a Low Income Community in Rio de Janeiro. World Health Organization, Special Programme of Research, Development and Research in Human Reproduction, 1988.

Hollerbach, P. "Factors that determine the appropriateness of new technologies to consumer needs." Working Paper No. 94. New York: Center for Policy Studies, 1982. 


\section{Chapter 10: \\ OTHER USES OF THE RISK APPROACH}

Reproductive risk assessment and the information that is developed as a result of reproductive risk assessment (that is, on the relationship between specific maternal characteristics and specific untoward pregnancy outcomes, on the distribution of "risky" characteristics between and within populations, and on the "risk status" of individual women) have many uses and make many contributions in addition to their application in the "risk approach" to reproductive health care.

1. Risk assessment is a tool for basic research; it can increase understanding of the pathophysiology or other chains of events that lead to bad outcomes.

2. Risk assessment creates the opportunity to provide health education to everyone who is screened and to provide specific advice to women with particular needs and vulnerabilities. The risk concept may help to develop more effective health education messages and to target health education more directly to the people who need it most.

3. Risk assessment can lead to the development of an outreach system, which in turn can lead to the development of more effective health care.

4. Information derived through risk assessment can be used to mobilize resources for reproductive health. It can serve to document that a problem exists, that one or more groups who are at greatest risk can be identified, and that effective methods are available to reduce their risks. That kind of information is very attractive to the policymakers who control access to resources. Risk information has a political aspect; for instance, ethnic differentials in the incidence of health problems or case-fatality ratios may become (or may be used as) political issues.

5. Information derived through risk assessment provides a rational basis for planning programs and allocating resources (between as well as within countries). Such information helps us to define problems; to design, monitor and evaluate programs to reduce or intervene in those problems (see information on the WHO Risk Approach in Appendix 2); and to target services where they are needed most. 


\section{Chapter 11: \\ ETHICAL CONSIDERATIONS}

(based on a presentation by Kathleen Nolan, M.D., of The Hastings Center, Briarcliff Manor,
New York, and on other discussions that took place during the seminar)

Ethics is about rights and wrongs, "shoulds" and "should nots." Ethicists help us to arrive at conclusions regarding what should and should not be done by helping us to analyze the strength of the arguments for or against a certain action, the clarity of the reasoning, the comprehensiveness of the analysis, and the degree of consistency between proposed actions and other deeply held values.

Dr. Kathleen Nolan, an ethicist who participated in the seminar, offered the following guideline for ethical decisionmaking in the controversy regarding maternal risk assessment: "We should use the best available tools to provide appropriate services to women and families in ways that are individually and socially acceptable and economically sustainabie." Every component of this statement touches on ethical issues.

In determining whether risk assessment is one of "the best available tools" for organizing reproductive health care, a central issue is the predictive value of the information that results from risk assessment. Resources should not be devoted to the development and maintenance of reproductive risk assessment programs unless it can be demonstrated that formalized risk-scoring predicts which asymptomatic pregnant women will need special care, and that it does so more accurately than alternative methods. It cannot be assumed a priori that the benefits from the use of risk-scoring systems will be either small or great. Instead, the outcomes of these programs must be evaluated objectively. If the benefits of a program have been relatively small, then it should be determined whether it is appropriate to expend additional resources to improve it. For example, if it is determined that the training is deficient, how much would it cost, and is it feasible, to correct the problem? If the risk-scoring tool is inadequately predictive, how much could it be improved through research, and at what cost? Whether such further investments are appropriate depends upon how much they would cost, the source of the financial support, alternative uses of the same financial resources, and predictions regarding the extent to which the current systems can be improved.

Are risk assessment programs appropriate to the individuals and communities to which they will be applied? "Appropriate" is a highly value-laden ethical term. However, in regard to 
reproductive risk assessment, one of the first considerations in determining appropriateness is whether an intervention is available to benefit the women who are classified as being at high risk. It is not ethical to conduct screening if resources have not also been devoted to ensuring appropriate follow-up and access to care for women with problems. But what counts as an intervention? Is closer follow-up an intervention, as opposed to referral to a different level of care?

It may be possible to justify risk assessment in the absence of an effective intervention when the information to be gained will be used as a tool to convince policymakers of the need for increased resources for reproductive health care. However this purpose utilizes risk assessment as part of a survey or other type of research. It might be ethical to conduct risk assessments of individual women in order to demonstrate the need for effective interventions, even in the absence of the interventions themselves, but only if the process of identifying women as "high-risk" is not harmful in itself. That rationale, however, is problematic, because being "high-risk" may stigmatize women in some developing countries. What is the impact of telling a woman, in a society where the ability to bear children is of utmost importance to an individual womans status, that she is more likely than other women to be unable to bear children safely? Being labeled "high-risk" may make a woman feel anxious and inadequate in .... vociety. In some locales, identification as high-risk may lead to iatrogenic complications - for instance, by increasing the likelihood that a woman will have an unnecessary cesarean section (see the related discussion in chapter 7). Since risk assessment is not necessarily harmless, one should be very, very careful about using it to leverage resources that will not provide a benefit to the population to which it is applied.

The interventions must be acceptable to individuals and to society. "Acceptability" is another ethical term: How do we know what is or is not "acceptable," and what about the difference between individual acceptance and societal acceptance? These two types of acceptability may be in conflict. Acceptance by individuals can be dealt with by counseling to determine what the person wants; the objective is to provide choice. Such counseling involves an ethical obligation to inform women about their risks and actual options as accurately as possible. It is not ethical either to withhold information or to present it in ways that make women think they are at a greater risk than is real. Explanations of risk based on concepts of absolute risk must be presented, in addition to information based on relative risk.

The ethical dilemma becomes most severe when some individuals consider a proposed 
treatment to be unacceptable for some reason. In such situations, several choices are available: Health care providers can defer to individuals who refuse the services, or they can attempt to educate the community, as well as individuals - remembering, however, that education involves changing people's world views, including, in some cases, cultural values that are deeply held. Another option (though an unacceptable one) is to deceive or coerce the individual, which costs less than education. Although overt coercion is usually ruled out, subtle forms of coercion have sometimes been used. But the best, though often the most expensive, option is to redesign the services to make them more acceptable. If a treatment is valuable to individuals, they will generally want it, press for it, and use it if it is available. If it is not seen as valuable for them, they will not want it. Although we may want to apply public health priorities, we have to be responsive to the perspective of the people who would be expected to use the service.

Some of the risk assessment-based programs described during this seminar provided very popular services to high-risk women. Many of the women served by the programs in Shunyi County, China and in Mexico wanted to go to a tertiary hospital. Therefore, the risk assessment process itself was generally well accepted. But in Karawa Province, Zaire, and to some extent in northeastern Brazil, referral to a hospital, especially if it involved cesarean section, was undesired, or at least inconvenient in terms of being very distant from the home. Using risk assessment to coerce a woman into accepting a treatment she does not want is ethically problematic, regardless of the intended health outcome.

The need for "acceptability" forces health and family planning professionals to look at what people consider to be the best or the worst possible outcomes; individuals, families, and societies often have quite different perspectives, especially on which outcomes are worst. Individuals are diverse. A woman and her husband may have different perspectives on which outcomes are worst. In addition, physicians, nurse-midwives, traditional birth attendants (TBAs), and societies in general have their own perspectives. Health professionals often view the worst outcome as a preventable death. If something could have been done to prevent a death and wasn't, they are very uncomfortable. However, a preventable death may not be the worst outcome from the perspective of society, or even of a particular family. Health professionals cannot presume to always determine the "best" or "worst" outcome for a particular individual, family, or society, although they can offer educated and sensitive guidance for making health care decisions.

A major argument in favor of using risk assessment in family planning programs seems 
to be that risk assessment can be used to justify providing access to contraception that otherwise might not be available. Although the provision of contraceptive services is a laudatory goal, it raises some problems. Since all pregnancies are associated with some degree of risk, any woman is at more risk when pregnant than when not. Therefore, all women should have access to contraception. However, in countries where contraception is not easily accessible and abortions are not legal, it is safe to conclude that women who have already had an abortion are at very high risk. At least in those settings, perhaps one should focus on women who simply do not want to become pregnant, rather than using more general risk assessment schemes.

The public health goal of using risk-scoring to promote family planning in order to decrease neonatal mortality does not fit well if a woman wants to become pregnant and have a child. Decreasing high-risk pregnancies in order to reduce neonatal mortality is not an acceptable objective for the use of risk assessment in family planning. The rationale for doing this is not unlike that of eugenics. Risk information should not be used to coerce women who want more children to practice contraception because of undue concern about their own "risk."

One other ethical consideration involves costs: Health services should be economically sustainable. (See chapter 8 for a discussion of costs.) One must be honest about what costs may actually be averted through the implementation of risk assessment. In addition to the other cost considerations, cost may increase if the care provided to high-risk women is improved enough to prevent perinatal deaths but not enough to prevent long-lasting morbidity among the surviving babies.

For society, the question is usually one of resource allocation. What is the most efficient way to use the available resources? Since costs are such an important constraint, one should be creative about options. For instance, some countries might obtain much more benefit from expenditures to improve transportation, as compared with using of the same funds to build maternity waiting houses and to supply food and other services to the women who live in them while waiting to give birth.

\section{Summary}

The ethical issues raised by the use of risk assessment in health service delivery are sometimes obscured by discussion of pragmatic and technical issues. Nonetheless, critical 
ethical considerations underlie the decision to use risk-scoring systems. Since the use of scoring systems can imply major decisions on the constellation of services offered, persons served, resource allocation, and attempts to alter the behavior of others, service providers must be clear about the reliability and validity of tools used to determine risk, the implicit choices made by using them, and the impact of the system on individuals. 


\section{Chapter 12: \\ CONCLUSIONS}

While it is possible to identify a group of women that will experience a higher or lower incidence of problems and bad outcomes associated with pregnancy, it is not possible to predict accurately which individual women will experience serious complications during labor and delivery. That is, it is possible to make predictions for a group, but not for the individuals who comprise the group. Risk assessment can be used to categorize individual women into such groups. Once that is done, it is possible and reasonable to develop health services appropriate to each group. However, the persons who plan such services must realize that some of the women in the so-called low-risk group will experience serious complications and that some (in many cases, most) of the women in the high-risk group will not. In many instances, most of the problems arise among women in the low-risk group.

Specificity and sensitivity are inversely related; fewer false negatives results in more false positives. When applied to a system in which women identified as high-risk get more effective but more expensive care, high specificity leads to more deaths because it results in many false negatives; high sensitivity (resulting in many false positives) wastes resources and leads to whatever consequences accrue as a result of that waste. Whether it is better to emphasize sensitivity or specificity is a matter of policy, not a scientific decision.

It is not realistic to expect that systems can ever be designed that will predict prior to the onset of labor the small percentage of pregnant women who will experience most of the intrapartum and immediate postpartum and neonatal complications and bad outcomes. False negatives and false positives are unavoidable in any screening system. The idea that risk screening can be refined until it is perfect is not consistent with an understanding of the nature of risk, which defines probabilities. Even the low-risk are at risk. The very best risk assessment schemes appear to be about as accurate as physicians' predictions. Complications, and some deaths, will continue to occur among even the lowest-risk groups of women.

Before the decision is made to implement a risk approach, planners need to consider whether the appropriate follow-through will be possible. It is neither useful nor ethical to identify high-risk women unless there is a functional referral system, including transportation, and accessible, effective services to meet their special needs. The hospitals in many developing countries are already understaffed, underequipped, undersupplied, and otherwise inadequately 
prepared to take care of all the women who go to them for labor and delivery. Furthermore, even when higher-level care is available, it may not always be used. Women may not be willing to use it; their families or husbands may object; the motivations of doctors, midwives, or traditional birth attendants (TBAs) may subvert the system; cultural norms and practices may dissuade them; and distance and problems related to transport may supersede any intentions to use the referral source of care.

Once the decision is made to use risk assessment, its purpose and its limitations must be understood. Risk assessment cannot substitute for quality medical care or for the ongoing provision of basic services to most people in the population. The usefulness of risk assessment depends on its operation within a functioning health care system. The risk approach has to be based on the health care system's current or potential service provision capabilities.

Screening and risk assessment have been important in the more developed countries, such as New Zealand, and risk screening provides the basis upon which out-of-hospital birth centers have been accepted in the United States. Although it isn't perfect, risk screening has been useful in the industrialized countries of the West.

Developing countries have different priorities; they need a rational way to allocate the use of their limited health care resources, and risk assessment has appeal as a way to do this. The current methods for organizing the use of these resources (for example, ability to pay, proximity to services, ethnicity) are not acceptable. Assessment to determine the likelihood of need is an attractive principle for guiding the rationing of finite financial, human, and other resources (for example, hospital beds, transportation, and the time of a limited number of physicians); the problem is that the screening methods are not now and may never be very accurate in predicting need.

Even in the absence of a basic health care system, the concept of risk assessment has value for the developing countries as a mind set. The question is whether, when, where, and how it is appropriate to convert informal risk assessment, which is part of all clinical health care, into a formal process and to use it as the basis for organizing the delivery of health services. Once basic health care is in place, formalized risk assessment may make a contribution. A particularly appealing notion is that it may be useful in the urban and periurban poor communities of large cities in the developing world to identify women who probably will not need to utilize hospital care during childbirth. 


\section{Costs and Allocation of Resources}

Significant financial and other costs are associated with the development and maintenance of an effective risk assessment system. Running a risk assessment system consumes resources that could otherwise be used to provide transportation and improved care for women who do develop serious complications and diseases, many of which occur unexpectedly to low-risk women.

Risk assessment programs may cause a disproportionate flow of resources and attention to the tertiary centers, which have an almost unlimited capacity to use them. Tertiary care is very expensive and often promises more than it can deliver. Most risk assessment programs have emphasized referral and transfer of high-risk women to tertiary hospitals. In some Western countries, this emphasis has increased costs and the inappropriate application of medical technology during otherwise normal childbirth. In less developed countries (LDCs), referral of large numbers of "high-risk" women (many of whom end up having normal deliveries) has contributed to the overutilization of scarce hospital resources. As a result, the hospitals become even less available to serve women who experience actual complications. Even where risk assessment has not been tried, obstetric services in LDC hospitals are becoming crowded with low-risk urban and suburban women who are able to pay for hospital care. However, depending on the purposes and design of the program, risk assessment could be used to deflect low-risk women away from hospital (especially tertiary hospital) obstetric services, and thus improve the ability of those hospitals to meet the needs of women with health and pregnancy problems and of women with actual serious complications. For this approach to work, it will be necessary to develop attractive, nontertiary models of low-risk maternity care.

\section{Information and Outreach}

Information about risk can be summarized and presented to women in many different ways, and there are ethical implications to how such information is presented. Has the woman been coerced in any way? Has the information been presented to her accurately and objectively? Can she make an informed choice? Will she be stigmatized if she is labeled as high-risk? How does family planning fit in? Those are just some of the questions that need to be considered when risk information is conveyed to a woman.

Risk assessment may stimulate efforts to find, educate, and screen all eligible women. Several programs that have used risk assessment in conjunction with active outreach and community and client education have reported good results - for example, the program 
conducted in Shunyi County, China and the family planning program conducted by the Mexican Social Security System (IMSS) in Mexico. Nonetheless, it is not clear if the positive effects of these programs were due to the use of risk assessment per se or to the education, outreach, and other innovations and improvements that were part of these programs.

\section{Objectives}

There is confusion regarding the definition and purposes of maternal risk assessment and the "risk approach." In the first chapter of this monograph the risk assessment approach to reproductive health care is described as "formalized efforts to predict poor outcomes through 'risk assessment,' to organize different intensities of care to meet the needs of women with different levels of risk, and to guide individual women into the kind of care that they have been predicted to need." Chapter 1 also explains that the World Health Organization (WHO) uses this terminology to refer to their specific, clearly outlined strategy for using epidemiologic data, including information obtained through the formal risk assessment of individual women, to plan and evaluate interventions designed to reduce the most important reproductive health problems in a particular community (Backett et al., 1984). The Shunyi County program is an example of the WHO Risk Approach.

At the other end of a continuum of scope and complexity are programs that focus primarily on screening and on teaching workers, often TBAs, to use a risk assessment tool for pregnant and laboring women and do not make other major changes in the health care system. The programs implemented in Karawa, Zaire, and in northeastern Brazil are examples.

In addition to differences in breadth and complexity, risk assessment-based programs have been developed to accomplish a variety of goals - to improve care and outcomes for high-risk women by directing them to a hospital, to reserve scarce hospital resources for highrisk women and women with actual complications, to identify a population of low-risk women in order to develop special services for them, to make full and efficient use of all levels of a country's maternal health care resources, and to increase the use of effective contraception especially among high-risk women - and improve acceptance and support for family planning. Some concerns about risk assessment are related to the purposes and designs of particular programs. For instance, many people are concerned that the risk approach focuses health care resources on too few people and diverts attention away from prevention and the need to provide all people with basic care. In a resource-rich environment, that outcome will not necessarily be the case. Risk assessment is only a tool; the outcomes of its use depend not only on its 
accuracy or lack of accuracy, but also on the purposes, design, and implementation of the systems within which it is used.

What all risk assessment-based programs have in common is the use of some standardized process to categorize individual women as higher-risk or lower-risk based on structured observations of specified risk factors and predetermined threshold criteria. However, the risk assessment processes used in these programs vary greatly in complexity and content. Some risk assessment tools give considerable weight to parity, age, and, in some cases, other socioeconomic and/or demographic characteristics that are statistically associated with a higher-than-average incidence of poor pregnancy outcomes. Some are complex, using many factors and assigning various weights to each factor. Others are simple, based on "yes" or "no" answers to a few specific questions.

\section{Predictive Ability}

Common characteristics such as age, race, and parity are weak predictors of risk; risk assessments that rely on such characteristics are very inefficient. In order to be reasonably sensitive (that is, to classify as "high-risk" most of the women who will experience serious problems), such tools assign high proportions of women to the high-risk group.

Risk factors that are part of the chain of causality are much more powerful predictors of actual adverse outcomes. As a result, many programs are moving away from reliance on true risk factors (associated with an increased probability of problems) and are moving toward screening for early indicators of actual complications or disease. Thus, risk assessment is merging, to some degree, with early detection of actual pathology. However, because many kinds of relatively common and minor pathologies are risk factors for other, more serious complications, it is hard to make a clear distinction between "risk factors" and "outcomes." The situation is further muddied because some risk-scoring systems give heavy weight to factors that cannot be detected until labor begins (for example, preterm labor), or even until after the baby has been born (for example, low birthweight). Although these late-occurring factors are powerful predictors of infant mortality, they are of little value for predicting complications or maternal mortality during childbirth.

The ability of antenatal risk screening to predict complications during childbirth varies, but the following general guidelines seem to hold: 
(1) Since most women have uncomplicated births, it is easier to identify women who will have normal births than to identify women who will experience complications.

(2) There is an inverse relationship between the accuracy of the prediction and the length of time between the risk assessment and the onset of labor.

(3) It is harder to predict the outcome for nulliparous women, as compared with parous women.

(4) Risk assessments that give heavy weight to demographic characteristics are least accurate; risk assessments based primarily on the early signs and symptoms of medical and obstetric pathology tend to be the most accurate.

(5) Very simple risk-scoring systems are usually less valid than those that consider more information. Although the causes of reproductive health problems are not well understood, it is clear that many factors play a role. Associations between many "risk factors" and the outcomes with which they are associated are complex and indirect.

It is easiest to predict which women will experience complications during childbirth if the assessment is conducted at the onset of labor, not as easy during pregnancy, more difficult among nonpregnant women, and most difficult among women who have never been pregnant. Even the most complex risk-scoring tools, moreover, do not seem to outperform clinical judgment, possibly because clinical judgment is integrative and interpretive, taking many factors and impressions into account.

\section{Risk Assessment and Family Planning}

Risk assessment can be used in several ways in family planning. Nevertheless, there is controversy and serious disagreement about using it as a way to focus family planning program efforts toward women who have been identified by the program as being at elevated risk for maternal and/or infant morbidity and mortality if they become pregnant. This approach contradicts much of what has been learned about how to provide effective family planning services - that is, to make contraception available to all who want to use it, to prevent health professionals from controlling access to contraception, to provide a choice of methods and then give individuals the method of their choice, to avoid coercion, to base care on the inherent right of all women and men to regulate their own fertility, and to reach out and be inclusive. 
The use of formalized maternal risk assessment in family planning programs makes sense only where local policies or scarcities make it impossible to offer family planning services to everyone. That is most likely to occur with tubal ligation services, where there are often real constraints in access to care.

Family planning programs avert many maternal and infant deaths by preventing unwanted pregnancies, regardless of women's risk status. Because unwanted pregnancies so often lead to unsafe abortions, family planning may make its greatest contribution to maternal health by preventing unwanted pregnancies, regardless of other aspects of a mothers risk. All women who have self-induced or other illegal abortions are at high risk of maternal mortality; special efforts should be made to reach women who do not want more births in order to provide them with contraceptive care.

As demonstrated in the IMSS program, the idea of reproductive risk may help to generate political and professional support for family planning. In addition to some degree of active opposition to family planning, such as that based on religion, family planning suffers from a general lack of interest in preventive health care; throughout the world, curative care is given more attention than preventive care. The risk assessment approach makes family planning fit into the curative medical care model, in which the professional decides what is needed and advises or treats the patient. While it is probably possible to increase health professionals' interest and motivation to participate in family planning through education, the appeal to physicians of converting family planning into a medical therapy should not be discounted. Improving maternal and child health is a legitimate goal of family planning, so the medicalized approach has a certain allure. Experience has shown, however, that this approach does not produce a well-rounded family planning program that is attuned to the perspective of the user and that emphasizes human rights.

The main motivation for practicing contraception is the desire to delay a first pregnancy, to space pregnancies, to control the timing of pregnancies, or to avoid having additional children. Except in extreme cases (for example, serious, chronic disease and/or serious complications during previous pregnancies), the actual risk of death from childbearing is small. The decision to have or not have children is one of central importance. Few women would base this decision primarily on a small increment in the remote likelihood that they would die or suffer injury as a result of practicing contraception or having a baby. 
The number of women who want to avoid pregnancy is very large, and very few LDCs are meeting the contraceptive needs of those women. It is not necessary to use risk assessment as a way to motivate women to practice contraception.

Although reproductive risk assessment is being used in increasing numbers of programs, its various applications have not been evaluated adequately. Few evaluations have been conducted, and most that have been done did not assess costs. In addition, it is difficult to interpret the findings from some evaluations, especially, as in the case of the IMSS program, to distinguish between improvements due to the use of risk assessment per se and those that result from other aspects of the program. It is also important to remember that the professional literature is biased toward good results. Programs that do not work are rarely reported. The risk approach, although not without merit, is not the only alternative to current states of service disorganization and underdevelopment, and it has not yet been proven to be the best.

\section{References}

Backett, E.M., A.M. Davies, and A. Petros-Barvazian. "The Risk Approach In Health Care: With Special Reference to Maternal and Child Health, Including Family Planning." Public Health Papers No. 76. Geneva: World Health Organization, 1984. 


\section{Chapter 13:}

\section{RECOMMENDATIONS}

To begin with, three major recommendations can be made about providing basic reproductive health care. First, in areas where no effective maternity care is available to the majority of pregnant women, the focus should be on preventing problems and early detection (rather than prediction) of actual complications (rather than risk factors). Effective care should be available to all pregnant women, not just those who are at high risk. Transportation must be provided to make sure that women with complications get to an adequate facility quickly.

Second, all persons who attend births should be trained and equipped to provide some emergency care (for example, breech deliveries and measures to stop postpartum hemorrhage). That is also true for traditional birth attendants (TBAs) who are based in the community and provide care to low-risk women.

Third, risk assessment systems have no value unless the following basic reproductive health services are in place:

1. First-level preventive health care should be available and accessible, including:

- family planning;

- preventive prenatal care (providing information about risky and protective health behaviors, signs and symptoms of pathology, and the need to seek further care if these signs develop; recording events that mark gestational age; administering tetanus toxoid; providing iron/folate supplements; and monitoring fetal growth);

- education of women in the community about signs and symptoms that indicate the need to seek help;

- pregnancy diagnosis and safe, legal abortion; and

- where abortion is not legal, training of first-level care providers to treat the often lifethreatening complications of illegal and self-induced abortions.

2. Trained birth attendants should know how to:

- assist and support the mother during childbirth; 
- avoid creating problems (for example, hygienic childbirth procedures, no use of dangerous interventions);

- solve some problems;

- detect serious problems as early as possible;

- apply first aid procedures as appropriate; and

- arrange for transportation.

3. Access to an intermediate (secondary) level of care should be provided. Women need access to something between the village TBA and a hospital that can do a cesarean section, some place where it is possible to start an intravenous infusion (IV), give plasma expanders and antibiotics, and perform emergency procedures such as the manual removal of the placenta and, perhaps, symphysiotomies. Secondary care centers must be provided with all necessary equipment, a reliable and continuous supply of essential drugs, appropriately trained personnel (not necessarily a physician), supervision, and access to transportation. They should be located in places where patient transfer to tertiary hospitals can take place easily - that is, they should be on well-maintained roads and have communication with and transportation to the nearest hospital, perhaps by facilitated use of vehicles and short-wave radios that are already in the community - such as equipment belonging to the police department or irrigation projects, and funds that are dedicated to vehicle maintenance and the purchase of fuel.

4. Women should have access to effective care in hospitals that have the ability to transfuse blood and perform cesarean sections. Although in some places midwives can be trained to perform cesarean sections, it must be recognized that safe cesareans require a team of people who are able not only to conduct the operation but also to provide a sterile surgical field and adequate postoperative care. Even if general physicians and nurses are trained to do this, they are unlikely to remain in remote areas. However, facilities with these capabilities should be distributed as broadly as possible.

The recommendations described above and those that follow are summarized in Figure 13.1. 


\section{Additional Recommendations}

In addition to the three recommendations discussed above, the seminar resulted in a number of other important observations about risk assessment.

The decision to implement a formalized risk assessment program should be based on an analysis of the anticipated costs and benefits of such a program as compared with those of alternative uses of the same amount of resources. The analysis of costs should include consideration of potential psychological and social costs to women. Once a decision to use maternal risk assessment has been made, the program planners and administrators should be clear about which bad outcomes or "risks" they are trying to prevent. Wherever maternal morbidity and mortality are high, reduction of maternal (rather than perinatal or infant) morbidity and mortality should be the primary concern.

Professionals should communicate about risk accurately. In most instances, women should be given information about absolute rather than relative risk.

Research is needed to determine the causes of maternal mortality in specific countries (or other geographic units) and to identify intermediate factors that are causally - not just statistically - related to the immediate causes of death (for example, contracted pelvic dimensions). Where hospital resources are extremely limited, risk assessment should be used to identify and refer only those women who have the intermediate factors that are causally related to maternal mortality. It is particularly important to find ways to identify those women for whom cesarean section is the only alternative to death - women with placenta previa, transverse presentations, or severely obstructed labor - and bring them to facilities where cesarean sections can be performed.

Facilities that are designed to handle serious complications are not enough, however. Attractive and appropriate alternative sources of maternity care are needed for low-risk women. Some attention should be directed to that need and not focused solely on efforts to develop high-level care for women who are at "high-risk." New models of service delivery, such as birth centers, are needed for certain kinds of middle-level developing countries, and for urban areas in many less developed countries (LDCs). It is important to develop and test criteria for maternal low-risk status. In rural areas, places designed to meet the requirements of low-risk women 
during childbirth are needed relatively close to where women live. Such places should be constructed in a manner that makes it easy to keep them clean and free of animals. They should also have a safe water supply and should facilitate the provision of both physical and social support to women during labor. In urban and periurban areas, it makes the most sense to design low-risk care that is attractive to the women who can exercise choice in their childbirth care, usually higher-income women. It would be best to start by finding out what such women like and do not like about their current options (if any) and what kind of care they think they would like to have while giving birth. Medical, midwifery, and nursing students need learning experiences in low-risk birth settings as well as in high-risk birth settings.

The use of maternal risk assessment in maternal health and family planning service delivery programs requires careful evaluation. When programs are evaluated and found to be successful, it is important to ask whether the success was or was not due to the risk assessment aspect of the program. When programs are evaluated and found to be unsuccessful, it is equally important to ask why. Was it because the risk assessment instruments being used are not good enough, because the program was not implemented properly, or because it was poorly conceived? How accurate must a reproductive risk assessment process be to result in successful programs? The concept of "waiting houses," where higher-risk women can spend the last few weeks of pregnancy close to a hospital, should be explored further and demonstrated, but must also be evaluated carefully. Scientists have a responsibility to publish reports that describe programs that fail, as well as programs that succeed.

Alternative strategies are needed for improving maternal health in developing countries. For example:

1. Establish ways to put all women into contact with the health care system. It is necessary to reach out actively to women who do not seek care on their own.

2. Develop public education strategies. All women and men need to be educated regarding behavior that protects or improves health, behavior that is risky, the availability of family planning and of pregnancy-related care, accurate and easy-to-understand information about health risks associated with pregnancy and with contraception, and information about the signs and symptoms of diseases and complications during pregnancy. Home-based maternal records may assist efforts to educate women about risk factors and the signs and symptoms that indicate they need to seek assistance. 
3. Provide more and better training to improve the quality of the work of TBAs and others who provide maternal health care at the village level. TBAs need training in settings that provide an adequate number of cases. It is important that they are taught what not to do, as well as what to do. They can and should be taught to provide life-saving emergency care for some kinds of emergencies - with the understanding, however, that most severe complications cannot be managed at the community level and that some deaths and other bad outcomes will occur. Programs to train and expand the role of TBAs need to be evaluated.

4. Improve the quality of existing services. For example, the availability of equipment and drugs, the training of staff, the cleanliness of the facilities, the promptness with which patients are attended, and staff courtesy might need to be improved.

Regardless of whether a country is developed, less developed, or developing, family planning services should be made available to everyone. Where the risk approach is used for family planning, the risk assessments should be based on desire to avoid pregnancy, risk of a dangerous illegal abortion, and actual (not potential) pathology. Demographic factors are not specific or valid enough to be used as a basis for telling a woman that she is in danger if she conceives.

The importance of unsafe abortion as a cause of maternal mortality should be emphasized, as should the need for family planning and safe legal abortions to deal with the problem.

Finally, it is necessary to emphasize and learn more about women's perspectives on risk - what "risk" means to women, as well as the psychological, social, and other costs and benefits to women, from their own viewpoints, of engaging in a risk assessment-based maternal health or family planning service program.

The risk approach should be seen as an evolving concept, to be experimented with and evaluated. The potential benefits of maternal risk assessment should not be oversold. It is important that program planners and clients of the health care delivery system are not led to have unrealistic expectations regarding the ability to predict which women will have problems. People need to understand that it is never possible to prevent all bad outcomes. 


\section{Summary of Recommendations for Using Risk Assessment}

$\checkmark$ Where no effective care is available for most pregnant women, focus on problem prevention and early detection of complications rather than risk factors.

$\checkmark$ Provide basic reproductive health services.

$\checkmark$ Train all birth attendants to provide some emergency care.

$\checkmark$ Evaluate carefully the use of risk assessment in MCH/FP service delivery programs.

$\checkmark$ Compare costs \& benefits of risk assessment with those of alternative approaches.

$\checkmark$ Clarify whether maternal or perinatal/infant mortality is the primary concern.

$\checkmark$ Develop attractive alternative sources of maternity care for low-risk women. $\checkmark$ Provide women with accurate information about absolute rather than relative risk.

$\checkmark$ Emphasize and learn about women's perspectives on risk.

$\checkmark$ Conduct research on the biologic causes of maternal mortality.

$\checkmark$ Do not overestimate the potential benefits of maternal risk assessment; view it as an evolving concept.

$\checkmark$ Develop alternative strategies for improving maternal health in developing countries.

$\checkmark$ Make FP services available to everyone; emphasize the role of unsafe abortion in causing maternal mortality; make legal abortions available. 


\section{Appendix 1:}

\section{DEVELOPING A REPRODUCTIVE RISK ASSESSMENT INSTRUMENT AND SCORING SYSTEM}

(based on a presentation by Beatrice J. Selwyn, Sc.D., Associate Professor of Epidemiology, University of Texas School of Public Health, as well as on other sources and discussion that took place during the seminar)

The ability of maternal risk assessment to separate women into groups with different probabilities of experiencing obstetric complications depends on the sensitivity, specificity, and predictive value of the risk assessment instrument and scoring system. This appendix discusses some aspects of the development of such a system.

The prevalence of specific reproductive health problems and the relationships between risk factors and actual complications vary from one community to another. In order to be effective, risk assessment systems should focus on the most important problems in the community where the screening will be applied and must be based on data from that community. It is not possible to develop a "generic" risk assessment tool and apply it in a wide variety of places. It is necessary to conduct a fairly sophisticated assessment of local reproductive health problems as the basis for developing a risk assessment tool.

\section{1: Decide What Problem(s) and/or Outcome(s) to Predict}

It is necessary to be clear as to whether one is trying to prevent maternal deaths, infant deaths, perinatal deaths, or damaged infants. Less intervention is required to prevent maternal deaths than to prevent infant deaths (for example, less training, less equipment, fewer referrals). Some risk factors are associated with both maternal and infant mortality, but others are not. It is not possible to develop a single risk-scoring system that will predict a large number of different adverse perinatal outcomes. When a woman is labeled as "high-risk," it is essential that both she and her care providers understand whether she herself is at risk (for example, of maternal morbidity and/or mortality), or whether she is at risk of having an infant who will die or will be born sick.

\section{2: Decide Which Risk Factors to Assess}

A large number and variety of variables are associated with perinatal outcomes. Decisions regarding which factors to assess should be based on the specific outcome(s) one is trying to predict.

Variables can be directly or indirectly associated with a complication; that is, the 
association between the factor and the outcome may be only statistical (for example, the association between low educational attainment and poor infant outcomes) or the factor may contribute to the biological cause of the outcome (for example, the association between poor maternal nutrition and low birthweight). Risk factors that are part of the chain of causality are most reliable; those that have a strong association with a specific outcome are most useful. A single variable may be associated with several different outcomes, but in different ways.

Risk-scoring systems to be used in remote areas of developing countries should not give heavy emphasis to factors that cannot be detected until after labor has started (for example, preterm labor) or until after the baby has been born (for example, low birthweight). Although these late-occurring factors are powerful predictors of bad outcomes, they occur too late to contribute to the prediction of problems during labor and delivery.

Although LDC programs need assessment tools that are valid and simple to use, most women have multiple risk factors; in some cases, it may be a specific combination of factors that is associated with a poor outcome. Very simple risk assessment tools are less accurate.

The complexity of the risk assessment process (directly related to the number and type of factors) determines how expensive and difficult it will be to apply the system and thus determines how widely the system can be used. It is better to screen many women for the most common and important problems, rather than screening a smaller proportion of women for a more complete list of problems.

How the instrument will be used and who will be expected to fill it out affects the choice and number of variables - for example, whether the risk assessment instrument will be incorporated into the regular medical records that are kept on all pregnant women or will be an additional (freestanding) record.

A. Reproductive history: Parity (nulliparity versus having had one or more children) is a very important factor. This is partially because some complications are much more common among women who are having their first babies. In addition, women who experience serious problems during any pregnancy are more likely to have problems again; conversely, women who have had uncomplicated prior pregnancies are likely to repeat their history, too. Knowledge of the course and outcomes of a woman's earlier pregnancies provides some of the most accurate and powerful information that can be included in a reproductive risk assessment. Because that information is not available in the case of women having their first pregnancies, risk assessment is less valid for them. The risk associated with complications that are more common during first pregnancies cannot be avoided except by women who want to have no children at all (at least until we understand the causes of these problems and how to prevent them). Very high parity is also associated with higher rates of both infant and maternal mortality. However, this relationship is almost certainly confounded by an association between high parity and poverty in most societies. That association did not hold in studies from Israel, where, unlike almost every other place, high parity is not associated with low socioeconomic status (Eidelman, 1988; 
Seidman, 1988).

B. Age and other common demographic tactors: These factors are often used but are not very specific. If age were considered a high-risk factor, in most developing countries more than one-fourth of pregnant women would be considered high-risk by virtue of age alone. Although some demographic characteristics are statistically associated with medical risk, in most cases the demographic characteristic is a proxy for one or more other factors that are the actual agents of risk - that is, the "risk" associated with young maternal age is due to social and behavioral factors rather than to biologic factors. On the other hand, maternal age greater than 35 is a relatively strong predictor of certain kinds of complications, especially in nulliparous older women, and is directly related to some biological causes of poor pregnancy outcomes, such as hypertension, obesity, and diabetes. In the more developed countries, however, this increased risk is limited to the fetus. Recent studies have demonstrated that, in the wealthier countries, higher age does not bring any significant health risk to older mothers (Kujansuu et al., 1981).

Other social/demographic factors that are strongly statistically associated with poor pregnancy outcomes both in Western and developing countries (for example, poverty, lack of education, being a member of an ethnic minority, not being married) are associated with a higher frequency of certain medical conditions that can cause problems during labor and cielivery. However, it seems to be the medical conditions, not the personal characteristics, that are really associated with increased risk. If the woman does not have or does not develop the medical problems, she is not at increased risk. In that case, if one can look for the pathology, the sociodemographic factors can be ignored. This approach avoids the high incidence of false positives that result from identifying all women with certain common demographic features as high-risk and leads to the identification of conditions that can be treated.

Demographic data on death and birth certificates has made this kind of information available to epidemiologists and has resulted in its use in risk assessment tools. Other, potentially more powerful risk factors - for example, residing far from the nearest hospital (especially in developing countries) or social isolation (especially in Western countries) - have not been used because the data are not consistently recorded or accessible.

Although common demographic factors are not powerful predictors of outcomes for individual women, their statistical association with poor outcomes makes them valuable for comparing the "risk status" or needs of various communities.

C. Medical tactors: These include evidence of chronic medical disease (for example, diabetes), acute medical disease (for example, urinary tract infection), or prenatal complications (for example, multiple gestation) or pathology (for example, pregnancy-induced hypertension) are of primary importance. However, it is important to be clear as to whether screening is being conducted (to pick up women with current pathology, so that it can be treated) or whether risk assessment is being conducted (to predict the probability of a future problem). Some medical conditions (for example, anemia) are both a form of current pathology and predict a higher 
probability of later problems. However, the difference between risk assessment and early detection of pathology should be understood clearly.

D. Modifiable factors: Some risk assessment tools differentiate between risk factors that can be modified and those that cannot. Modifiable factors include health problems, such as anemia, that can be treated during the pregnancy, and risks related to the woman's life-style, habits, or environment, which could be ameliorated through education or other interventions. Once such risk factors have been modified, the chance of an unhealthy outcome should be lessened.

E. Heakth service factors: These include, for example, distance to the nearest place where the woman could obtain a transfusion or cesarean section, and they are important but are rarely included in risk assessment systems. In some places in Africa, a woman with contracted pelvic dimensions (CPD) who lives 60 miles from a hospital may be at great risk of dying, whereas a woman with CPD who lives only 5 miles from the hospital may have little increased risk of death.

\section{3: Decide How to Use Numeric Scores}

Establishing cut-off points for individual risk tactors. In a place like Africa, most of the women will have some of the variables that are associated with bad pregnancy outcomes. Thus, a very large proportion of the women may be identified as high-risk. For example, based on the WHO definition of anemia, almost all of the women in some countries have anemia. In that situation, it does not make sense to identify every woman with less than 11 grams of hemoglobin as high-risk. In Jamaica, every woman with anemia is directed to the tertiary hospital. As a result, the hospital is so overcrowded that every bed holds at least two women. That does not mean, however, that it is not useful to screen for anemia; some very severe cases of anemia will occur that should be considered higher-risk. Decisions regarding an appropriate cut-off point for determining a common risk factor should be made on the basis of circumstances in the local situation. It is important to avoid overloading the health care system.

Weighting the risk factors. Numeric weights or scores can be assigned to the individual risk factors in an assessment system on the basis of clinical judgment or on the basis of data (using relative risks or multivariate analysis). Weighting a factor enhances or lessens its importance within the risk assessment system. Assigning a weight of one to factor $A$ and a weight of five to factor $B$ implies that factor $B$ is five times more important than factor $A$ in predicting the outcome that the risk assessment system is intended to predict. Some risk assessments do not use weights, but only count whether each factor is present or absent. In those cases, the objective is to distinguish between major factors and minor factors. But a judgment is still being made about which factors are more closely associated with the outcome.

Using summary numeric scores. Numeric risk scores, which are used to decide which women are high-risk enough to need special care, are simple and therefore easy to apply (for example, if the score is less than $X$, the woman is low-risk; if greater than $X$, she is high-risk). They force very disparate kinds of risk indicators into a single scale and force all of the women into one of 
two groups. They can be developed in several ways:

- Summing the weights of the separate risk factors attributed to each woman: This method has been the most frequently used. It entails marking each of the risk factors possessed by an individual pregnant woman and then adding the numeric weights assigned to each of the factors. The sum of the factor weights is the "risk score" for the woman.

- Using a multivariate technique: This technique involves marking the risk factors for each woman and using a programmed calculator or microcomputer to compute her score based on a program that takes interaction between risk factors into account. For example, instead of getting 10 points for being only 17 years old and 5 points for being anemic (adding to a total of 15 points), the multivariate score might come out as 25 , since young age and anemia may interact in a way that increases the overall risk.

- Calculating relative risks and then multiplying them: Relative risk (also discussed in chapter 3 ) is expressed as a number that describes the incidence of poor outcome among persons with a particular risk factor in relation to the incidence among persons without the risk factor, which is set at 1.0. If the risk factor is associated with an increased incidence of the outcome, the relative risk is greater than 1.0. If the factor is "protective" (that is, associated with a less-than-average incidence of the poor outcome), the relative risk is less than 1.0. Some risk assessment instruments use the relative risk associated with each risk factor as the weight assigned to that factor in calculating each woman's total risk score. The relative risk weights are then multiplied to derive each woman's total risk score.

- Adding up the total number of risk factors: In the last several years the more complicated methods of deriving numeric risk scores have tended to give way to a simple counting of risk factors. With this method all risk factors are treated equally. A variation is to designate some risk factors as "major risk factors" and others as "minor risk factors" and then to decide, for example, that even one major risk factor puts a woman at high risk while at least two minor factors are needed to constitute a high-risk.

Almost no careful evaluation has been undertaken to determine which of these approaches is most effective.

Establishing the "Cut-off Point." The cut-off point for a summative numeric score is the score above which women will be classified as high-risk. The cut-off point controls admission to the high-risk group and thus has a profound effect on the sensitivity, specificity, and predictive value of the risk assessment system. If the cut-off point is low, a large proportion of the women will be identified as high-risk; consequently, the system will be very sensitive but not very specific. If the cut-off point is high, a small proportion of the women will be identified as high-risk and the system will be less sensitive but more specific.

Risk actually occurs along a distribution. However, most risk assessment systems try to 
classify women into only two levels, high-risk and low-risk. This approach is equivalent to taking the actual birthweight of infants but then only classifying them as low birthweight or not low birthweight. The dynamics of the score are removed, and all women within each category are treated the same. Use of cut-off points simplifies decisionmaking but reduces the usefulness of raw risk scores as more accurate probability statements.

Quite specific risk assessment tools are needed where hospital care is scarce. Otherwise, too many women are referred to the hospital and the hospital becomes overloaded with women who do not have serious problems, rendering it incapable of providing care to the women who really need it.

\section{Problems Related to Numeric Scoring of Identified Risk Factors}

Numeric scores force some very disparate kinds of risk indicators into a single scale. It is difficult, and perhaps impossible, to assign useful weights to such different factors. For example, what weight should be given to twin gestation as compared with low maternal age? Clinicians have always tried to identify women who are likely to develop problems and to give them additional attention - for example, if it seems that a woman might be carrying twins, or if she had problems with a previous pregnancy. This concept is not new and makes sense to everyone. But converting this process into an arithmetic scoring system may not seem to make sense. Clinicians are the first to recognize the weaknesses of these systems. If the scoring system is not efficient, they learn to ignore the numbers and focus on specific factors. (This situation occurred in the risk assessment program implemented near Fortaleza, Brazil; see chapter 5) By the time the evaluators recognize the inaccuracy, the people expected to use the system may have lost faith in it. The effort to simplify screening may actually make it seem foreign or less understandable to the person doing the screening. Why should someone with a score of 9 be low-risk while someone with a score of 10 is high-risk? That distinction may not make sense to an experienced and intelligent traditional birth attendant.

With numeric scoring, factors associated with specific problems contribute to a womans overall risk score. But, for instance, a factor associated with an increased risk of preterm labor becomes insignificant once the pregnancy has come to term. Nevertheless, a woman with a high score based on a previous preterm birth may be categorized as high-risk even after she has completed 37 weeks of gestation.

In addition, translating specific risk factors into a numeric score makes the risk assessment seem more accurate than it really is (in the same way that data generated by a computer may seem more accurate than the same information calculated by hand, especially if all divisions are carried out to several places beyond the decimal point). 


\section{The Timing of Risk Assessment}

When and how often should risk assessment take place? Before pregnancy occurs? As early in pregnancy as possible? At the twenty-fourth and/or thirty-sixth weeks of pregnancy, at the onset of labor, or during early labor? The closer in time to the event to be predicted, the more accurate the prediction will be. Although early identification of problems allows more opportunity for intervention, the specificity and sensitivity for detecting intrapartum problems improves in inverse proportion to the time between the assessment and the onset of labor. For prediction of problems that occur during labor and delivery, assessment at the onset of labor is the most accurate of all.

Data on different variables can be collected at different phases of the pregnancy. If the assessment is repeated, it becomes possible to observe changes, such as weight gain, growth of the uterus, and changes in blood pressure; the changes in these measurements over time may be more valuable predictors of outcome than are the actual measurements.

\section{Assuring the Quality of the Information Used to Create Risk Scores}

The reliability and validity of the risk factor assessment itself are often not adequately addressed. Each risk factor needs a standard definition. The persons who conduct the assessments must be taught those definitions and they must adhere to them. The medical and obstetric history is the most important source of information on risk factors. That information should be obtained directly from the woman (not from her record). Interviewing technique is important in ascertaining whether the risk factor is present or not; the answer to a question often depends on how the question is asked. Ethnographic studies may be needed to learn how to ask questions so that women will understand what they are being asked, which is surely a requisite for accurate answers.

Using Traditional Birth Attendants to Conduct Risk Assessments. TBAs are crucial people in some countries, especially in Africa, and will continue to be important for some time to come. A major drawback to using TBAs to conduct screening is that in most countries the TBA does not have contact with the pregnant woman until she is in labor.

Programs that use TBAs for screening tend to get a high rate of false positives. That rate can be reduced if one or more other levels of screening occurs between the TBA and the final decision regarding whether an individual woman should go to a hospital for labor and delivery - that is, if the TBA refers questionable cases to a health facility where the pregnant
woman can be diagnosed as well as screened.

The ability of TBAs to learn is often underestimated because many of them are illiterate. Their role can be expanded, but they need effective training: 


\section{Outreach to Bring All Pregnant Women Into the Program}

The highest-risk women are often the least likely to enter any care system (see chapter 6); thus, a need for outreach always exists. Several models have been tried: Most developing countries use some kind of community-level worker for case identification. It may even be necessary to enumerate all women of reproductive age in order to have complete outreach coverage.

\section{References}

Eidelman, A.l., R. Kamar, M.S. Schimmel, and E. Bar-On. "The grandmultipara: Is she still at risk?" American Journal of Obstetrics and Gynecology 158 (1988): 389-92.

Kujansuu, E., S. Kivinen, and R. Tuimala. "Pregnancy and delivery at the age of forty and over." International Journal of Gynaecology and Obstetrics 19 (1981): 341-45.

Seidman, D.S., Y. Armon, D. Roll, and D.K. Stevenson. "Grandmultiparity: An obstetric or

neonatal risk factor?" American Journal of Obstetrics and Gynecology 158 (1988):
1034-39. 


\title{
Appendix 2:
}

\section{THE WORLD HEALTH ORGANIZATION RISK APPROACH IN MATERNAL AND CHILD HEALTH AND FAMILY PLANNING}

\begin{abstract}
(based on a paper by Brian J. McCarthy, M.D., Program Evaluation Branch, Division of Reproductive Health, Centers for Disease Control, United States Public Health Service, and on documents produced by the World Health Organization and the Centers for Disease Control. Organization in Geneva from 1980 to 1983 maternal and child health at the World Health
\end{abstract}

Documents describing the World Health Organization (WHO) Risk Approach in maternal and child health care identify it as part of a strategy to achieve the goal of "Health for All by the Year 2000" - a strategy by which health care systems can provide "something for all, but more for those in need . . . in proportion to that need" (Backett et al., 1984; WHO, 1984).

WHO published two documents on the risk approach in 1984 - a monograph entitled The Risk Approach in Health Care. With Special Reference to Maternal and Child Health. Including Family Planning (Backett et al., 1984) and A Workbook on How to Plan and Carry Out Research on the Risk Approach in Maternal and Child Health Including Family Planning (WHO, 1984). Although the monograph does not include a succinct definition of "the risk approach," a definition can be constructed from information presented throughout the document.

- The Introduction states that special vulnerability to illness results from the possession of a number of interacting biologic, genetic, environmental, psychosocial, and other characteristics that can be measured and converted into scores as "a shorthand expression of the probability of future need for care." The "risk strategy" uses these estimates of the mothers need for help "as guides to action, to resource reallocation, to better coverage and referral and to family and clinical care." Although this strategy is identified as the "simple and classic use of the risk approach," the introductory chapter also discusses collection and use of data on collective or community risks as one of several new uses of the risk approach (Backett et al., 1984: 1-2).

- Chapter 2 refers to the risk approach as the collection and "exploitation" of risk data ("the tools of the risk approach"), and states that the risk approach begins with "decisions as to priority 'targets', [sic] or unwanted outcomes," followed by measurement of associations between risk factors and outcomes, interventions, and evaluation and modification of the interventions before wider application (Backett et al., 1984: 15, 17).

- Chapter 5 presents eight suggested uses of risk information in health care, but warns that, although the suggestions are "prompted by experience," they "constitute a series of hypotheses still to be tested under field conditions" (Backett et al., 1984: 43-59). The eight suggested uses include five that are within the formal health care system and three that are 
outside of the health care system - one at the level of the individual and the family, one at the level of the community, and one related to intersectoral policy, as follows:

(1) strategies by which individuals and tamilies use risk data to establish realistic health priorities, to adopt healthful lifestyles and behavior, to recognize and attend at an early time to threats and potential threats to their health, and to seek appropriate health care;

(2) use of the risk approach by the local community (neighbors and village members); spreading information about the nature and extent of relationships between the environment and health and interpreting risk information to demonstrate cause and effect in the genesis of disease in order to foster community action to control risk factors, develop locally appropriate interventions, improve referral, and foster an earlier, anticipatory, or preventive and promotive approach to primary health care;

(3) increasing access to needed health care by screening everyone and by reallocating available resources to those who need them most;

(4) improving referral by facilitating the movement of individuals along the referral chain in order to ensure that all people reach the level and kind of care they need;

(5) modifying risk factors and otherwise intervening in the causes of illness that have been shown to be of particular importance in a specific community as demonstrated by calculation of attributable risk;

(6) use of risk data to assist in the local reorganization of health care and as a basis for the local retraining of health care workers to improve the "fit" between needs and skills, facilities, technology, and the capacity of institutions in the referral chain;

(7) use of risk data for planning health care at the regional and national levels; and

(8) use risk data to facilitate intersectoral collaboration.

- The summary chapter describes the risk approach as "both a method of measuring the need of individuals and groups for care (thus providing a means of assisting them to determine their priorities) and a tool for the reappraisal and reorganization of health and other services to meet that need" (Backett et al., 1984: 111).

The four fundamental steps in the WHO Risk Approach are: (1) using epidemiologic methods to identify priority health problems and risk factors associated with those problems, (2) assessing the performance of the local health care system as regards prevention and treatment of the identified problems, (3) developing and implementing strategies to modify the risk factors and to improve the performance of the health care system, and (4) monitoring and evaluating the effectiveness, efficiency, and acceptability of the intervention strategy. The results of this 
monitoring and evaluation then become the basis for redefining the problem (Yan et al., 1989).

Although this dynamic process has clear implications for national policy, it should be used at the level of the country's operational units - for example, districts, counties, or provinces. The Shunyi Risk Approach Project in Perinatal Health (described in chapter 5 of this monograph), provides an example.

The WHO Risk Approach addresses two pivotal questions: First, are we doing the right things? That is, have we directed our resources toward reducing the health problems that have the greatest impact on our population's health, and have we selected the most effective and efficient interventions to reduce those health problems? Second, are we doing things right? That is, are the planned interventions really being carried out and are they being performed correctly?

\section{Identifying Health Problems}

The WHO Risk Approach begins by determining which health problems pose the greatest risk to the health of individuals and communities; in this way, the risk approach identifies which subgroups within a society have the greatest needs. The risk approach involves a continuing cycle of data collection and response to the information obtained from the data (see Figure A2.1). The data collection (or "surveillance") system should be adaptable, responsive, cheap, and simple (see Figure A2.2). 


\section{FIGURE A2.1}

\section{The WHO Risk Approach in Maternal and Child Health}

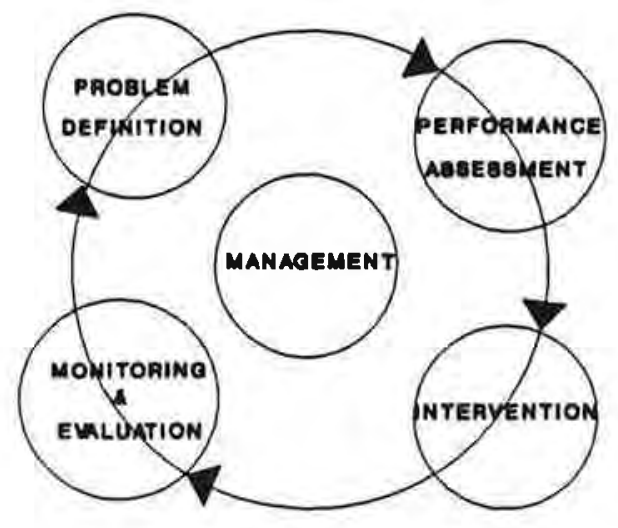

McCarthy/Centers for Disease Control

\section{FIGURE A2.2}

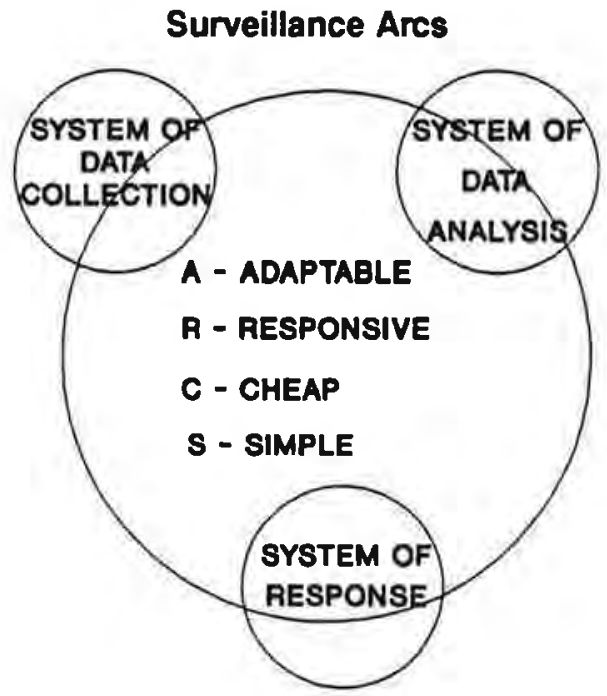

Information is a difference

that makes a difference

"What are we doing that we can measure?" instead of

"What do we need to measure to know what we are doing?"
Every pregnancy counts, so count overy pregnancy

Every baby has weight, so weigh every baby

McCarthy/Centers for Disease Control 
Application of the WHO Risk Approach to maternal and child health requires collection of data on the pregnancies of all women in the target community and on their utilization of organized health care. The distribution of adverse outcomes can be plotted by monitoring the complications that pregnant women and their infants experience. Rates are determined for low birthweight, perinatal mortality, birthweight-specific mortality, infant mortality, and maternal mortality.

Perinatal health surveillance requires a clear description of the subpopulation being monitored. This description is obtained by gathering additional data from the perinatal health records of an appropriately sized sample of the total population of pregnant women. Data should be collected to describe the general health status of this sample of women, as well as information on their demographic characteristics, outcomes of their previous pregnancies, and how they utilize the health care system. An examination of these data should include a look at the distribution of adverse outcomes, so that associations between poor outcomes and risk factors can be detected. Not only should "risk factors" be monitored, but so should actual pathology that occurs during the antepartum period, such as hypertension, pre-eclampsia, anemia, nonvertex position of the fetus near term, and placenta previa. ${ }^{11}$ Intrapartum complications that should be recorded include eclampsia, prolonged second stage of labor, rupture of the membranes before the onset of labor, fetal distress, dystocia, nonvertex fetal presentation, prolapsed cord, and maternal shock. Then the adverse outcomes should be measured - low birthweight and maternal, perinatal, neonatal, and infant mortality - and associations between those outcomes and various maternal, antepartal, intrapartal, and even newborn "risk" conditions should be identified, if they exist. Some of the "risk factors" most strongly associated with perinatal and infant mortality are conditions that cannot be observed until the infant is born (for example, cord problems) or problems that are manifested by the infant itself, such as asphyxia, fever, jaundice, birth defects, and birth injuries.

The major risk factors for selected adverse outcomes are identified by determining (1) the incidence of each risk factor among the pregnancies with each type of adverse outcome, (2) the relative risk (ratio of the incidence of the adverse outcome in pregnancies with the risk factor as compared with the incidence in pregnancies without the risk factor), and (3) the impact of the risk factor within the population (considering the underlying incidence of each risk factor, as well as its relative risk). The epidemiologic tools used in the WHO Risk Approach are well known and can be used in many settings. They include rates, relative risk, attributable risk, sensitivity and specificity, tests of statistical significance (chi-square, t-test), tests of power, and general surveillance techniques (data collection, tabulation, analysis, and dissemination).

Analysis of these data can reveal which adverse outcomes are of greatest significance in the community being studied - for example, stillbirths, maternal mortality, neonatal mortality, or postneonatal mortality. Maternal and perinatal mortality are crude categories because many

11 WHO refers to all antecedent conditions as "risk factors," including complications and other manifestations of actual pathology. 
causes of death contribute to the overall rates. If reduction of maternal and/or perinatal mortality is the goal, it is necessary to prioritize the most significant contributing factors. A review of the literature reveals which risk factors can be influenced through interventions. Focusing on risk factors that have a significant impact but are preventable helps to identify a small number of specific problems and effective interventions.

The Risk-Screening System

Once a decision has been made regarding a goal (for example, reducing perinatal mortality) and the risk factors that have the greatest impact on the targeted outcome have been identified, a system can begin to be developed to screen pregnant women for the presence of those factors. The purpose is to identify high-risk pregnant women who should be referred for special care. A sound screening system must provide reasonable and feasible answers to five questions:

- Why is the screening being done?

- Who will do the screening?

- When will the screening be done?

- Where will the screening be done?

- What technology will be used in the screening?

Some pregnant women will have no risk factors, some will have one or two, and others may have several. Each risk factor poses a different degree of risk of the adverse outcome. It is necessary to assign an estimated relative risk to each risk factor in order to "weight" its influence on each woman's final risk score. The health care workers assess each woman for the presence of the risk factors, find the weighted value of each risk factor present in an individual case, and sum the weighted values to find each womans total risk score.

\section{Assessing Performance}

The goal is to determine how well the health care system could function to reduce the identified health problems and risk factors. Could the system support the needed changes? Does the system utilize poorly some resources that could be reallocated to effect the needed interventions? It is important to determine what is already being done to reduce the targeted health problems. An assessment of current practices enables the identification and eventual correction of performance problems.

Case reviews of perinatal and maternal mortality provide a qualitative assessment of performance. During the process of reviewing each death, representatives from all levels of the health care system come together to determine (1) which tasks should be performed at each 
level of the system, (2) whether those tasks were performed, and (3) whether the tasks were performed correctly. Through systematic enquiry, it is possible to examine the skill, knowledge, attitude, and resources being applied at all three levels of the health care system - the individual and community level, the organized health care delivery system, and the intersectoral system.

For a more quantitative assessment, it is necessary to determine the number of trained caregivers, the sites where care is provided and how many pregnant women and newborns receive care at each site, how early pregnant women begin to receive prenatal care, how frequently each method of delivery is used and the outcomes associated with each method, what proportion of women have postpartum visits, and the adequacy of the resources allocated to reducing the identified risk factors and other aspects of maternal and child health.

Health care problems generally fall into three categories:

(1) Lack of knowledge or skill. This problem arises from a lack of information, education, or training. Lack of information hampers the community if members do not know which behaviors are healthful, how to recognize health problems, or where to turn for help. People within the health care system may be unable to recognize or handle health problems, and assignment or selection of personnel may be inappropriate. Members of the intersectoral system may be unaware of the needs or of the obstacles imposed by the environment or through political decisions.

(2) Poor attitude. For various reasons, individuals at all three levels may lack the desire to perform. Good performance may not be rewarded or may result in some form of punishment; for instance, a pregnant woman may be criticized for calling attention to her problems, a health care worker who recognizes a problem may need to work longer hours, and intersectoral-level leaders who acknowledge certain problems may face a dilemma regarding the allocation of limited resources.

(3) Inadequate resources. Resources (personnel, money, materials, and management systems) may not be available or may not be properly organized and managed. Geography, climate, and/or politics may also pose constraints.

\section{Designing and Evaluating a New Strategy}

The goal of primary prevention is to reduce risk factors that contribute to bad outcomes. The goal of secondary prevention is to prevent risk factors from resulting in bad outcomes. Intervention strategies include health education and early detection and treatment of complications. The strategy should depend primarily on technologies and resources that are available within the local community, province, or region. A strategy designed for application in a relatively large area, such as a whole province, should be flexible enough to accommodate a variety of solutions reflecting local circumstances and conditions. The strategy should be 
compatible with government policies, regulations, and directions. It should be designed to reach the largest possible percentage of the target population, especially socially vulnerable groups and people who live in rural areas.

All levels of the health care system - individuals, the community, the organized health care delivery system, and the intersectoral system - should be involved in developing the strategy and implementing the program.

The individual and community levels are the pivotal points for health education; individuals must learn about health and disease in order to adopt healthy behaviors and to identify signs and symptoms that may indicate the need for health care. Individuals and communities can also conduct some risk screening, and local communities can develop systems for noncritical, routine health care.

The organized health care system should participate in the strategy in several ways - by increasing the proportion of women screened, by improving referrals so that provider skills are better matched with each patient's level of risk, by modifying risk factors, and by recognizing and treating complications. In addition, the health care system should be involved in training to improve the performance of the system. If necessary, the strategy should include enhancement of the health care facilities to meet the identified needs.

Other sectors of the community should be brought into the strategy. In some cases, these sectors may need to be reorganized to make them capable of supporting the riskreduction plan. The resources provided by intersectoral policies should reflect the distribution of need and risk factors among the population.

Strategies to improve perinatal care require appropriate technology, staff, facilities and procedures. The health care system should be examined to identify obstacles and constraints to carrying out the strategies. Efforts should be made to overcome the identified obstacles; if they cannot be overcome, it may be necessary to modify the strategies.

Evaluating the New Strategy. Evaluation is conducted to determine whether the objectives that is, modifying risk factors, improving performance of the health care system, and decreasing poor outcomes of pregnancy - have been achieved. Evaluation requires a predetermined set of measurable objectives. Five different kinds of indices should be assessed:

(1) Improvement in outcomes measured by changes in the target rate among women with specified risk tactors. For example, perinatal mortality may have been reduced among mothers who experienced hypertension during pregnancy.

(2) Improvement in health care system performance measured by determining whether the system is functioning vertically. For example, are greater percentages of high- 
risk women receiving care at more appropriate levels of the organized health care system?

(3) Whether selected appropriate forms of technology have become more available, such as hemoglobinometers.

(4) Whether the decisions and actions of the health care workers are appropriate for example, whether the nurses and/or midwives recognize and act upon risk factors present in pregnant women.

(5) Improvement in the level of knowledge in the community, measured, for example, by determining whether pregnant women are alerting their health care providers to the appearance of risk factors such as swollen ankles.

\section{The Need for Caution and Evaluation}

Although the WHO documents reflect great hope for the potential of the risk approach, they also advise caution and emphasize the need for objective evaluative research. The 1984 WHO monograph includes a chapter entitled "Lessons from the Risk Approach," which states:

[A]lthough there are special reasons for its usefulness in the case of women and children, there would seem to be few barriers to applying it elsewhere, particularly in primary health care. One reason for caution, however, must be the shortage of support from the results of evaluative research so far, and another lies in the very attractiveness of the idea itself. . . The attractiveness of the idea of the risk approach is sometimes in danger of obscuring the fact that the chances of the future event (the adverse outcome) actually occurring in a particular person are relatively limited . . . it is important that, whenever possible, the extent of its contribution should be studied and measured operationally (Backett et al., 1984: 79).

\section{$\underline{\text { References }}$}

Backett, E.M., A.M. Davies, and Petros-Barvazian. The Risk Approach in Health Care: With Special Reference to Maternal and Child Health, Including Family Planning. Public Health Papers No. 76. Geneva: World Health Organization, 1984.

World Health Organization (WHO). A Workbook on How to Plan and Carry Out Research on the Risk Approach in Maternal and Child Health Including Family Planning. Geneva: Division of Family Health, World Health Organization, 1984.

Yan, R.Y., B.J. McCarthy, H.F. Ye, C.Y. Qu, Z. Li, T.X. Chen, and D. Kowal. The Risk Approach 
in Perinatal Health: Sunyi County, People's Republic of China. U.S. Department of Health and Human Services Publication No. HHS 89-8412. Atlanta, GA: Centers for Disease Control, 1989. [A copy of this report can be obtained from the Centers for Disease Control, Atlanta, GA 30333.] 